\title{
Cranial osteology of the pampathere Holmesina floridanus (Xenarthra: Cingulata; Blancan NALMA), including a description of an isolated petrosal bone
}

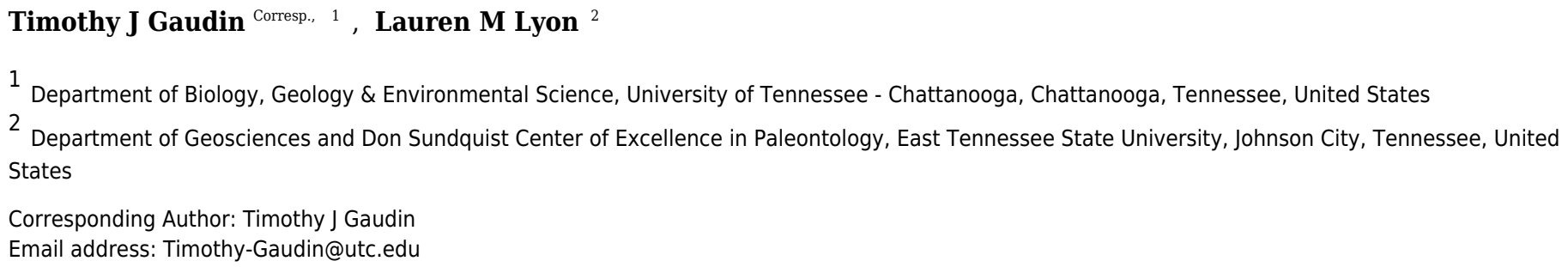

The present study entails descriptions of several well-preserved skulls from the pampathere species Holmesina floridanus, recovered from Pliocene localities in central Florida and housed in the collections of the Florida Museum of Natural History. Bone by bone descriptions have allowed detailed reconstructions of cranial morphology. Cranial foramina are described and illustrated in detail, and their contents inferred. The first ever description of an isolated pampathere petrosal is also included. Cranial osteology of $H$. floridanus is compared to that of Pleistocene species of Holmesina from both North and South America $(H$. septentrionalis, $H$. occidentalis), as well as to the other well-known pampathere genera, to closely related taxa among glyptodonts (Propalaehoplophorus), and to extinct and extant armadillos (Proeutatus, Euphractus). This study identifies a suite of apomorphic cranial features that serve to diagnose a putative, progressive series of more inclusive monophyletic groups, including the species Holmesina floridanus, the genus Holmesina, pampatheres, pampatheres plus glyptodonts, and a clade formed by pampatheres, glyptodonts, and Proeutatus. The study highlights the need for further anatomical investigations of pampathere cranial anatomy, especially those using modern scanning technology, and for analyses of pampathere phylogenetic relationships. 
1 Cranial osteology of the pampathere Holmesina floridanus (Xenarthra: Cingulata; Blancan

2 NALMA), including a description of an isolated petrosal bone

3

4 Timothy J. Gaudin ${ }^{1}$ and Lauren M. Lyon ${ }^{2}$

5

$6{ }^{1}$ Department of Biology, Geology, and Environmental Science, University of Tennessee at

7 Chattanooga, 615 McCallie Avenue, Dept. 2653, Chattanooga, TN 37403-2598, USA

$8 \quad{ }^{2}$ Department of Geosciences and Don Sundquist Center of Excellence in Paleontology, East

9 Tennessee State University, 325 Treasure Lane, 70357, Johnson City, TN 37614-6502, USA

10

11 Corresponding author: Timothy J. Gaudin, Timothy-Gaudin@utc.edu

12

13

14 
16 Abstract - The present study entails descriptions of several well-preserved skulls from the

17 pampathere species Holmesina floridanus, recovered from Pliocene localities in central Florida

18 and housed in the collections of the Florida Museum of Natural History. Bone by bone

19 descriptions have allowed detailed reconstructions of cranial morphology. Cranial foramina are

20 described and illustrated in detail, and their contents inferred. The first ever description of an

21 isolated pampathere petrosal is also included. Cranial osteology of $H$. floridanus is compared to

22 that of Pleistocene species of Holmesina from both North and South America (H. septentrionalis,

23 H. occidentalis), as well as to the other well-known pampathere genera, to closely related taxa

24 among glyptodonts (Propalaehoplophorus), and to extinct and extant armadillos (Proeutatus,

25 Euphractus). This study identifies a suite of apomorphic cranial features that serve to diagnose a

26 putative, progressive series of more inclusive monophyletic groups, including the species

27 Holmesina floridanus, the genus Holmesina, pampatheres, pampatheres plus glyptodonts, and a

28 clade formed by pampatheres, glyptodonts, and Proeutatus. The study highlights the need for

29 further anatomical investigations of pampathere cranial anatomy, especially those using modern

30 scanning technology, and for analyses of pampathere phylogenetic relationships. 
34 Living armadillos, the only mammals to bear a carapace of dermal bony armor, are the most

35 diverse of the extant groups of Xenarthra, numbering at least 21 of the 31 currently recognized

36 xenarthran species (Aguiar and Fonseca 2008- although armadillo taxonomy is currently in flux;

37 e.g., see Abba et al. 2015; Feijó and Cordeiro-Estrela 2016; Billet et al. 2017; Hautier et al.

38 2017). However, the diversity of extinct armored xenarthrans, i.e., the Cingulata, far surpasses

39 its extant representatives, not only in taxonomic diversity, but in terms of body size, locomotory

40 diversity, and dietary diversity, even including a "horned" taxon Peltephilus (Fernicola et al.

41 2008; Gaudin and Croft 2015; Croft 2016). Regarding diet, it is particularly noteworthy that

42 there are omnivorous extant armadillos, but no herbivores (McDonough and Loughry 2008;

43 Gaudin and Croft 2015), whereas the fossil cingulates include two herbivorous clades,

44 pampatheres and glyptodonts. Both are comprised of large bodied taxa with complex dentitions

45 (lobate teeth composed of multiple dental tissues of differing hardness; Kalthoff 2011). The

46 former numbers only a few genera, whereas the latter encompasses at least 65 genera (McKenna

47 and Bell 1997). Both are understudied, particularly given their conspicuous nature, often bizarre

48 anatomies, and their abundance and ecological importance in late Cenozoic faunas of South and

49 North America.

50 Pampatheres are a particularly poorly studied group. The oldest undoubted pampathere does

51 not appear until the middle Miocene (Gaudin and Croft 2015; with the possible exception of a

52 very poorly preserved taxon from the late Eocene of Patagonia, Machlydotherium, De Iuliis and

53 Edmund 2002). The group's basic taxonomy has long been unsettled. McKenna and Bell (1997)

54 recognize only 4 valid pampathere genera, though several new taxa have since been added 
55 (Edmund and Theodor 1997; Góis et al. 2015). One of their genera, Pampatherium, includes as a

56 junior synonym at least one genus that is widely recognized as a separate, valid taxon,

57 Holmesina; however, which of the species described in the literature belong in Holmesina and

58 which in Pampatherium has been uncertain (Edmund 1987; De Iuliis et al. 2000). In addition,

59 McKenna and Bell (1997) recognize the taxon name Plaina as a junior synonym of the genus

60 Kraglievichia, whereas subsequently, De Iuliis and Edmund (2002) synonymize Plaina with

61 McKenna and Bell's genus Vassallia. Part of the taxonomic difficulties lie with the paucity of

62 fossil material. The majority of preserved pampathere remains consist of isolated osteoderms.

63 DeIuliis and Edmund (2002, p. 50) note that "taxa based on small samples of osteoderms [are]

64 unreliable," and yet osteoderms have been used extensively in the alpha taxonomy of

65 pampatheres and other cingulates (e.g., Castellanos 1946; Edmund 1985a; Scillato-Yané et al

66 2005; Góis et al. 2013).

67 The nature of the pampathere record has also hindered an understanding of their basic

68 skeletal anatomy. Most of the described postcranial skeletal remains are based on very

69 incomplete material, have received only cursory descriptions, and are poorly illustrated, if at all,

70 by unlabeled photographs showing only one or two views (Castellanos 1937; James 1957;

71 Robertson 1976; Cartelle and Bohórquez 1985; Edmund 1985b; Edmund and Theodor 1997;

72 Góis et al. 2015). Despite the fact that several complete skeletal reconstructions have been

73 published (James 1957; Edmund 1985b), the postcranial osteology of pampatheres remains

74 scarcely known.

75 For the skull, mandible, and dentition, the situation is somewhat better. A fair number of

76 complete, or nearly complete skulls and mandibles are known from a variety of taxa, including

77 Kraglievichia (Castellanos 1937), Vassallia (De Iuliis and Edmund 2002), Pampatherium 
78 (Bordas 1939; De Iuliis et al. 2000), and various species of Holmesina (Simpson 1930; James

79 1957; Cartelle and Bohórquez 1985; Edmund 1985b; Vizcaíno et al. 1998; Góis et al. 2012),

80 though several other genera remain incompletely known (e.g., Scirrotherium, Edmund and

81 Theodor 1997; Tonnicinctus, Góis et al. 2015). More detailed examinations of cranial anatomy

82 have been published, including several studies of the ear region (in Pampatherium, Bordas 1939;

83 Guth 1961; and in Vassallia, Patterson et al. 1989) and a recently published study on brain

84 anatomy based on a digital endocast (Tambusso and Fariña 2015). However, many of these

85 cranial descriptions are fairly cursory, and virtually all are illustrated with unlabeled photographs

86 that leave out many details. Even the ear region studies fail to address or adequately illustrate

87 the detailed anatomy of the petrosal bone, as is common among more modern treatments of

88 mammalian auditory region osteology. To date, there remains no study of the cranial osteology

89 of pampatheres that clearly illustrates suture patterns and provides a bone by bone description of

90 the anatomy, including the cranial foramina and their likely contents.

91 Fossil pampatheres have been known from the state of Florida, in the extreme southeast of

92 North America, for more than a century (Simpson 1930). Two species in the genus Holmesina

93 are currently recognized: a late Pliocene-early Pleistocene (Blancan NALMA) form, $H$.

94 floridanus; and, a middle to late Pleistocene taxon (Irvingtonian and Rancholabrean NALMA),

95 H. septentrionalis (Hulbert and Webb 2001). Both are known from extensive material, but the

96 older material is particularly complete, abundant, and well-preserved (see, e.g., the skull

97 illustrated in Hulbert and Webb 2001, fig. 10.7, currently on exhibit at the Florida Museum of

98 Natural History), though it remains mostly undescribed. Multiple individuals, including both

99 adults and subadults, are derived largely from two sites: Haile 7G in Alachua County, Florida;

100 and Inglis 1C in Citrus County, Florida. The goal of the present study is to describe the cranial 
101 osteology of Holmesina floridanus, based on this material. Because of the preservation quality,

102 these fossils will allow us to conduct a thorough, bone by bone analysis of the skull, and to

103 provide a fairly comprehensive view of the cranial foramina and their reconstructed contents.

104 There is even an isolated petrosal among this material, which will allow us to describe the bony

105 anatomy of the auditory region in unprecedented detail. These descriptions are accompanied by

106 a carefully executed series of drawings, including both drawings of the best preserved fossils

107 themselves, as well as reconstructions of the anatomy as we believe it would have appeared in

108 life. The present study will provide the most detailed glimpse yet into the cranial anatomy of

109 pampatheres, and should serve as an important basis for future studies of the paleontology,

110 systematics, and evolution of this enigmatic group of cingulate xenarthrans.

113 Our goal was to base our description on the best preserved specimens of Holmesina floridanus

114 available. Unfortunately for our purposes, the best preserved skull, UF 121742 (one of the best

115 preserved fossil skulls we have ever seen!), is currently on exhibit at the Florida Museum of

116 Natural History. Although the museum staff was kind enough to allow our examination of this

117 specimen for an afternoon, it was not possible for us to borrow the skull for more careful study.

118 Therefore, the descriptions below are based largely on three other specimens, UF 191448, UF

119 224450, and UF 248500, which were also in excellent condition and were available for loan

120 (Figure 1). UF 191448 is an almost perfectly complete adult skull, with only minor damage in

121 the orbital wall and nasopharyngeal roof; but, as an adult, most of the sutures are closed, and the

122 specimen retains only four of eighteen teeth (left M3-5, and right M8). UF 224450 is an isolated

123 but nearly perfectly preserved left mandible, however it retains only three of nine teeth ( $\mathrm{m} 2$ and 
124 m6-7). UF 248500 is a subadult specimen with some significant damage to the middle portions

125 of the skull, including parts of the skull roof, orbital wall, nasopharynx and left basicranium; but,

126 it retains many if not most of its sutures, all its dentition is intact, and those portions of the skull

127 that are present are very well preserved. In addition, it has a complete, isolated left petrosal that

128 we were able to examine in three dimensions.

129 In order to examine interspecific variation, including ontogenetic variation, the three

130 specimens that form the primary basis for this description were compared to the other skulls and

131 mandibles of $H$. floridanus in the collections of the Florida Museum of Natural History. Most of

132 these, with the exception of the aforementioned display specimen, are not fully prepared, several

133 are incompletely preserved, and at least one represents a subadult likely even younger than UF

134 248500; age was estimated based on the level of sutural fusion present in the skull, and the

135 surface texture of the skull bones. These specimens include the following: UF 121742 [exhibit

136 skull], UF 223813 [skull only], 248000 [partial mandible], 275496 [juvenile skull], 275497 [skull

$137 \&$ mandible], 275498 [skull \& mandible]; 278000 [partial skull \& mandible]; 285000 [skull \&

138 mandible], 293000 [skull \& mandible]. None of the H. floridanus material examined preserved

139 any trace of the ectotympanic bone or the auditory ossicles, or showed any trace of an

140 entotympanic (an element commonly present in other xenarthrans and likely a synapomorphy of

141 Xenarthra; Patterson et al. 1992; Gaudin 2004; Gaudin and McDonald 2008), though, as noted

142 above, some specimens are not yet fully prepared.

143 In order to assess generic level variation within Holmesina, the H. floridanus material

144 described above was compared to two specimens of the North American Pleistocene species $H$.

145 septentrionalis (UF 889 [partial skull only] and UF 234224 [cast skull only]) and one specimen

146 of the South American Pleistocene species H. occidentalis (ROM 3881 [skull], ROM 4955 
147 [mandible]), as well as any literature available on these taxa. Likewise, in order to gain a

148 comparative perspective on pampathere cranial anatomy, our material was compared to one

149 specimen of Vassallia maxima (FMNH P14424), as well as the available literature on this and

150 other pampathere skulls. Finally, in order to place this anatomy in a broader context among

151 cingulates, $H$. floridanus was compared to specimens of the basal glyptodont

152 Propalaehoplophorus (YPM VPPU 15007, 15291; FMNH 13205; glyptodonts are the putative

153 sister taxon to pampatheres; Gaudin and Wible 2006; Porpino et al. 2009; Billet et al. 2011), the

154 extinct eutatine armadillo Proeutatus (FMNH P13197, P13199; Proeutatus is the putative sister

155 taxon to pampatheres and glyptodonts; Gaudin and Wible 2006; Billet et al. 2011), and an extant

156 euphractine, the six-banded armadillo Euphractus sexcinctus [CM 6339; UTCM 1481, 1486,

157 1491, 1500; one of the living armadillos that is most closely related to pampatheres in the most

158 comprehensive morphology-based cingulate phylogenies, those of Gaudin and Wible (2006) and

159 Billet et al. (2011), but see Porpino et al. (2009) for contrasting view]. In certain specific

160 instances, other comparative taxa have been utilized (e.g., the pampathere Scirrotherium, the

161 extinct armadillos Peltephilus and Kuntinaru, and sloths). In instances in which a specific

162 specimen number has been noted as part of a comparison, the information derives from personal

163 observations made by the authors of the present study. If a literature citation is provided in

164 addition to or in place of a specimen number, the observation derives in part or in whole from the 165 observations of other authors.

166 Descriptions of the dorsal surface of the petrosal are only available for a small number of

167 cingulate taxa. Therefore, we will be comparing the anatomy of the dorsal surface of our isolated

168 petrosal in Holmesina floridanus to the detailed description of Dasypus novemcinctus by Wible

169 (2010), to a bisected skull of Euphractus sexcinctus (UTCM 1486), and to a specimen of 
170 Vassallia maxima, FMNH P14424, in which the braincase has been bisected (though its

171 endocranial anatomy was never described; the cut is visible in De Iuliis and Edmund, 2002, fig.

172 2). Because these are the only three cingulates for which we have information on the lateral

173 surfaces of isolated petrosals, we shall restrict our comparisons of this surface to these three taxa,

174 H. floridanus, Dasypus novemcinctus (Wible 2010), and an Eocene dasypodine lacking a specific

175 taxonomic assignment (Babot et al. 2012).

176 The mandible is preserved in a number of UF H. floridanus specimens, including UF

$177223813,248500,275497,275498,285000$ and 293000. In all but the first two it remains

178 incompletely prepared and attached to the skull, so that the occlusal surfaces of the teeth are not

179 completely visible and the medial mandibular surfaces are also largely obscured. The mandible is

180 prepared free in UF 223813 and 248500, but both are damaged to some extent. The left

181 mandible of UF 224450 has also been prepared free. In this specimen the bone is almost

182 perfectly preserved, although it only retains three of nine lower teeth (the second, sixth and

183 seventh), along with what appears to be a pathological remnant of the fourth. Nevertheless, as

184 the most complete available specimen, it will serve as the primary basis for our description of the 185 mandible.

186 The pampathere mandible has been described many times in the literature (e.g., Simpson

187 1930; Castellanos 1937; James 1957; Edmund 1985b; Edmund and Theodor 1997; Vizcaíno et

188 al. 1998; De Iuliis et al. 2000; De Iuliis and Edmund 2002), and, as many of these authors have

189 noted, is broadly similar in its morphology among the various taxa. Since much has already been

190 written about the comparative morphological differences among pampathere mandibles at the

191 generic level, we will focus our comparisons on the species level variation within Holmesina. 
Anatomical terminology, wherever possible, follows that of Wible and Gaudin (2004)

193 and Wible (2010). Stereophotographs of UF 248500 were prepared with the assistance of Dr.

194 Stelios Chatzimanolis (Univ. of Tennessee at Chattanooga) in accordance with the procedure

195 outlined in Gaudin (2011).

196 Institutional Abbreviations: CM, Carnegie Museum of Natural History, Pittsburgh, PA,

197 USA; FMNH, Field Museum, Chicago, IL, USA; UF, Florida Museum of Natural History,

198 University of Florida, Gainesville, FL, USA; UTCM, University of Tennessee at Chattanooga

199 Museum of Natural History, University of Tennessee at Chattanooga, Chattanooga, TN, USA;

200 YPM VPPU, Princeton University Collection, Peabody Museum of Natural History, Yale

201 University, New Haven, CT, USA.

202 Other abbreviations: c.n., cranial nerve; GSL, greatest skull length; Mf1-9, upper

203 molariform teeth; mf1-9, lower molariform teeth; MML, maximum mandibular length; NALMA,

204 North American Land Mammal Age; SALMA, South American Land Mammal Age. 205

\section{RESULTS (DESCRIPTIVE ANATOMY)}

207 Nasal

208

The nasals in Holmesina floridanus (UF 191448, 248500) consist of two long,

transversely convex bones that cover most of the visible surface of the snout in dorsal view

210 (Figures 2, 3). The outline of the bones is somewhat variable, with the bones accounting for

211 anywhere between $32-43 \%$ of the skull's total length, and the width to length ratio varying from

212 0.32-0.49 (Table 1, 2). Euphractus sexcinctus (UTCM 1491) falls into the same range for both

213 values, whereas the nasals of Proeutatus oenophorus (FMNH P13197) are of similar length but

214 narrower. H. septentrionalis (UF 234224) has longer but narrower nasals, Vassallia maxima 
215 (FMNH P14424) has longer nasals of comparable width, and Propalaehoplophorus australis

216 (YPM VPPU 15007) has nasals that are both shorter and wider (Table 1). In lateral view, the

217 nasals of $H$. floridanus slope gently anteroventrally as in other pampatheres (Castellanos 1937;

218 Bordas 1939; James 1957; Cartelle and Bohórquez 1985; Edmund 1985b; Edmund and Theodor

219 1997; Vizcaíno et al. 1998; De Iuliis et al. 2000; De Iuliis and Edmund 2002), as well as in

220 Propalaehoplophorus (Scott 1903-4), and the extant E. sexcinctus (CM 6399, UTCM 1486,

221 1491). This condition is exaggerated in Proeutatus oenophorus (FMNH P13197; Scott 1903-4),

222 where the posterior half of the nasal bones curve upwards steeply towards the frontal bone.

223 In dorsal view, the anterior margin of the nasal bones in H. floridanus is convex, which is

224 an synapomorphy of Cingulata (Gaudin and Wible 2006; Gaudin and McDonald 2008). UF

225284500 has distinct lateral sutures running the length of the nasals, whereas the sutures with the

226 maxilla and premaxilla are largely fused in UF 191448. Nasal width is uniform from the anterior

227 tip to the maxillo-premaxillary suture, where it then gently narrows posteriorly as it approaches

228 the frontal bone. There appears to be two major fronto-nasal suture patterns that occur in $H$.

229 floridanus. One of the patterns occurs in UF 191448, as a roughly straight though highly

230 irregular suture (Figure 2). The other pattern, observed in multiple specimens (UF 223813,

$231275496,275497,275498 ; 285000)$ is a shallow V-shaped suture with the apex directed

232 anteriorly. The nasals of UF 248500 are fractured posteriorly, and the bone is clearly incomplete

233 in places, making it hard to discern the course of its fronto-nasal suture. In H. septentrionalis

234 (UF 889), the overall shape of the nasal is similar to that of H. floridanus. However, the fronto-

235 nasal suture varies in form and may differ substantially from that of $H$. floridanus. In UF 889 it

236 forms a distorted $\mathrm{W}$-shape, due to a large median peak with a posteriorly directed apex.

237 Conversely, in UF 234224 it is roughly straight, but irregular, as in H. floridanus (UF 191448). 
238 The fronto-nasal suture in H. occidentalis (ROM 3881) forms a very shallow, anteriorly concave

239 jagged "U." In Vassallia (FMNH P14424) and H. rondoniensis (Góis et al. 2012) the suture is a

240 shallow V-shape, reminiscent of some H. floridanus specimens, except that the apex is directed

241 posteriorly. Similarly, Pampatherium humboldti has a W-shaped fronto-nasal suture, but with the

242 median apex directed anteriorly (Góis et al. 2012). It is clear from our survey that the shape of

243 the fronto-nasal suture varies widely among pampatheres; large variation in this suture has also

244 been observed in other mammals (e.g., typotherian notoungulates, Sinclair 1909). In our

245 reconstruction of $H$. floridanus we have chosen to illustrate a condition like that in UF 191448

246 (Figure 2).

247 The suture is unknown in Propalaehoplophorus (Scott 1903-4; Vizcaino et al. 1998).

248 Like some Holmesina, the fronto-nasal suture of Proeutatus (FMNH P13197) forms a V-shape,

249 with the apex pointing anteriorly. In Euphractus it is roughly straight near the lateral edges of the

250 nasal bones, but as it approaches the median suture it too forms an anteriorly-directed V-shape,

251 albeit a smaller one than that of Proeutatus (Wible and Gaudin 2004).

252

253 Premaxilla

254 In lateral view, the premaxilla has a broad rectangular facial process, with its

255 dorsoventral height slightly exceeding its anteroposterior length (Figures 4, 5). The maxillo-

256 premaxillary suture of the facial process in H. floridanus (UF 248500) forms a single posteriorly

257 convex curve. The premaxillary sutures are harder to distinguish in UF 191448, but they appear

258 similar. The dorsal suture between the premaxilla and nasal is relatively short in Holmesina (7-

$25910 \%$ of GSL in H. floridanus; Table 1, 2 - though not listed in the table, the value for $H$.

260 occidentalis [ROM 3881] is about 7\% of GSL) relative to the extant Euphractus (15\% of GSL, 
261 UTCM 1491), though not as short as in glyptodonts (4\% of GSL, Propalaehoplophorus YPM

262 VPPU 15291; Table 1). Proeutatus (11\% of GSL, FMNH P13197) is similar in this regard to

263 Holmesina.

264 The free anterior edge of the facial process is vertical but irregularly shaped. The dorsal

265 portion of this edge has a deep and narrow notch in UF 248500 (Figure 4B, C) and UF 121742 ,

266 which slopes anteroventrally into a large triangular prong. In both UF 191448 (Figure 4A) and

267 UF 285000 the anterior edge is marked by a shallower, more rounded notch, ending in a small

268 bump on its ventral margin. H. septentrionalis and Vassallia maxima (Edmund 1985b; De Iuliis

269 and Edmund 2002) also have notches that are deep and narrow, as in UF 191448, whereas $H$.

270 occidentalis (ROM 3881) has a shallower C-shaped notch more like UF 248500.

271 Propalaehoplophorus has a very shallow C-shaped notch on the anterior edge of its very tall and

272 narrow premaxillary facial process (YPM-VPPU 15291). In Euphractus, the anterior margin of

273 the premaxilla is variable in shape - it may be a relatively straight edge sloping posteroventrally

274 (Wible and Gaudin 2004), it may be marked by a wide, shallow, C-shaped notch (e.g., UTCM

275 1500), or the entire edge may form a single shallow concavity (e.g., UTCM 1486, 1491). The

276 anterior edge of the premaxilla in Proeutatus (FMNH P13197) slopes posteroventrally in lateral

277 view, as in Euphractus, and it lacks the notch that is present in pampatheres, glyptodonts, and

278 some Euphractus (Wible and Gaudin 2004).

279 The external nares of $H$. floridanus are widest transversely near the nasopremaxillary

280 suture. From there the premaxilla slopes steeply inward ventromedially. In anterior view UF

281248500 appears to have irregularly rounded, upside-down triangular shaped nasal opening. The

282 nares in UF 191448 have a more rounded, inverted pentagonal cross-section, much like that of $H$. 
283 septentrionalis (UF 234224). The nasal opening is more ovate and dorsoventrally compressed in 284 both Proeutatus (FMNH P13197) and Euphractus (CM 6399; UTCM 1486, 1491).

285 In ventral view, the premaxilla of $H$. floridanus forms a roughly M-shaped palatal suture 286 with the maxilla (Figures 5, 6), similar to that of $H$. septentrionalis (UF 889). The maxillo287 premaxillary suture exhibits a high degree of variability in other species.

In H. floridanus, the anteroventral tip of the premaxilla extends forward in the midline as 289 a rounded prong in UF 191448, though this prong is strongly reduced in UF 248500. $H$. septentrionalis (Edmund 1985b) has a similar, though transversely broader, U-shaped anteroventral prong, and a prong very like that of UF 191448 is also present in Vassallia (De Iuliis and Edmund 2002). Propalaehoplophorus differs in that the anteroventral edge of the premaxilla forms extensions that project forward to form a distorted M-shape, with long anterolateral edges and a short V-shaped median notch. The premaxillae of Proeutatus and Euphractus lack anteroventral extensions (Scott, 1903-4; Wible and Gaudin 2004). The palatal process of the premaxilla in H. floridanus is incised by a deep groove that emerges from the front of the incisive foramina (Figures 6,7). The incisive foramen transmits the nasopalatine duct, which connects the oral and nasal cavities with the vomeronasal organ. It also transmits the nasopalatine nerve, artery and vein (Wible and Gaudin 2004). The incisive

300 foramina themselves are deeply recessed posterodorsally, with separate left and right openings

301 that empty into a single midline fossa. This appears to be a general feature of pampatheres, but it 302 is an unusual morphology among cingulates. Other cingulates, such as Proeutatus (FMNH

303 P13197) and Euphractus (CM 6399; UTCM 1481, 1486), have a common fossa that houses the 304 two separate incisive foramina, and all cingulates (except perhaps glyptodonts; see Gillette and 305 Ray 1981, fig. 11c) have close set incisive foramina. However, in no other cingulates are they as 
306 deeply recessed, and no other cingulates possess the deep anterior groove found in pampatheres.

307 As in all other cingulates, aside from Peltephilus (Gaudin and Wible 2006), the incisive foramina

308 in H. floridanus are completely encompassed by the premaxilla.

309 The premaxilla retains a single tooth near its posterior border with the maxilla. The right

310 maxillary-premaxillary suture runs into the mesial portion of the socket of the second tooth. The

311 premaxilla encompasses the labial half of the second tooth socket, but forms only the front of the

312 socket on the lingual side. The presence of premaxillary teeth is a synapomorphy of euphractine

313 armadillos, glyptodonts, and pampatheres (Node C of Gaudin and Wible 2006), though it is lost

314 secondarily in glyptodonts. The premaxillary tooth of $H$. floridanus is angled anteriorly and

315 slightly medially. It has beveled wear facets on the occlusal surface. The surface area of the

316 mesial facet is greater than that of the distal facet in most specimens, though the distal is larger in

317 UF 293000 and highly reduced in UF 121742 and 275496, and the two facets lie at a 110 degree

318 angle to one another. The fact that UF 275496 appears to be a juvenile based both on its open

319 sutures and the less finished surface texture of its skull bones, whereas UF 293000 and 121742

320 appear to be adults based on the same criteria, suggests that these differences in wear facet shape

321 are not necessarily age-related. The overall outline of the occlusal surface is ovate, with its

322 mesiodistal length exceeding its transverse width (Table 1). The left premaxillary tooth in UF

323248500 possesses a small lenticular island of osteodentine in the center, whereas the right tooth

324 has a narrow linear island of osteodentine. Presence of an elevated core of osteodentine is a

325 synapomorphy of Proeutatus, glyptodonts, and pampatheres (Node 7 of Gaudin and Wible

326 2006), as is the presence of beveled wear facets only in the anterior portion of the tooth row. In

327 both H. occidentalis (ROM 3881), and Proeutatus (FMNH P13197) the premaxillary tooth has

328 an ovate occlusal surface, similar to H.floridanus. In Vassallia and H. septentrionalis the 
329 premaxillary teeth are missing, (Edmund 1985b; De Iuliis and Edmund 2002), but it can be

330 ascertained from the shape of the tooth alveoli in these animals that they too had ovate occlusal

331 surfaces, making this a shared trait among cingulate taxa that possess premaxillary teeth. In

332 Euphractus (CM 6399; UTCM 1486, 1491) the premaxillary tooth is mostly flat at its tip, with a

333 small discolored island in the center, likely formed from orthodentine (Ferigolo 1985; Kalthoff

334 2011).

335

336 Maxilla

337 The facial process of the maxilla contacts the nasal dorsally, the premaxilla anteriorly,

338 and the frontal and lacrimal posteriorly (Figures 4-7). The large zygomatic process of the maxilla

339 contacts the jugal posteriorly. The facial process is marked by a ridge that runs anteroposteriorly

340 just below the nasomaxillary suture (Figure 5). In Holmesina, this ridge begins as an indistinct,

341 broad elevation above Mf2/Mf3 (=second and third molariform teeth; note all teeth in

342 pampatheres and glyptodonts are molariform) that becomes a more pronounced, low ridge above

343 Mf4, and finally forms a sharply defined ridge over Mf6. The ridge then curves posteroventrally

344 to become confluent with the maxilla/jugal suture and a large rounded ridge that marks the

345 anterior termination of the jugal and outlines the distinct antorbital fossa (Figure 5; Wible and

346 Gaudin 2004; = buccinator fossa from Gaudin 2004). A nearly identical lateral maxillary ridge is

347 present in the other Holmesina species (H. occidentalis, H. septentrionalis). The ridge in

348 Vassallia, though present, is less distinct (De Iuliis and Edmund 2002) than it is in Holmesina.

349 Euphractus (CM 6399; UTCM 1486, 1491) also has a distinct maxillary ridge that begins over

350 M3 and marks the dorsal edge of a strong antorbital fossa (Wible and Gaudin, 2004). In $H$.

351 floridanus, the antorbital fossa is particularly large and deep posteriorly behind the infraorbital 
352 foramen, as well as on the anterior surface of the zygomatic process of the maxilla. This fossa

353 accommodates the nasiolabialis muscles (Smith and Redford 1990; Vizacaíno et al. 1998; Wible

354 and Gaudin 2004). In dorsal view, the maxilla forms a small portion of the roof of the snout as it

355 touches the nasal bone (Figures 2, 3). It also comprises the majority of the lateral walls of the

356 snout, which taper anteriorly in both lateral and dorsal views (Figures 2-5). The antorbital fossa

357 is less well marked in Proeutatus, and is absent in Propalaehoplophorus (Scott, 1903-4; Gaudin

358 and Wible 2006).

359 The palatine process of the maxilla is broadly concave anteroposteriorly from Mf1 to

360 Mf7. The palate, including both maxillary and palatine contributions, is convex from Mf7 to the

361 posterior edge of the palate, but concave transversely along its whole length. Both the

362 longitudinal and transverse concavities are especially deep anteriorly, near the junction of the

363 maxilla and premaxilla. The hard palate is marked by numerous foramina (Figures 6,7 ), as in

364 other xenarthrans (Gaudin and Wible 2006). This is due to the fact that the major palatine

365 arteries, veins, and nerves travel within the palatal process of the maxilla (Wible and Gaudin,

366 2004), rather than on its ventral surface, as in other mammals (e.g., Canis, Evans and

367 Christiansen 1979; Homo, Clemente 1985). These nerve and vessels finally emerge ventrally

368 from their canal in the maxilla near the front of the palate, through the anterior palatal foramina.

369 Anterior palatal foramina are typically located near Mf4 (e.g., in UF 248500) in H. floridanus,

370 but they exhibit some variation in their position in different specimens. For example, in UF

371 191448, both are near the distal half of Mf3 (Figures 6, 7), but on the left side of UF 121742,

372 they are as far back as the mesial half of Mf5. The anterior palatal foramina occupy similar,

373 somewhat varying positions in H. occidentalis, H. septentrionalis, and Vassallia, showing only

374 slightly greater variation than that found in H. floridanus itself - one specimen of $H$. 
375 septentrionalis (UF 234224) had the foramina situated a little further forward, at the mesial edge

376 of Mf3 or between Mf2 and Mf3. In all of these species, the foramina open anteriorly into

377 distinct grooves that travel forward, ending just short of the maxillo-premaxillary suture. This

378 anterior palatal foramina and grooves are also present in glyptodonts (Gaudin 2004) and

379 Proeutatus (FMNH P13197). The characteristic is convergent on similar features shared by

380 pilosans (Gaudin 2004; Wible and Gaudin 2004; De Iuliis et al. 2011).

381 The median suture of the maxilla is slightly raised from the distal edge of Mf5 posteriorly

382 to the junction with the palatine in H. floridanus (Figures 6, 7). This trait is also present in $H$.

383 occidentalis (ROM 3881), Vassallia (De Iuliis and Edmund 2002), Propalaehoplophorus (Scott

384 1903-4), Proeutatus (FMNH P13197), and Euphractus (CM 6399). In H. floridanus, the apex of

385 the U-shaped maxillary/palatine suture reaches as far anteriorly as the middle of Mf8. The suture

386 travels posteriorly just medial to the tooth alveoli of Mf8 and Mf9, and then curves laterally

387 behind this last tooth in front of the pterygoid process. A U-shaped maxillo-palatine suture with

388 rounded anterolateral corners is a derived feature of Proeutatus and living euphractines (Node 6

389 of Gaudin and Wible 2006), but this condition also occurs in H. floridanus and H.occidentalis

390 (ROM 3881). The maxilla/palatine suture is unknown in H. septentrionalis and

391 Propalaehoplophorus, whereas in Vassallia, the suture is M-shaped (De Iuliis and Edmund

392 2002; Gaudin and Wible 2006).

393 The zygomatic process of the maxilla is sizeable, and forms most of the anterior wall of

394 the orbit in pampatheres (Gaudin and Wible 2006). In ventral view, the zygomatic process is

395 triangular with a broad base and narrow apex extending laterally at a right angle to the main

396 body of the maxilla (Figures 6, 7). The ovate infraorbital foramen in H. floridanus is situated

397 above Mf6, and opens anteriorly into a short groove. The maxillary foramen lies above the 
398 posterior half of Mf7 (UF 121742, 248500; 285000) or the anterior half of Mf8 (UF 191448). It

399 is triangular in shape, and serves as the posterior entrance to a long infraorbital canal that

400 perforates the base of the zygomatic process. This canal is riddled with many smaller foramina

401 along its medial wall, as occurs in Euphractus (Gaudin and Wible 2004). In H. occidentalis, $H$.

402 septentrionalis and Vassallia, the infraorbital canal also extends from Mf8-Mf6 (ROM 3881; UF

403 234224; Edmund 1985b; De Iuliis and Edmund 2002); thus, this appears to be a characteristic of

404 pampatheres in general. In contrast, Propalaehoplophorus has a more dorsally situated

405 infraorbital canal than that of pampatheres. The canal is relatively short, its entire length located

406 above Mf6-Mf5 (Scott 1903-4). Proeutatus also has a short, dorsally positioned infraorbital canal

407 that begins above Mf7 and exits above Mf5/Mf6, and lies above the antorbital fossa. In

408 Euphractus (CM 6399), the canal is intermediate in length between that of Proeutatus and

409 Holmesina, beginning over the posterior half of Mf7 and exiting over the anterior half of Mf6.

410 The infraorbital canal transmits the infraorbital nerves and vessels from the orbit to the snout

411 (Wible and Gaudin 2004).

412

Sutures are fused or poorly marked in the orbit of UF 191448, and large portions of the

413 orbital process of the maxilla are missing or heavily fractured in UF 248500 , though the sutures

414 are more clearly visible in the latter specimen. That said, the orbital process of the maxilla

415 appears to comprise the anteroventral part of the medial wall of the orbit (Figure 8) as in most

416 cingulates, with the exception of dasypodine armadillos (Gaudin and Wible 2006). The orbital

417 exposure of the maxilla borders the lacrimal, anterodorsally, the frontal posterodorsally, and the

418 alisphenoid, pterygoid (or palatine; see description of palatine below), and orbitosphenoid

419 posteriorly. Atypical of other mammals and even other cingulates, pampatheres and glyptodonts

420 possess a sphenopalatine foramen that is housed in a common fossa with the sphenorbital fissure, 
421 though this fossa in H. floridanus is partially walled laterally by an anterior bridge of the

422 alisphenoid that contacts the maxilla (Figure 8). The opening of the sphenopalatine foramen is

423 directed cranially (UF 121742). Within the orbit the maxilla forms the anterior edge of the

424 sphenopalatine foramen, whereas the alisphenoid (or palatine; see description of palatine below)

425 forms the posterior edge. In Euphractus, the sphenopalatine foramen lies between the maxilla 426 and palatine (Wible and Gaudin 2004).

427 The presence of nine upper teeth is the primitive condition in Proeutatus, euphractine 428 armadillos, and pampatheres (Node 3 of Gaudin and Wible 2006), with all but the first (Mf2429 Mf9) housed in the maxilla. Propalaehoplophorus has only eight teeth, since it is missing the 430 premaxillary tooth, as noted above. Therefore, we believe the first tooth in Propalaehoplophorus 431 is homologous with Mf2 in pampatheres (though see González Ruiz et al. 2015 for contrasting 432 interpretation), and we will label it as such for comparative purposes. UF 248500 preserves a 433 complete dentition (Figure 6B), whereas in UF 191448 there are only four teeth remaining (the 434 left Mf3-Mf5, and the right Mf8; Figure 6A). Among other H. floridanus, UF 121742 also has a 435 complete dentition, whereas at least partial dentitions are visible in the incompletely prepared 436 specimens UF 223813, 275496, 285000, and 293000. The upper molariforms in H. floridanus 437 are relatively short and broad compared to those in other pampatheres or glyptodonts (Table 1, 438 2). The occlusal surfaces of Mf2 and Mf3 are ovate in outline. The occlusal surface of Mf4 is 439 ovate in UF 191448 and almost rectangular in UF 293000, but reniform in UF 248500 and most 440 other specimens, with an occlusal surface that is concave lingually and convex labially. In UF 441 191448, Mf5 is reniform and concave labially, and Mf5 is bilobate in UF 285000 and 275498, 442 whereas in UF 248500 and the other H. floridanus specimens, Mf5-Mf7 are trilobate on the 443 lingual side, and bilobate on the labial side of the tooth, though the middle lingual lobe is often 
444 poorly marked. This causes these teeth to retain a bilobate gestalt, as is typical for pampatheres

445 (Hoffstetter 1958; Edmund 1985b; Edmund and Theodor 1997; De Iuliis and Edmund 2002).

446 Mf8 and Mf9 are bilobate on both sides of the jaw. The presence of reniform occlusal surfaces

447 on the anterior teeth and bilobate occlusal surfaces on the posterior teeth appears to be a

448 characteristic of pampatheres. H. septentrionalis has occlusal surfaces that are reniform from

449 Mf2-Mf4, but bilobate from M5-M9, as in H. floridanus (Edmund 1985b). H. occidentalis (ROM

450 3881) differs from H. floridanus and H. septentrionalis in that Mf3-Mf4 are more ovate in

451 outline, and the posterior lobes are displaced slightly laterally in Mf6-Mf9, whereas in other

452 pampatheres the lobes are linearly arranged. Vassallia is missing most of its teeth, but the

453 occlusal surface of the left Mf6 appears to be similar in shape to that of H. floridanus, albeit with

454 deeper lateral lobes (De Iuliis and Edmund 2002). Scirrotherium, Kraglievichia, and

455 Pampatherium appear to differ mainly in the size and shape of Mf4, with the tooth smaller and

456 more ovate in Scirrotherium (Edmund and Theodor 1997), and relatively larger than Holmesina

457 and bilobate in shape in the latter two genera (Simpson 1930; De Iuliis et al. 2000). In

458 Propalaehoplophorus, the anterior teeth are reniform, or weakly lobate in the case of Mf4,

459 reminiscent of the condition in pampatheres. However the posterior teeth are distinct in outline,

460 with Mf5-Mf6 irregularly shaped, weakly bilobate labially and trilobate lingually, whereas Mf7-

461 Mf9 are strongly trilobate on both sides. This trilobate pattern is a defining feature of glyptodonts

462 (Hoffstetter 1958; Gillette and Ray 1981). Proeutatus possesses anterior teeth with ovate cross-

463 sections as in Euphractus, whereas the back teeth are shaped like tear drops with the apex

464 pointing anteriorly and lingually (Scott 1903-4). Euphractus has ovate or circular occlusal

465 surfaces on all its teeth, as in other armadillos (Wible and Gaudin 2004; Gaudin and Wible

466 2006). 
In UF 248500, Mf2 possesses an oval island of osteodentine in the center of the tooth,

468 which becomes narrow and linear in Mf3-Mf4 and Mf9. Mf5 through Mf8 have a line of

469 osteodentine that is either Y-shaped or triangular at either end (Figure 6B). This osteodentine

470 pattern was consistently present among the other $H$. floridanus specimens that were examined

471 and appears in other pampatheres as well. In Propalaehoplophorus, each lobe of the molariforms

472 has a branched central ridge of osteodentine, as in other glyptodonts (Scott 1903-4; Gillette and

473 Ray 1981; Ferigolo 1985; Kalthoff 2011). In Proeutatus the posterior teeth also possess an

474 osteodentine core like glyptodonts and pampatheres, but this core forms a loop rather than a

475 linear or branched structure (FMNH P13197; Scott 1903-4). In Euphractus (CM 6399; UTCM

$4761486,1491)$, as in other armadillos, there is no osteodentine in the teeth. There is only an ovate

477 region of modified dentine in the center of each tooth (Ferigolo, 1985; Gaudin and Wible 2006;

478 Kalthoff, 2011).

Mf2 and Mf3 both have beveled crowns, with a mesial facet that is much larger than the 480 distal facet. The angle between the mesial and distal facets on Mf2 is more acute than that of Mf1, whereas in Mf3 the two facets form nearly a right angle. Mf4 and all of the remaining teeth

482 have but one flat occlusal surface. The long axis of the tooth crowns in UF 248500 are all angled 483 anteroventrally in lateral view (Figures 4, 5). Additionally, Mf2 and Mf3 are lingually oriented in 484 anterior view, Mf5-Mf7 are vertical, and Mf8-Mf9 are tilted labially. The corresponding occlusal 485 surfaces form a gently rolling planar surface that faces slightly ventrolaterally in the posterior 486 teeth, and faces progressively more ventromedially near the front of the toothrow. This is similar 487 to the condition occurring in glyptodonts, where the upper teeth slant lingually anteriorly and 488 labially posteriorly (Gaudin 2004). The posterior molariforms take on a stairstep appearance in 489 lateral view, with the occlusal surfaces slanting posteroventrally (Figures 4, 5). In ventral view, 
490 both Holmesina and Vassallia, the anterior left and right toothrows bend inward to form a nearly

491 closed dentition (Figures 6, 7). This is also the case in Kraglievichia and (to a lesser extent)

492 Pampatherium (Simpson 1930; Bordas 1939; De Iuliis et al. 2000), and likely represents a

493 derived trait of pampatheres. This feature is unusual among cingulates, but it is also present in

494 Macroeuphractus (Vizcaíno and De Iuliis 2003). This differs from the condition that occurs in

495 the extinct "horned" armadillo Peltephilus, where the dentition is fully closed anteriorly (Scott

496 1903-4; Vizcaíno and Fariña 1997; Gaudin and Wible 2006).

497

498 Palatine

499 The palatine bone consists in part of a large horizontal process that forms the back of the

500 hard palate, with the left and right bones separated medially by a raised suture (Figures 6, 7).

501 This elongated median ridge is a synapomorphy among euphractine armadillos, Eutatus,

502 Proeutatus, glyptodonts, and pampatheres (Node A, Gaudin and Wible 2006). However, the

503 median palatine ridge in both Euphractus and Proeutatus is more sharply defined than that of $H$.

504 floridanus. As noted above, the anterior apex of the maxillo-palatine suture in H. floridanus (UF

505 248500) lies opposite the midpoint of M8. The ventral surface of the horizontal process has a

506 few small perforations that appear to accommodate branches of the major palatine arteries, veins,

507 and nerves. The posterior-most region of the palatal surface may have one or two minor palatine

508 foramina of varying size (size and number vary both bilaterally and among specimens; these are

509 identified as minor palatine foramina because their openings are directed posteriorly, toward the

510 soft palate), and the posterior margin in some specimens is marked (on one side or both right and

511 left) by a deep notch that presumably served the same purpose (Figure 9), accommodating the

512 minor palatine nerves and vessels that service the soft palate (Wible and Gaudin 2004). The 
513 minor palatine foramen in UF 248500 opens into a caudal palatine foramen that is situated in the

514 floor of the sphenopalatine canal, just medial and anterior to the aperture of the sphenopalatine

515 foramen. This suggests that the caudal palatine foramen accommodated both the major and

516 minor palatine nerves and vessels, as in other xenarthrans (Wible and Gaudin 2004).

517 The posterior edge of the palatine, which forms the anteroventral margin of the choanae,

518 takes on a narrow U-shape. This configuration is a synapomorphy of glyptodonts and

519 pampatheres (Gaudin and Wible 2006). Moreover, the palatine extends only a short distance

520 beyond the toothrow posteriorly, which is a synapomorphy among Tolypeutes, euphractine

521 armadillos, Eutatus, Proeutatus, glyptodonts, and pampatheres (Node 5 of Gaudin and Wible

522 2006).

523 In several $H$. floridanus specimens examined, there was a transverse crack present behind

524 M9 but anterior to the minor palatine foramina. Although it is more or less symmetrical on the

525 right and left sides in UF 248500 (Figure 6B), and a similar crack is present in roughly the same

526 place in a couple of other specimens (UF 223813, 275496 [juvenile]), we have ultimately

527 decided that it is just a crack in the palatine, and not a suture. The posterolateral corner of the

528 palatine's horizontal process curves ventrally to form a large triangular flange. This flange

529 covers the robust pterygoid process on its anterior, ventral, medial surface. In H. floridanus (UF

530248500 ) this flange forms distinct sutures laterally and posteriorly with the pterygoid bone.

531 In lateral view, there is typically no exposure of the palatine in the orbit (UF 191448, UF

532 121742; Figure 8). In the juvenile specimen, UF 248500, there is a narrow portion of the

533 palatine's perpendicular process visible as a vertical splint lying between the maxilla anteriorly,

534 and the alisphenoid and pterygoid posteriorly. As noted above, this may be a temporary

535 condition, and the alisphenoid may have grown over it to cover the maxilla later in life. The 
536 dorsal edge of the palatine bone is broken in UF 248500, and the orbital sutures are fused in UF

537 191448. Thus the connections with the orbitosphenoid are unclear, though there is clearly no

538 contact with the squamosal. The lack of an orbital palatine exposure is likely an autapomorphy of

539 Holmesina, since an exposure is present in Vassallia (De Iuliis and Edmund 2002), glyptodonts

540 (Guth 1961) and Proeutatus and Euphractus (Wible and Gaudin 2004). The vertical process of

541 the palatine forms the anterolateral wall of the nasopharynx, contacting the presphenoid,

542 basisphenoid, and probably the vomer dorsally, although sutural fusion in UF 191448 and UF

543121742 and damage to UF 248500 make it difficult to determine the posterior extent of this part

544 of the palatine.

545

546 Pterygoid

547 The pterygoid in cingulates is generally a small bone that forms the posteroventral

548 margin of the orbit's medial wall, extending posteroventrally into a short pterygoid process or

549 hamulus. It typically forms a somewhat larger portion of the posterolateral wall of the

550 nasopharynx (Wible and Gaudin 2004). Although the sutures in this region of the skull are

551 difficult to interpret in the various specimens of $H$. floridanus, it would appear the pterygoid

552 bone occupies a similar position in this taxon. Its small, rectangular lateral surface contacts the

553 alisphenoid dorsally and the maxilla (and perhaps the palatine) anteriorly (Figures 4, 5, 8). There

554 is no contact between the pterygoid and squamosal bones, which is designated a derived feature

555 of Cingulata by Gaudin and Wible (2006), though it is likely a primitive feature of eutherian

556 mammals (Novacek 1986; Wible et al. 2004; Wible et al. 2009). Therefore, among xenarthrans,

557 the presence of a pterygoid/squamosal contact should be considered a derived feature of pilosans

558 instead. 
560 process. This kind of blunt, rough, thickened pterygoid process is a synapomorphy of

561 glyptodonts and pampatheres (Gaudin and Wible 2006; albeit an ambiguous synapomorphy, due

562 largely to the absence of preserved pterygoids in Proeutatus and a number of other fossil

563 armadillos closely allied to this clade). In H. floridanus, H. occidentalis (ROM 3881; Vizcaíno et

564 al. 1998) and Vassallia (FMNH P 14424; the relevant area in H. septentrionalis is not preserved

565 in the specimens we examined), the lateral surface of the pterygoid is covered with a variable

566 number of rugose ridges, typically around six, which are slanted in a generally anterodorsal to

567 posteroventral orientation. These ridges are also present in Propalaehoplophorus (Scott 1903-4)

568 although the pterygoid is much more dorsoventrally elongate in this genus. These ridges serve as

569 an attachment point for the robust medial pterygoid muscle in these herbivorous cingulates.

570 There are similar ridges on the lateral surface of the pterygoid of some sloths, although they are

571 less densely packed and organized somewhat differently (Gaudin 2004, 2011). The pterygoid

572 process is positioned lateral to the toothrow in ventral view (Figures 6, 7), which is also a

573 synapomorphy of pampatheres and glyptodonts (Gaudin and Wible, 2006).

574 In ventral view, the pterygoid of UF 248500 forms an L-shaped exposure that contributes

575 to the posterolateral corner of the hard palate, with a narrow portion comprising the pterygoid

576 process/lateral exposure of the pterygoid extending anteroposteriorly, and a narrow transverse

577 portion that extends medially (Figure 6B). A similar morphology is probably present in UF

578 121742, though the sutures are not always clear, whereas in some specimens (e.g., UF 191448,

579 UF 223813, UF 275496) there is no evidence of a suture between the pterygoid process and

580 palatine, though we suspect that this is the result of fusion. A palatal exposure of the pterygoid is

581 an unusual feature among cingulates (and among placental mammals in general; O`Leary et al., 
582 2013), but is a synapomorphy of the dasypodine armadillos Dasypus and Stegotherium (Gaudin

583 and Wible, 2006). At least the pterygoid process contribution to the palate may be more

584 widespread among pampatheres and glyptodonts. Though it is not mentioned in De Iuliis and

585 Edmund (2002), such a contribution is visible in Vassallia (FMNH P14424), and Guth illustrates

586 a similar morphology in Glyptodon (Guth 1961, fig. 123).

587 The dorsal portion of the pterygoid in UF 248500, which normally forms much of the 588 posterolateral wall of the nasopharynx in cingulates (Wible and Gaudin 2004), is strongly

589 reduced, extending dorsally as a triangular wedge only a short distance. In UF 121742, the

590 dorsal and medial exposure of the pterygoid appears larger, but still does not reach the roof of the

591 nasopharynx. Because of suture closure, it is unclear whether the area dorsal to the pterygoid in

592 the latter specimen is formed by palatine extending posterodorsally, or basisphenoid extending 593 ventrally.

594 We have observed several unusual morphologies associated with the pterygoid region in

595 individual specimens of H. floridanus. UF 121742 possesses two pterygoid processes - a large,

596 more laterally situated process that is clearly homologous to the pterygoid process of the other $H$.

597 floridanus specimens and other cingulates, and a smaller, more medially situated process

598 extending posteriorly from the back margin of the hard palate (Figure 9A). The presence of two

599 pterygoid processes or crests, an entopterygoid process/crest and an ectopterygoid process/crest,

600 is a feature that is widely observed among primitive eutherians [e.g., Zalambdalestes (Wible et

601 al., 2004); Lepticitis (Novacek, 1986)] and many extant placental mammals [e.g., Atelerix

602 (UTCM 727, 1553; Frost et al., 1991); Tupaia (UTCM 1980; Wible 2011); Elephantulus (UTCM

603 1482, 1512)]. The ectopterygoid process/crest is typically formed mostly by the alisphenoid, so

604 for those taxa with a single pterygoid process or hamulus formed by the pterygoid, it is generally 
605 homologized with the entopterygoid process/crest, as has been done for the armadillo

606 Euphractus by Wible and Gaudin (2004). If the lateral pterygoid process of UF 121742 is

607 indeed the entopterygoid process, as seems almost certain, the more medial process represents a

608 neomorph. We suspect this process represents an attachment point for enlarged pharyngeal or

609 masticatory muscles. If the muscular anatomy of Canis (Evans and Christiansen, 1979) can be

610 used as a model, the pterygopharyngeus seems a likely candidate.

611 In UF 191448, there is an unusual, vertical mass of cancellous pneumatized bone that lies

612 at the junction between the medial wall of the orbit and the lateral wall of the choanae. This mass

613 may be part of the pterygoid, due to its position in the skull, and the fact that it has a small

614 palatal exposure along the posterior margin of the palate that appears to match the medial,

615 transverse portion of the pterygoid palatal exposure in UF 248500 and other H. floridanus

616 specimens (Figure 9B). On the other hand, this mass appears to be completely surrounded by

617 sutures (including the palatal exposure), which would suggest that it too is a neomorphic feature.

618 Pneumatization of the pterygoid is rare among cingulates. However, it is commonplace among

619 pilosans, where inflated, often bullate pterygoids are known among myrmecophagid anteaters,

620 Megalocnus, Mylodon, some nothrotheriid sloths, the three-toed sloth Bradypus torquatus, and

621 the two-toed sloth genus Choloepus (Stock 1925; Guth 1961; Patterson et al. 1992; Gaudin 2004;

622 De Iuliis et al. 2011). This separate pneumatized mass of bone is only present in UF 191448, but

623 other $H$. floridanus specimens did display pneumatized bone around the posteromedial edge of

624 the choanae. This mass of bone in UF 191448 forms a discrete suture with the palatine and

625 basisphenoid anteriorly and dorsally, the palatine anteriorly and ventrally, and the pterygoid and

626 alisphenoid bones laterally.

627

628

\section{Lacrimal}


The lacrimal is shaped roughly like a parallelogram, with its long axis tilted

630 anterodorsally (Figures 4, 5, 8). It contacts the maxilla anteriorly and posteroventrally, the frontal

631 posterodorsally, and the jugal ventrally. The lacrimal consists of a facial and orbital process; the

632 boundary between these two processes is not particularly distinct. In Wible and Gaudin (2004),

633 the low ridge that runs from the postorbital process of the frontal ventrally onto the jugal, the

634 antorbital ridge, was used as a rough boundary between the facial and orbital processes. The

635 antorbital ridge exhibits some variation in its development among $H$. floridanus specimens. The

636 position of the lacrimal foramen also varies among pampatheres. In the majority of pampathere

637 specimens examined in this study, the lacrimal foramen is located on the antorbital ridge, that is,

638 on the boundary between the facial and orbital processes, as it is in Proeutatus (FMNH P13199)

639 and Euphractus (Wible and Gaudin 2004). In H. septentrionalis (UF 889, 243224) and Vassallia

640 (P 14424), however, the lacrimal foramen is located anterior to the antorbital ridge; therefore, it

641 is clearly situated on the facial process. This is apparently also the condition in primitive

642 glyptodonts (Scott 1903-4). In Euphractus, Proeutatus, and most of the pampatheres and

643 glyptodonts examined, the lacrimal foramen is relatively small. However, in H. septentrionalis

644 (UF 889) the lacrimal foramen is situated within a much larger, circular depression. A similar,

645 but more dorsoventrally ovate depression appears to be present in $H$. septentrionalis (UF

646 243224), as well as in Propalaehoplophorus (YPM VPPU 15007), although in this specimen the

647 depression opens posteriorly. The lacrimal foramen transmits the nasolacrimal duct from the eye

648 to the nasal cavity (Wible and Gaudin 2004). Just dorsal to the lacrimal foramen is a rugose area,

649 the lacrimal tubercle (Figures 4, 5, 8). In UF 191448, the tubercle is small, and continuous with

650 a crest that extends ventrally onto the zygoma anterior to the lacrimal foramen (Wible and

651 Gaudin 2004). The lacrimal tubercle is much larger in UF 248500, and contacts not only this 
652 anterior crest, but the antorbital ridge as well. A lacrimal tubercle is present in all cingulates,

653 with the exception of Dasypus and Stegotherium (Gaudin and Wible 2006), and is distinct from

654 the rest of the lacrimal surface, which is generally smooth.

655 The facial process of the lacrimal bone in H. floridanus (UF 191448, et al.), and other

656 pampatheres (H. occidentalis; Vassallia), is typically triangular in shape (Figures 4, 5, 8). The

657 shape is more variable in $H$. septentrionalis. In UF 889 , it is triangular as in other pampatheres,

658 but the anterodorsal apex of the triangle is elongated with a rounded tip, whereas in UF 234224

659 the facial process is more ovate than triangular, elongated dorsoventrally. Euphractus has a

660 quadrangular facial process (Wible and Gaudin 2004; Gaudin and Wible 2006). According to

661 Gaudin and Wible (2006), a quadrangular facial process is a synapomorphy of the clade

662 including Eutatus, euphractine armadillos, Proeutatus, glyptodonts, and pampatheres (Node B of

663 Gaudin and Wible 2006), although the latter revert to the triangular shape characteristic of

664 dasypodine and tolypeutine armadillos.

665 The orbital process of the lacrimal bone in H. floridanus is also triangular, but it is

666 somewhat smaller than the facial process (Figures 4, 5, 8). The lacrimal contributes to a small

667 portion of the anterior orbital wall, where it contacts the jugal anterolaterally, and the frontal

668 posteriorly. There is also a small lacrimal contact with the maxilla posteroventrally, on the

669 orbital side of the jugal in H. floridanus (UF 191448, 248500), as in Euphractus (UTCM 1486,

670 1491; Wible and Gaudin 2004). This trait, the presence of lacrimal contact with the orbital

671 process of the maxilla, is a synapomorphy of Tolypeutes, Eutatus, euphractine armadillos,

672 Proeutatus, pampatheres, and glyptodonts (Node 4 of Gaudin and Wible 2006). The lacrimal

673 fenestra, which perforates the lower edge of the orbital process of the lacrimal, serves as the site

674 of origin for the inferior oblique muscle, and is present at the intersection of the lacrimal, frontal, 
675 and maxilla in H. floridanus (Gaudin and Wible 2006; Wible and Gaudin 2004). This condition

676 is primitive, and occurs in all cingulates with the exception of Dasypus, Stegotherium, Zaedyus,

677 and Chlamyphorus (Gaudin and Wible 2006).

678

679 Jugal

680 The jugal forms the anterior portion of the zygomatic arch. In H. floridanus (UF 248500,

681 UF 191448) the dorsal edge of the jugal is U-shaped, whereas the ventral edge is irregular

682 (Figures 4, 5). The jugal can be divided into two processes, facial and zygomatic. Roughly half

683 of the anterior root of the zygoma is comprised of the transversely broad facial process of the

684 jugal bone, which contacts the lacrimal dorsally, the maxilla anteriorly, ventrally, and medially.

685 The zygomatic process is oriented almost perpendicular to the facial process, and is strongly

686 compressed mediolaterally and deep dorsoventrally. It has a dorsoventrally convex surface

687 laterally, and is concave medially. In lateral view it broadens posteriorly toward its posterior

688 contact with the squamosal, near the middle of the zygomatic arch. The jugal-squamosal suture

689 in UF 248500 is asymmetrically concave posteriorly, with the anterodorsally oriented ventral

690 portion more elongate than posterodorsally sloped dorsal portion (Figure 4B, C). In UF 191448,

691 the junction between these dorsal and ventral portions is more angular (Figure 4A). In UF

692248500 , the posterodorsal edge of the zygomatic process is extended into a sharp, triangular

693 postorbital process. In UF 191448, the postorbital process is more rounded, and formed jointly

694 by the jugal and squamosal. The jugal/squamosal contact in H. occidentalis (ROM 3881) and

695 Vassallia (De Iuliis and Edmund 2002) shows a similar pattern, though in the latter the

696 postorbital process is carried largely by the squamosal rather than the jugal. In contrast to the

697 pampathere condition, in both Propalaehoplophorus and Proeutatus (Scott 1903-4) there is a 
698 substantial posterior extension of the jugal underneath the zygomatic process of the squamosal,

699 so that much of the jugal/squamosal suture is horizontal, as in euphractine armadillos (Wetzel

700 1985; Wible and Gaudin 2004). The postorbital process on the zygomatic arch is also less well

701 developed in Euphractus (but not Chaetophractus or Zaedyus; Wetzel 1985; Wible and Gaudin

702 2004), Proeutatus (FMNH 13197; Scott 1903-4), and some specimens of Propalaehoplophorus

703 (e.g., FMNH P13205, Propalaehoplophorus sp.; P. australis, Scott 1903-4 plate 23; but not

704 YPM VPPU 15007, P. australis, or P. minor, Scott 1903-4 plate 27).

705 The facial process extends ventrally and slightly laterally into a prominent ventral (or

706 descending) process of the zygomatic arch. This ventral process is in fact an anteromedial to

707 posterolaterally extended, cresecent-shaped complex, comprised of a variable number of strong

708 rugose bumps or transverse ridges. In UF 248500, there are only two bumps/ridges (Figure 4B,

7095,7 ), with the more anterior being formed in part by the jugal and in part by the maxilla. In other

710 specimens, there may be as many as four (e.g., UF 275498, 285000 on L only). In some

711 specimens, this ventral zygomatic process (or complex of processes) appears worn, although it is

712 unclear if this is reflective of the age of the specimen (they do seem less "worn" in juvenile

713 specimens) or due to some sort of post-mortem abrasion.

714 Holmesina occidentalis and Vassallia have ventral zygomatic processes quite similar to

715 those in H. floridanus, with three bumps or ridges that are heavily worn in the Vassallia

716 specimen [FMNH P14424; De Iuliis and Edmund (2002), who also report a similar morphology

717 in Pampatherium; Vizcaíno et al. (1998: p. 297-298) note that the ventral process is "narrower

718 and less rugose" in H. occidentalis than in Vassallia]. The ventral zygomatic process of

719 pampatheres is comparable in position to the small boss present in Euphractus (Wible and

720 Gaudin 2004; Gaudin and Wible 2006) and Proeutatus (FMNH P13197; Gaudin and Wible 
721 2006), but is much larger in size. Propalaehoplophorus and other glyptodonts possess a gigantic

722 descending process (Hoffstetter 1958; Gaudin and Wible 2006) that forms a greatly elongated,

723 anteroposteriorly compressed plate of bone, but unlike Holmesina, this process is primarily

724 formed by the maxilla (YPM VPPU 15007; Gillette and Ray 1981), the jugal forming only a

725 small portion of the dorsolateral margin. This descending process is greatly enlarged in order to

726 accommodate the bulky masseter muscle in glyptodonts (Gillette and Ray 1981), and this is

727 likely the case in pampatheres, though the masseter would have been enlarged to a lesser degree.

728

729 Frontal

730 The frontal bone in H. floridanus forms slightly less than a third of the total skull length,

731 including the anterior half of the braincase. It is shaped roughly like a pentagon in dorsal view,

732 broadening dramatically in its anterior reaches (Figures 2,3). This is due to the presence of

733 enlarged sinuses beneath the frontal bone, a feature present in many other cingulates (Gaudin and

734 Wible 2006; Billet et al. 2017). The median interfrontal suture is fused in all the adult and

735 subadult specimens of $H$. floridanus, with the sole exception of the youngest specimen, UF

736 275496. The interfrontal suture is also fused at least posteriorly in H. occidentalis (ROM 3881),

737 and along its entire length in Vassallia (FMNH P14424) and Propalaehoplophorus (YPM-VPPU

738 15007; although apparently not in Scott's 1903-04 illustration of P. australis, pl. XXIII, fig. 3),

739 but not in H. septentrionalis (UF 889), Proeutatus (FMNH P13197), or Euphractus (UTCM

740 1486, 1491; Wible and Gaudin 2004). The frontal bone contacts the nasal, maxilla, and lacrimal

741 bones anteriorly and the parietal posteriorly on the skull roof. It dips ventrally and laterally into

742 the orbit to form a sizeable portion of the medial orbital wall (Figures 4, 5, 8). The orbital portion

743 of the frontal likely contacts the maxilla, orbitosphenoid and alisphenoid ventrally, and the 
744 squamosal posteroventrally, creating a triangular exposure in lateral view that is similar to that of

745 Euphractus (UTCM 1491; Wible and Gaudin 2006). The fronto-parietal suture is a very irregular

746 and jagged line that travels slightly anterodorsally across the top of the braincase from a position

747 even with the anterior edge of the glenoid fossa, as in Proeuphractus, Proeutatus, other

748 pampatheres, and glyptodonts (Node E of Gaudin and Wible 2006). This differs from

749 Euphractus in which the most lateral part of fronto-parietal suture lies posterior to the anterior

750 edge of the glenoid fossa (Wible and Gaudin 2004; Gaudin and Wible 2006).

751 The frontal bone in H. floridanus has very distinct temporal lines curving postermedially

752 from the large, blunt postorbital processes (Figures 2, 3). The posterior half of the fused

753 interfrontal suture is elevated by a prominent midline crest in UF 248500, that extends unbroken

754 between the temporal lines back along the midline of the parietal, all the way to the nuchal crest.

755 A ridge of similar extent is present in UF 191448, but it is much more weakly developed. Wible

756 and Gaudin (2004) describe a weakly developed crest in a similar position in Euphractus, where

757 it serves as a site of origin for the orbito-auricularis muscle. The crest is also present in $H$.

758 occidentalis and Proeutatus (FMNH P1319; Scott 1903-4). It is present on the frontal only in $H$.

759 septentrionalis (UF 889) and Vassallia (FMNH P14424), being replaced posteriorly by a true

760 sagittal crest. It is missing entirely in Propalaehoplophorus, where again there is a strong

761 sagittal crest (FMNH P13205; YPM VPPU 15007; Scott 1903-4). It is likely that the presence of

762 a strong ridge in this position is related to the presence of large pinnae for the ears.

763 As is typical of euphractine armadillos, Proeutatus, pampatheres and glyptodonts, there

764 are numerous small nutritive foramina in UF 191448 that coalesce around the midline of the

765 frontal dorsally, just anterior to the frontal-parietal suture, in a depression between the temporal

766 lines and behind the frontal sinuses (Node $\mathrm{C}$ of Gaudin and Wible 2006). These foramina are less 
767 evident in UF 248500. In lateral view, within the temporal fossa, there are also foramina along

768 the posterolateral region of the frontal bone in eutatine armadillos, euphractine armadillos,

769 Proeutatus, Vassallia and glyptodonts (Node A of Gaudin and Wible 2006). These appear to be

770 absent in H. floridanus, though they are present in H. occidentalis (ROM 3881).

771 In addition to these foramina, the frontal is marked by two other types of foramina within

772 the orbit (Figure 8). UF 191448 has a pair of asymmetrical foramina for the frontal diploic vein

773 (sensu Wible and Gaudin 2004; =supraorbital foramina of Gaudin 2004 and others). On the left,

774 there is a single opening situated ventral and posterior to the broad, low, rugose area that marks

775 the postorbital process. On the right, there are two foramina, one mirroring the opening on the

776 left, the other, smaller opening situated further anterior and dorsal, virtually on the process itself.

777 The left side of UF 248500 is damaged in the region of the postorbital process, but the right side

778 has a single foramen like that described for UF 191448. In UF 121742, the foramen is more

779 anteriorly situated, lying in front of a strong infratemporal crest that extends posteroventrally

780 from the postorbital process, a crest that is only weakly developed in UF 191448. The

781 morphology of UF 121742 is also found in H. septentrionalis (UF 889, UF 234224) and

782 Vassallia (UF P14424). The foramen for the frontal diploic vein also occurs in a similar position

783 in glyptodonts (Gaudin 2004), whereas in Proeutatus it is situated more posteriorly (FMNH

784 P13197).

785 The ventral portion of the orbital wing in UF 121742 is marked by a ventrally directed

786 foramen that lies between the infratemporal crest and a rounded ridge that marks the dorsal

787 margin of the optic foramen (Figure 8). Given the position of this opening, anterodorsal to the

788 optic foramen, and its connection to an anteriorly-directed canal, we identify it as the ethmoid

789 foramen (sensu Wible and Gaudin 2004; transmits the ethmoidal nerve and vessels). Other 
790 cingulates may have as many as three ethmoid foramina (Gaudin and Wible 2006). Although

791 sutures are not unambiguous in this area, the opening appears to be contained entirely within the

792 frontal, in contrast to some cingulates in which there is orbitosphenoid participation in the rim

793 (Gaudin and Wible 2006). In UF 248500, there appears to be a second ethmoid foramen, just

794 dorsal to the first and separated from it by the infratemporal crest.

795

796

Parietal

797

The parietal bone is roughly rectangular and forms the posterior half of the braincase

798 (Figures 2-5). It contacts the frontal anteriorly, the squamosal ventrolaterally, and the supraoccipital posteriorly. As in most cingulates, with the exception of Peltephilus, there is no

800 contact between the parietal and the alisphenoid bones (Figure 8) due to an extensive contact

801 between the frontal and squamosal bones (Node 2 of Gaudin and Wible 2006; see also Novacek

802 and Wyss 1986; Rose and Emry 1993; Gaudin et al. 1996). Although the parietal tends to be

803 relatively flat transversely in eutatine and euphractine armadillos and in glyptodonts (Gaudin and

804 Wible 2006), in H. floridanus and other pampatheres (Cartelle and Bohórquez 1985; De Iuliis et

805 al. 2000; De Iuliis and Edmund 2002) it is strongly convex transversely, giving the braincase a

806 much more tubular appearance. The parietals are marked by strong temporal lines, which

807 approach one another, but do not unite to form a midline sagittal crest. As noted above in the

808 description of the frontal, the parietals do carry a midline crest for the extrinsic ear muscles

809 between the temporal lines. This morphology, which also characterizes H. occidentalis (ROM

810 3881), is very reminiscent of the pattern in Proeutatus (FMNH 13197; Scott 1903-4) and some

811 specimens of Euphractus (Wible and Gaudin 2004). A true sagittal crest is present on the

812 parietals in H. septentrionalis (UF 889), Vassallia (De Iuliis and Edmund 2002), and 
813 Propalaehoplophorus (Scott 1903-4) and other glyptodonts (Gillette and Ray, 1981), as noted

814 above. Both the temporal lines and the midline crest unite posteriorly with a robust nuchal crest.

815 The nuchal crest is of uniform thickness along the posterior edge of the skull, as is characteristic

816 of Tolypeutes, eutatine armadillos, euphractine armadillos, Proeutatus, pampatheres, and

817 glyptodonts (Node 5 of Gaudin and Wible 2006). It is strongly convex posteriorly, overhanging

818 the dorsal potion of the occiput.

819 Within the temporal fossa in H. floridanus, the parietal surface is heavily pitted with a

820 large but variable number of foramina (12-16 in UF 191448 and 248500), especially in the

821 ventrolateral half of the bone. The more dorsally located foramina open into distinct grooves,

822 traveling at various angles, through which the rami temporales emerge. The presence of so many

823 temporal foramina (greater than 5) is a synapomorphy of Priodontes, Tolypeutes, eutatine

824 armadillos, euphractine armadillos, Proeutatus, pampatheres, and glyptodonts (Node 3 of Gaudin 825 and Wible 2006).

826

\section{Squamosal}

828 The squamosal consists of two broad regions, the squamous part and the zygomatic

829 process (Figures 2-8). The squamous part comprises a roughly rectangular, vertical exposure in

830 the lateral wall of the braincase, contacting the frontal anteriorly, the alisphenoid and petrosal

831 ventrally, and the parietal dorsally. It also has a lappet that wraps around the nuchal crest to

832 form a small, triangular exposure on the occiput, contacting the occipital exposure of the mastoid

833 petrosal ventrally, and the supraoccipital dorsally. Euphractus has a very similar occipital

834 exposure of the squamosal (Wible and Gaudin 2004), and according to Gaudin and Wible

835 (2006), this feature is a synapomorphy of euphractine aramadillos, pampatheres and glyptodonts 
836 (Node C of Gaudin and Wible 2006). The anterior portions of the squamosal/ parietal suture and

837 the dorsal portions of the squamosal/frontal suture form a slightly raised ridge, as they do in

838 some Euphractus (Wible and Gaudin 2004) and in Vassallia (De Iuliis and Edmund 2002) and

839 Propalaehoplophorus (YPM VPPU 15007). Like the parietal, the squamous region's posterior

840 and dorsal surface is marked by a variable number (5-12 in UF 191448 and UF 248500) of

841 foramina for the rami temporales. This is a common feature in cingulates. The squamous part of

842 the squamosal is crossed horizontally by a crest that connects the dorsal edge of the zygomatic

843 process to the nuchal crest, marking the lower limit of the temporal fossa (Figures 4,5 ). This is

844 also a feature in H. occidentalis (ROM 3881) and H. septentrionalis (UF 234224), as well as

845 Proeutatus (FMNH P13197) and Propalaehoplophorus (YPM VPPU 15007; Scott 1903-4),

846 whereas in Vassallia (De Iuliis and Edmund 2002) the ventral end of the nuchal crest passes

847 lateral to the crest extending posteriorly from the dorsal edge of the zygoma, so that the two

848 approach but do not contact. The latter is similar to the condition in Euphractus (Wible and

849 Gaudin 2004).

850 The region of the squamosal immediately ventral to the lower ridge of the temporal fossa

851 is strongly convex anteroposteriorly, forming a porus acousticus that would have accommodated

852 the external auditory meatus. The posterior wall of the porus is formed by a flat, roughly ovate

853 ventral projection that abuts the anterior base of the petrosal's paroccipital process (=mastoid

854 process of Patterson et al. 1989; Gaudin 1995). This projection is the post-tympanic process of

855 the squamosal (Figure 7). In UF 191448, it has a somewhat thickened ventral edge that may

856 have participated in the facet for the posterior crus of the ectotympanic. The lower anterior wall

857 of the porus is formed by a freestanding ridge, the postglenoid process (Figure 10). As in

858 Euphractus (Wible and Gaudin 2004) and a few other eutherians (e.g., Zalambdalestes, Wible et 
859 al. 2004), the postglenoid process lies posterior to the postglenoid foramen in $H$. floridanus. The

860 postglenoid process and post-tympanic process approach one another medially at roughly a $60^{\circ}$ -

$86175^{\circ}$ angle in ventral view (it is more acute in UF 248500 than in UF 191448), with the porus

862 narrowing accordingly (Figures 7, 10). The morphology of this region of the skull in Vassallia

863 (FMNH P14424) is very similar to that of H. floridanus. Propalaehoplophorus (YPM VPPU

$86415007)$ is also similar, though the porus is narrower, with a much more acute angle $\left(<20^{\circ}\right)$

865 between the postglenoid and post-tympanic process, and the former is much larger that it is in $H$.

866 floridanus. Proeutatus (FMNH P13197) has a very odd morphology in this region of the skull.

867 The glenoid is situated so far posteriorly that it approaches the ventral end of the nuchal crest.

868 As a consequence, the porus acousticus is reduced to a narrow vertical groove, and the process

869 identified as the post-tympanic process by Patterson et al. (1989) is actually two processes, the

870 post-tympanic process and the immediately adjacent postglenoid process (the two distinct tips of

871 these processes are visible in the lateral view of the skull in Patterson et al. 1989, fig. 13A). In

872 H. floridanus 191448, there is a bilateral foramen just lateral and dorsal to the anterior end of the

873 postglenoid process (Figures 4A, 5). This is likely homologous to the suprameatal foramen

874 found in some Euphractus specimens (Wible and Gaudin 2004; it transmits a ramus temporalis

875 of the stapedial artery system). Like Euphractus, the presence of this foramen may be variable in

876 Holmesina, because it is absent in UF 248500 and UF 121742.

877 Anterior and medial to the postglenoid process is a small, circular depression that

878 represents the squamosal contribution to the epitympanic recess, accommodating the

879 mallear/incudal articulation (Figure 10). The squamosal forms roughly $2 / 3$ of this depression, the

880 remainder formed by the lateral reaches of the petrosal. In Propalaehoplophorus (YPM VPPU 
881 15007), the epitympanic recess is ovate rather than circular, elongated along a posterolateral to 882 anteromedial axis.

883 Anterior and medial to the epitympanic recess is a massive process that extends as a

884 broad ridge laterally and ventrally, forming the anterolateral wall to the tympanic cavity. This is

885 the entoglenoid process, which extends across the squamosal/alisphenoid suture and onto the

886 alisphenoid behind the foramen ovale (Figure 10). The posterior surface of this process is

887 marked by a circular depression that almost certainly represents the facet for the anterior crus of

888 the ectotympanic. At its posterior, dorsal and medial extremity, the entoglenoid process abuts

889 the small anteroventral process of the tegmen tympani on the petrosal (=processus crista facialis

890 of Patterson et al. 1989; Gaudin 1995; Wible and Gaudin 2004), which may have a small

891 contribution to the ectotympanic facet. A similar entoglenoid process is present in Vassallia

892 (FMNH P14424), Propalaehoplophorus (YPM VPPU 15007), and Proeutatus (FMNH P13197).

893 In the latter two, it appears to be somewhat inflated.

894 In ventral view, the root of the zygomatic process is triangular, extending (and

895 narrowing) laterally, as it does in all pampatheres and glyptodonts (Node 8 of Gaudin and Wible

896 2006). Its dorsal surface is deeply concave transversely to house the temporalis muscles. On its

897 ventral surface, it carries the glenoid articulation for the mandible. Just beyond the lateral edge

898 of the glenoid, the process curves anteriorly in a graceful arc. In lateral view, it deepens

899 considerably in a dorsoventral plane as it approaches its anterior contact with the jugal, with

900 which it forms the zygomatic arch. As noted above, it may or may not contribute to the

901 postorbital process on the zygoma. Propalaehoplophorus (Scott 1903-4), Proeutatus (Scott

902 1903-4), and Euphractus (Wible and Gaudin 2004) and other euphractine armadillos (Wetzel

903 1985) all lack the anterior broadening of the zygomatic process seen in pampatheres (Cartelle 
904 and Bohórquez 1985; De Iuliis et al. 2000; De Iuliis and Edmund 2002). Like the zygomatic

905 portions of the jugal, the zygomatic region of the squamosal is convex laterally and concave 906 medially.

907 The glenoid articular surface on the ventral side of the zygomatic root is convex in both 908 transverse and anteroposterior planes, as it is in most eutatine and euphractine armadillos and in 909 glyptodonts and other pampatheres (Node B of Gaudin and Wible 2004; Vizcaíno et al. 1998).

910 Its shape is somewhat more unusual however, forming a rounded triangle, narrowing laterally,

911 with its transverse width much greater than its anteroposterior length (Tables 1,2). Glyptodonts

912 show similar transverse extension of the glenoid, though the shape of the facet is generally more

913 rectangular and even narrower anteroposteriorly (Scott 1903-4; Gaudin 2004; Gaudin and Wible

914 2006), whereas in eutatine and euphractine armadillos the glenoid is more U-shaped, and as long

915 or longer in the anteroposterior as opposed to the transverse dimension (Gaudin and Wible

916 2006). As in other cingulates, there is a postglenoid foramen in H. floridanus. Like other

917 pampatheres and glytopdonts, this foramen is clearly visible in ventral view (Figures 7, 10),

918 because the external auditory meatus is positioned well behind the glenoid, exposing the

919 postglenoid fossa in which the foramen is situated (Gaudin and Wible 2006). In euphractine and

920 eutatine armadillos this area tends to be obscured by the nearby ectotympanic. The postglenoid

921 foramen transmits the capsuloparietal emissary vein in Euphractus (Wible and Gaudin 2004).

922

\section{Petrosal}

924 The petrosal bone is preserved in situ in UF 191448 and on the right side of UF 248500

925 (Figures $6,7,10$ ), whereas a nearly complete, isolated left petrosal is available in the latter

926 specimen (Figure 11). This will allow us to describe in detail not only the ventral exposure of the 
927 bone, but also its dorsal and lateral surfaces. The petrosal, which houses the inner ear, is

928 bordered by the squamosal laterally, the exoccipital posteromedially, the supraoccipital dorsally,

929 and the basioccipital and basisphenoid medially. It is comprised of two primary regions, the pars

930 canalicularis housing the semicircular canals and vestibular apparatus, and the pars cochlearis

931 housing the cochlea (MacIntyre 1972). In ventral and lateral view, these are represented most

932 notably by the mastoid region and promontorium, respectively.

933 The promontorium of H. floridanus is globose, and lacks any clear grooves for arteries or

934 nerves, as is typical for cingulates (Guth 1961; Bugge 1979; Patterson et al. 1989; Wible and

935 Gaudin 2004; Wible 2010). At its anterior pole, it is marked by a distinctive, elongate triangular

936 process, the rostral tympanic process of the petrosal (Figures 7, 10, 11). Wible (2010) describes

937 a small blunt rostral tympanic process that is present to a varying degree in some Dasypus

938 novemcinctus, but no such process is present in Euphractus (Wible and Gaudin 2004). In

939 Vassallia, Propalaehoplophorus and other glyptodonts, and Proeutatus (Guth 1961; Patterson et

940 al. 1989), the entire promontorium is elongated anteromedially, giving the promontorium a

941 teardrop shape in ventral view. It seems likely that the anteromedial elongation of the

942 promontorium in the pampathere/glyptodont/Proeutatus clade is homologous to the rostral

943 tympanic process in $H$. floridanus; i.e., the rostral process broadens posteriorly in the former

944 group, so that it blends in with the contour of the promontorium, whereas the process in $H$.

945 floridanus is substantially reduced in length and breadth, especially posteriorly, but this makes it

946 look like a more distinct, separate process than in the related taxa. The Eocene dasypodine

947 described by Babot et al. (2012) also has an anteromedially elongate petrosal, but this is

948 attributed to the presence of a short epitympanic wing and elongate tensor tympani fossa rather

949 than the presence of a rostral tympanic process. The anterolateral surface of the promontorium 
950 in UF 248500 is marked by a large, slightly raised circular boss of unclear function (Figure 11A-

951 D). This feature is also present in UF 223813, but is less clear in UF 191448, and is not at all

952 evident in Vassallia (FMNH P14424).

953 Extensive shelving surrounds the promontorium of $H$. floridanus in ventral view. This

954 includes not only the lateral facial sulcus and crista parotica typical of mammalian petrosals

955 (MacIntyre 1972; Wible et al. 2009), but also an extensive epitympanic wing anteriorly and a

956 medial flange medially (Figure 11A-D). The epitympanic wing is separated by a sizable gap

957 from the underlying rostral tympanic process. In its anterolateral corner, it carries a fossa,

958 particularly well developed in UF 191448 (also UF 223813, 275496), just medial to the groove

959 for the greater petrosal nerve (Figure 11A-D; see description of groove below). A small

960 epitympanic wing is present is Dasypus (Wible 2010) and Eocene dasypodines (Babot et al.

961 2012), but is much better developed in Euphractus (Wible and Gaudin 2004). An epitympanic

962 wing is also present in Vassallia (FMNH P14424), though it is somewhat less extensive

963 anteriorly. Like Holmesina, there is a depression between it and the anteromedial extension of

964 the promontorium, lying just medial to a groove for the greater petrosal nerve. The epitympanic

965 wing is evidently absent in Proeutatus (Patterson et al. 1989) and Propalaehoplophorus (YPM

966 VPPU 15007; FMNH P13205).

967 In extant Dasypus (Wible 2010) and Euphractus (Wible and Gaudin 2004), the tensor

968 tympani muscle attaches to the tegmen tympani, lateral to the greater petrosal nerve. However,

969 the tegmen is much reduced in Holmesina and Plaina, and thus we think the tensor tympani

970 likely attached someplace medial to the greater petrosal nerve, as in the the Eocene dasypodine

971 described by Babot et al. (2012) and the basal eutherian Zalambdalestes (Wible et al. 2004),

972 where it attaches to the anterolateral surface of the promontorium. This attachment site in 
973 pampatheres could be either the fossa in the epitympanic wing, or the boss on the anterolateral

974 surface of the petrosal, both described above (Figures 10, 11A-D). Given that the fossa is

975 present in Vassallia and Holmesina, whereas the boss is present in only some specimens of $H$.

976 floridanus, we believe the fossa the more likely location, but we cannot rule out the other. In

977 Proeutatus (Patterson et al. 1989) and Propalaehoplophorus (YPM VPPU 15007; FMNH

978 P13205), which have a reduced tegmen tympani like pampatheres, but lack an epitympanic wing

979 of the petrosal, the tensor tympani likely attaches to the anterolateral surface of the

980 promontorium, as in Eocene dasypodines and Zalambdalestes (Wible et al. 2004; Babot et al.

981 2012).

982 The medial flange of the petrosal in H. floridanus is quite extensive both transversely and

983 anteroposteriorly (especially in juvenile specimen UF 275496) when compared to that of

984 Dasypus (Wible 2010) or Eocene dasypodines (Babot et al. 2012). In contrast to both of the

985 latter forms, it extends as far forward as the epitympanic wing, creating a squared off anterior

986 edge for the petrosal, and it is covered by a variety of pits and low ridges. The most prominent

987 of these is a pit that is situated at roughly the midpoint of the medial flange, which serves as a

988 point of attachment for the basioccipital (Figure 11A-D). In Dasypus, a patent basicochlear

989 fissure is maintained into adulthood, so that there is no medial connection between the petrosal

990 and the floor of the basicranium (Wible 2010). Immediately behind this basioccipital facet is a

991 prominent foramen, the cochlear canaliculus (for the perilymphatic duct-see Clemente 1985;

992 Evans and Christiansen 1979; Wible 2010). The medial flange in H. floridanus also differs from

993 that of Dasypus and Eocene dasypodines in that it extends posteriorly beyond the cochlear

994 canaliculus, reaching the region termed the "triangular shelf" in Dasypus (Wible 2010), that is,

995 the roof of the post-promontorial sinus. In so doing it forms a shallow jugular notch, i.e., the 
996 anteromedial edge to the jugular foramen. The medial flange of the petrosal is difficult to

997 observe in Vassallia, Propalaehoplophorus, Proeutatus, and even the extant Euphractus,

998 because of the lack of preserved, isolated petrosals in these taxa. However, it is clear the latter

999 has an extensive contact between petrosal and basicranium, whereas only a small

1000 basioccipital/petrosal contact is present in Vassallia (FMNH P14424) and Proeutatus (FMNH

1001 P13197), as in Holmesina.

1002 Holmesina floridanus has three prominent foramina in the ventral exposure of the pars

1003 cochlearis. The most anterior of these is the laterally directed primary facial foramen, which is

1004 hidden in ventral view by a low ridge at the base of the promontorium, and in lateral view by the

1005 anteroventral process of the tegmen tympani. This opening transmits the facial nerve (c.n. VII)

1006 to the middle ear space (Wible and Gaudin 2004). In some Dasypus (as in most therians - Wible

1007 1990, 2003), the space immediately lateral to the primary facial foramen, the cavum

1008 supracochleare, has a bony floor, creating a discrete hiatus Fallopii and secondary facial foramen

1009 anterior and posterior to the cavum, respectively (Wible 2010). This floor is not present in any

1010 Holmesina floridanus specimen, nor is it known to occur in Eocene dasypodines (Babot et al.

1011 2102), Euphractus (Wible and Gaudin 2004), Proeutatus (FMNH P13197), Vassallia (FMNH

1012 P14424), or any glyptodont (e.g., Propalaehoplophorus, YPM VPPU 15007, FMNH P13205;

1013 see also Patterson et al. 1989).

1014 The second foramen in the ventral pars cochlearis is a larger, laterally directed opening

1015 posterior to the primary facial foramen, the fenestra vestibuli, which accommodates the footplate

1016 of the stapes (Figure 11A-F). As in Dasypus and Euphractus (Wible and Gaudin 2004; Wible

1017 2010), the opening of the fenestra vestibuli is somewhat recessed, and surrounded by a narrow

1018 rim of bone. The opening is rounder in H. floridanus than in the extant forms, with a stapedial 
1019 ratio (sensu Segall, 1970; Length/width) of $\sim 1.4$, whereas it is 1.9 in Dasypus and 1.9-2.0 in

1020 Euphractus. Proeutatus (FMNH P13197) and Propalaehoplophorus (FMNH P13205) also

1021 resemble the living taxa in this regard, with ratios of 2.4 and 1.8 respectively. The Eocene

1022 dasypodine described by Babot et al. (2012) is intermediate in this regard, with a stapedial ratio 1023 of 1.6.

1024 The third opening in the pars cochlearis' ventral surface is a posteriorly directed foramen 1025 separated from the rim of the fenestra vestibuli by a broad bar of bone, the crista interfenestralis, 1026 This opening is generally called the fenestra cochleae (we follow Patterson et al. 1992; Gaudin 1027 1995; Wible and Gaudin 2004 in using this widely recognized term), although, as Wible (2010)

1028 points out, the latter is actually a separate hole recessed within the cochlear fossula, and this 1029 more superficial, posteriorly facing foramen is actually the external aperture of the cochlear 1030 fossula. The "fenestra cochleae" of $H$. floridanus is unusual in several respects. First, it is very

1031 wide and low, with a ratio of width to depth equal to approximately 3.4 (Figure 12B). In Dasypus 1032 (Wible 2010) and Propalaehoplophorus (FMNH P13205), the ratio is closer to 2, whereas in 1033 Euphractus (UTCM 1491) and Proeutatus (FMNH P13197, P13199) the ratio is between 1.0-

1034 1.2. Although we could not obtain measurements for Vassallia, it appears similar in dimensions

1035 to Holmesina. The fenestra cochleae is also unusual in Holmesina in that it is shielded in ventral

1036 view by a prominent ridge, and, in UF 191448, it is divided by a ventral process into two 1037 separate openings. Neither feature is known to occur in other cingulates.

1038 The crista interfenestralis, between the fenestrae vestibuli and cochleae, also exhibits 1039 unusual characteristics in H. floridanus. For one, it is quite broad, its maximum width clearly 1040 exceeding the maximum diameters of either of the openings flanking it. This is a feature that 1041 also occurs in Vassallia (FMNH P14424), but not in extant armadillos (Wible and Gaudin 2004; 
1042 Wible 2010), Proeutatus (FMNH P13197, 13199), or Propalaehoplophorus (YPM VPPU 15007,

1043 FMNH P13205), though it is also fairly broad in the Eocene dasypodine described by Babot et al.

1044 (2012). In addition, the crista is connected laterally by a bony bridge to the base of the

1045 tympanohyal, the bridge forming a partial floor to the facial sulcus. This bridge is broken in

1046 most specimens of H. floridanus, as it is in the isolated left petrosal of UF 248500 (Figure 11A,

1047 B), but is intact on the right side of that specimen (Figure 10), as well as in UF 275496. This

1048 appears to be a unique apomorphy of Holmesina, although there are low ridges on the crista

1049 interfenestralis of Vassallia (FMNH P14424), and low tubera in Euphractus (UTCM 1491) and

1050 Proeutatus (FMNH P13197).

1051 There is a narrow elongate groove that runs lateral to the promontorium along its entire

1052 length (Figure 11C, D). Anterior to the primary facial foramen, this groove accommodates the

1053 greater petrosal nerve. The portion posterior to the primary facial foramen is the facial sulcus for

1054 the facial nerve (c.n. VII). The sulci are bordered laterally by a well-developed, sharp edge crista

1055 parotica. The latter forms a rounded, U-shaped ventral extension immediately opposite the

1056 primary facial foramen. This extension is somewhat rugose and broadened mediolaterally

1057 relative to the rest of the crista, and likely represents the anteroventral process of the tegmen

1058 tympani (Figure 11C-F). The anteroventral process, which is termed the processus crista facialis

1059 by Patterson et al. (1989) and others (e.g., Gaudin, 1995; Wible and Gaudin 2004), is much

1060 better developed in extant armadillos, where it typically forms a mediolaterally expanded, cup-

1061 shaped depression (Patterson et al. 1989; Wible and Gaudin 2004; Wible 2010). It may also

1062 contact the squamosal, malleus, ectotympanic, entotympanic or alisphenoid bones in living

1063 armadillos (Wible and Gaudin 2004; Wible 2010), whereas in H. floridanus it is much reduced,

1064 and only contacts the squamosal. The anteroventral process is also small in Vassallia (FMNH 
1065 P14424), Proeutatus (FMNH P13197), and Propalaehoplophorus (FMNH P13205), lacking any

1066 concavity and contacting only the squamosal.

1067 Just posterior to the fenestra vestibuli, the facial sulcus traverses the ventral surface of the

1068 petrosal pars cochlearis, becoming confluent medially with a large, ovate depression, the

1069 stapedius fossa for the stapedius muscle (Figure 11C, D). The sulcus then turns laterally and

1070 ventrally, terminating at a shallow stylomastoid notch in the isolated left petrosal of UF 248500.

1071 However, on the right, the facial sulcus passes posterior to the tympanohyal, which abuts the

1072 large caudal tympanic process of the petrosal posteriorly, enclosing a stylomastoid foramen for

1073 the emerging facial nerve (c.n. VII; Figure 10). An enclosed stylomastoid foramen is also

1074 present in Dasypus (Wible 2010) and Euphractus (Wible and Gaudin 2004). Patterson et al.

1075 (1989, fig. 15B) illustrate a very similar morphology for Vassallia, though our inspection of their

1076 specimen (FMNH P14424) reveals the tympanohyal has subsequently broken off. An enclosed

1077 stylomastoid foramen is lacking, however, in both Proeutatus and Propalaehoplophorus, where

1078 the tympanohyal and the paroccipital and caudal tympanic processes of the petrosal frame only

$10792 / 3$ or $3 / 4$ of an opening. The tympanohyal of UF 248500 is broken through its base on the left, at

1080 the posterior terminus of the crista parotica, but on the right it is straight, elongated ventrally and

1081 expanded distally, forming a concave, ovate stylohyal fossa similar to, but much smaller and

1082 simpler than the structure of the same name so characteristic of sloths (Patterson et al., 1992;

1083 Gaudin 1995, 2004). A similar anatomy was apparently present in Vassallia (Patterson et al.,

1084 1989; though, as noted above, the tympanohyal in this specimen is now broken), but not in

1085 Dasypus (Wible 2010), Proeutatus (FMNH P13197, P13199) or Propalaehoplophorus (YPM

1086 VPPU 15007, FMNH P13205). In Euphractus (Wible and Gaudin 2004), the circular depression

1087 that Wible and Gaudin (2004) label a stylohyal fossa has a small tympanohyal exposure in its 
1088 center, but is formed largely by the ectotympanic anteriorly, and the mastoid region of the

1089 petrosal posteriorly and laterally. The tympanohyal is typically not straight in other cingulates,

1090 as it is in Holmesina. It curves medially and posteriorly at its distal end in Dasypus (Wible

1091 2010) and Proeutatus (Patterson et al. 1989, figure 13C), it is posteroventrally directed in

1092 Euphractus (Wible and Gaudin 2004), and it bends laterally at its distal end in

1093 Propalaehoplophorus (YPM VPPU 15007, FMNH P13205).

1094 Although it is not evident in the isolated petrosal (due to postmortem breakage), both the

1095 right petrosal in UF 248500 and both left and right petrosals in UF 191448 are characterized by a

1096 massive caudal tympanic process of the petrosal on the ventral pars cochlearis (Figure 10). The

1097 process is concave posteriorly in both specimens, apparently articulating posteriorly with a small

1098 elevation on the anterior edge of the exoccipital, although the petrosal is anteriorly displaced

1099 from its suture with the exoccipital in both specimens. The caudal tympanic process forms the

1100 lateral half of the posterior wall to the stapedius fossa, and lies well lateral to the fenestra

1101 cochleae. It occupies a similar position in Vassallia (FMNH P14424) and Dasypus (Wible

1102 2010), though it is less massive in both taxa. In Proeutatus (FMNH P13197) and

1103 Propalaehoplophorus (YPM VPPU 15007, FMNH P13205) it is both smaller and more medially

1104 placed. The caudal tympanic process of $H$. floridanus is separated laterally by a deep notch from

1105 the massively enlarged paroccipital process of the petrosal (=mastoid process of Patterson et al.

1106 1989; Gaudin 1995; and others). This huge paroccipital process is slightly hooked medially and

1107 angled anteriorly at its distal extremity, and extends ventral to the level of the basicranial plate

1108 (Figures 4-7, 10). Though almost cylindrical in appearance, its transverse diameter is in fact a

1109 good deal larger than its anteroposterior diameter, and it tapers distally to a rounded tip. The

1110 great enlargement of the paroccipital process is evidently a feature of pampatheres in general, 
1111 because it is present in H. septentrionalis (UF 234224; Edmund 1985b), H. occidentalis (ROM

1112 3881), Vassallia (Patterson et al. 1989; De Iuliis and Edmund 2002), and Pampatherium (Bordas

1113 1939; Guth 1961; Paula Couto 1984). The paroccipital process of glyptodonts is massive, but

1114 not as elongated as that of pampatheres (YPM PU 15007; Patterson et al. 1989), whereas the

1115 process is much smaller, though still sizable, in Proeutatus (labeled as "mastoid process" in

1116 Patterson et al. 1989) and Euphractus (Wible and Gaudin 2004). It is also flattened in the latter

1117 two taxa, anteroposteriorly in Euphractus and obliquely in Proeutatus (in an

1118 anterolateral/posteromedial plane). The notch separating the caudal tympanic and paroccipital

1119 processes of the petrosal in H. floridanus is saddle shaped, separating the stylomastoid foramen

1120 anteriorly from the sulcus for the occipital artery posteriorly (Figure 10).

1121 The caudal tympanic process is also separated by a medial notch from a small process

1122 attached to the back of a broad shelf of bone that lies behind the promontorium. The notch is

1123 likely for the auricular branch of the vagus nerve (c.n. X; Figure 10) based on comparisons with

1124 Dasypus (Wible 2010). The broad shelf, which is trapezoidal in shape, widening anteriorly

1125 (Figure 11A-D), is the roof of the postpromontorial sinus, the structure Wible (2010) terms the

1126 "triangular shelf" in Dasypus. This shelf is considerably broader in H. floridanus, as it is in

1127 Vassallia (FMNH P14424) and Propalaehoplophorus (YPM VPPU 15007, FMNH P13205).

1128 The shelf is semicircular but similar in size to that of Dasypus in Proeutatus (FMNH P13197),

1129 whereas in Euphractus (UTCM1491) it remains triangular but is larger and extends further

1130 anterolaterally than in Dasypus.

1131 As a final aspect visible in ventral view, we note that the area of the petrosal lateral to the

1132 crista parotica in H. floridanus is a concavity that forms the medial half of the epitympanic

1133 recess, which accommodates the mallear and incudal heads in mammals. The lateral half of the 
1134 recess is formed by squamosal, and is bisected transversely by the postglenoid process. The

1135 petrosal portion of the recess has a small divot in the lateral portion of its posterior wall that

1136 presumably represents the fossa incudis. The fossa lies immediately above a low ridge that

1137 extends anteromedially from the base of the tympanohyal. In Dasypus, the lateral wall of the

1138 anterolaterally facing fossa incudis is formed by the squamosal (Wible 2010), as was likely true

1139 in the Eocene dasypodine described by Babot et al. (2012), but this does not appear to be the case

1140 in Holmesina, nor in Vassallia (FMNH P14424), Propalaehoplophorus (FMNH P13205), or

1141 Proeutatus (FMNH P13197), where the fossa is more anteriorly oriented. Euphractus also lacks

1142 squamosal participation in the fossa incudis, but in this case it is due to the presence of an open

1143 epitympanic sinus above the ossicles (Wible and Gaudin 2004), as is typical for euphractine

1144 armadillos (Patterson et al. 1989; Gaudin 1995; Node 6 of Gaudin and Wible 2006).

1145 Because of the presence of an isolated petrosal, we are able to describe and illustrate

1146 (Figure 11G, H) details of the dorsal surface (i.e., the cerebellar face) of the petrosal that have

1147 never been described before in pampatheres. The most distinctive feature visible in a dorsal view

1148 of the H. floridanus petrosal is a large opening in the anteroventral region of the endocranial

1149 exposure (in the pars cochlearis), the internal acoustic meatus. This opening is much deeper than

1150 that of Dasypus (Wible 2010) and is ventrally displaced, so that it is separated from the

1151 endocranial roof of the basicranial plate by only a thin, sharp crest. This arrangement also differs

1152 from that in Vassallia, Euphractus, and Eocene dasypodines (Babot et al. 2102), in which the

1153 meatus is equally deep but more dorsally positioned.

1154 At the bottom of the internal acoustic meatus is a series of openings that have been

1155 identified (Figure 11G, H) based on Wible's (2010) description of Dasypus. The openings are

1156 clustered into two groups, separated by a sharp transverse crest. In Dasypus, the transverse crest 
1157 is broad and rounded, whereas in Euphractus it is broad but with a sharp medial edge. The

1158 anatomy in Vassallia (FMNH P14424) and Eocene dasypodines (Babot et al. 2012) is much like

1159 that of Holmesina. The two openings above (i.e., dorsal and lateral to) the transverse crest are

1160 the facial foramen for the facial nerve (c.n. VII), and posterior to that and roughly equivalent in

1161 size, the superior vestibular area. Below the transverse crest there are three openings:

1162 anteromedially, the large spiral cribriform tract, separated by a strong crest from two smaller,

1163 more posterior openings in a common fossa, a more posteromedial foramen singulare and a more

1164 anterolateral inferior vestibular area. The arrangement of these openings is very similar in

1165 Vassallia, whereas in Dasypus there is no real crest separating the spiral cribriform tract from the

1166 more posterior foramina. Moreover, the posterior foramina are clearly visible in medial view in

1167 pampatheres, whereas in Dasypus they face more anteriorly (foramen singulare) or ventrally

1168 (inferior vestibular area; Wible 2010; UTCM 801[isolated petrosal]). Euphractus also lacks the

1169 septum between the spiral cribriform tract and the two posterior foramina, which are quite small,

1170 and located in close proximity along the posterior wall of the lower opening of the internal

1171 acoustic meatus (UTCM 1486). At the medioventral edge of the petrosal's endocranial surface,

1172 slightly posterior to the internal acoustic meatus, lies the opening of the cochlear canaliculus. It

1173 occupies the same position in Vassallia, Dasypus (Wible 2010), and Eocene dasypodines (Babot

1174 et al. 2012), whereas in Euphractus, where the ventromedial edge of the petrosal contacts the

1175 basicranial plate along its whole length, the cochlear canaliculus occupies a more dorsal,

1176 endocranial position.

1177 Anterior to the internal acoustic meatus is a distinct concavity, which may have

1178 accommodated the inferior petrosal sinus (Figure $11 \mathrm{G}, \mathrm{H}$ ). A similar concavity is present in

1179 Vassallia and Euphractus, but is absent in Dasypus (Wible 2010). In the Eocene dasypodine 
1180 described by Babot et al. (2012), the sulcus for the inferior petrosal sinus is clearly marked along

1181 the ventral edge of the petrosal. The region immediately dorsolateral to the meatus, the so-

1182 called prefacial commissure, is broad and swollen in both pampatheres. In Dasypus (and

1183 apparently in Eocene dasypodines; Babot et al. 2012) it is a narrow bar of bone (Wible 2010),

1184 whereas in Euphractus is is broad like the pampatheres, but flat rather than swollen. The

1185 prefacial commissure in Holmesina is surmounted by a rounded crista petrosa that at its

1186 posterodorsal end is divided into medial and lateral ridges by a vascular groove (Figure $11 \mathrm{G}, \mathrm{H}$ ).

1187 This groove is situated too far medially to carry the postglenoid vein described by Wible (2010)

1188 in Dasypus, and so we suspect it carried the superior petrosal sinus. This groove is also present

1189 in Vassallia and Eocene dasypodines (Babot et al. 2012), though it is missing in both Dasypus

1190 and Euphractus, both of which have a much sharper crista petrosa. Indeed, in Euphractus

1191 (UTCM 1486), the crista petrosa is so elevated that it resembles a low ossified tentorium, like

1192 that of pangolins and carnivorans (Gaudin et al. 2016), extending a short distance dorsally

1193 between the cerebrum and cerebellum. Euphractus also has a very large, concave cerebral

1194 surface of the petrosal, whereas in Dasypus (Wible 2010), Eocene dasypodines (Babot et al.

1195 2012), and pampatheres this surface is much smaller.

1196 The endocranial exposure of the pars canalicularis is occupied by a broad, deeply

1197 concave subarcuate fossa in all the cingulates examined in this report. It is narrower

1198 anteroposteriorly in Euphractus than in Dasypus or pampatheres (whereas the subarcuate fossa is

1199 very incompletely preserved in Babot et al.'s [2012] specimen). In the latter forms it takes on a

1200 rounded triangular shape, with its apex pointing ventromedially. In pampatheres and

1201 Euphractus, it is divided by a low, rounded, roughly transverse ridge into upper and lower

1202 concavities. The upper concavity is further divided by a low ridge into anterior and posterior 
1203 concavities in Holmesina and Vassallia. The first, more horizontal ridge is almost certainly

1204 created by the lower portion of the posterior semicircular canal, whereas the second, more

1205 vertical ridge is created by the crus commune of the anterior and posterior semicircular canals.

1206 The aqueductus vestibuli, which transmits the endolymphatic duct, takes the form of a vertical

1207 slit opening into the ventromedial corner of the subarcuate fossa (Figure 11G, H). It has the

1208 same shape and position in Vassallia. In Euphractus, this opening is quite close to the

1209 exoccipital bone posteriorly, in contrast to pampatheres, and in Dasypus (Wible 2010) and Babot

1210 et al.'s Eocene dasypodine (2012), it is located just outside the subarcuate fossa, in a slightly

1211 more ventral, medial and anterior position. Billet et al. (2015) note that the vestibular aqueduct

1212 displays a derived orientation in euphractines, perpendicular rather than subparallel to the crus

1213 commune. The position of this aperture suggests that pampatheres share with dasypodines the

1214 more plesiomorphic orientation. A small opening into the recessus angularis, like that described

1215 for Dasypus by Wible (2010), is present on the dorsolateral rim of the subarcuate fossa in $H$.

1216 floridanus. On the right side of the UTCM 1486 specimen of Euphractus there is a similar

1217 opening; however, on the left side, there are three or four small vascular foramina in this area,

1218 some within and some outside the subarcuate fossa, the middle opening on the rim the largest.

1219 As noted by Wible (2010), the recessus angularis opening may or may not lie within the

1220 subarcuate fossa in Dasypus.

1221 We have illustrated the isolated left petrosal of $H$. floridanus (UF 248500) in lateral view

1222 (Figure 11E, F), much as Wible (2010) has done for Dasypus. As in Dasypus, there are three

1223 broad regions of the petrosal of Holmesina recognizable in lateral view. There is a cerebral

1224 surface, exposed in the floor of the middle cranial fossa of the endocranium. Like Dasypus this

1225 surface is elongated along an anteroventrolateral to posterodorsomedial axis, and is relatively 
1226 narrow transversely, though it is less triangular and more ovate in Holmesina. The tympanic

1227 exposure includes the promontorium, with its prominent elongated rostral tympanic process and

1228 large lateral, circular boss of unknown function. The fenestra vestibuli is also visible laterally,

1229 but not the primary facial foramen, which is hidden by a distinct ventral, semicircular ventral

1230 extension, the anteroventral process of the tegmen tympani. This process is present in Dasypus

1231 (Wible 2010), but does not extend ventrally to the same degree. Like Dasypus, this tympanic

1232 exposure also includes portions of the epitympanic recess situated lateral to the crista parotica.

1233 The petrosal contribution to the fossa incudis lies at the posterior and dorsal extremity of this

1234 surface, as in Dasypus (Wible 2010), but is less clearly marked. The tympanohyal is prominently

1235 exposed in Dasypus in lateral view, but is broken off in UF 248500. The remainder of the lateral

1236 exposure in UF 248500 is comprised of a posterodorsal contact surface for the squamosal, and

1237 the broken remains of the paroccipital process. Because the latter is so much larger in

1238 Holmesina than in Dasypus, it accounts for a much larger portion of this lateral surface, despite

1239 the fact that most of the process is broken off in the illustrated specimen.

1240 The mastoid exposure of the petrosal is largely missing from the isolated petrosal, due to

1241 postmortem breakage, and so this region of the petrosal will be described based on the in situ

1242 right petrosal from UF 248500, and on UF 191448. In lateral view, the dominant feature of the

1243 mastoid exposure in H. floridanus is the gigantic paroccipital process (Figures 4, 5, 8), which, as

1244 noted above, has a slight medial hook and is angled anteriorly at its distal extremity, extends

1245 ventral to the level of the basicranial plate, and is slightly compressed anteroposteriorly with a

1246 rounded tip. It has a clear, sigmoid suture dorsally with the squamosal (and its post-tympanic

1247 process) in both specimens, extending in a posterodorsal to anteroventral direction. The lateral

1248 edge of the paroccipital process is continuous dorsally with the nuchal crest. As previously 
1249 observed, the morphology of this region is similar in all pampatheres (Bordas 1939; Guth 1961;

1250 Paula Couto 1984; Edmund 1985b; Patterson et al. 1989; De Iuliis and Edmund 2002), whereas

1251 the shape and size of the paroccipital process is variable in other cingulates (Patterson et al.

1252 1989; Wible and Gaudin 2004; Wible 2010).

1253 In posterior view, the mastoid region has a broad, rectangular (UF 191448) or rhomboid

1254 (UF 248500) exposure on the occiput (Figure 13). In UF 191448, the transversely elongated

1255 exposure is marked by two narrow vertical depressions. The deeper and more medial of these is

1256 the sulcus for the occipital artery, which arises as a deep notch between the paracondylar process

1257 of the exoccipital and the paroccipital process, and terminates dorsally at the posttemporal

1258 foramen (the posterior opening of the posttemporal canal for the arteria diploetica magna - see

1259 Wible and Gaudin 2004). This opening lies just below the suture between the mastoid and the

1260 occipital exposure of the squamosal. The second, more lateral and much shallower vertical

1261 depression represents the attachment surface for the digastric muscle, travelling along the inside

1262 edge of the nuchal crest. This depression does not reach the tip of the paroccipital process

1263 ventrally, but dorsally it extends beyond the mastoid, crossing the occipital surface of the

1264 squamosal onto the supraoccipital. It terminates just below a large muscular boss on the nuchal

1265 crest. The morphology of UF 248500 differs from that of UF 191448 in several respects. Most

1266 importantly, the shape of the occipital exposure is different - it is more rhomboid than

1267 rectangular, with its dorsal border sloping ventrolaterally. Additionally, the digastric fossa is

1268 shallower, and has a sigmoid shape. In H. septentrionalis (UF 234224), the digastric fossa takes

1269 on a shape similar to that in UF 248500 , and the occipital artery sulcus is bowed medially. The

1270 mastoid occipital exposure is even broader mediolaterally in Vassallia than in Holmesina, taking

1271 on a "Y-shape" as indicated by De Iuliis and Edmund (2002: p. 56), with medial and lateral 
1272 extensions passing dorsal to the posttemporal foramen (= "mastoid foramen" of De Iuliis and

1273 Edmund 2002). In Propalaehoplophorus (YPM VPPU 15007), Proeutatus (FMNH P13197),

1274 and Euphractus (UTCM 1491), the digastric fossa is much shorter vertically than in

1275 pampatheres, restricted to the posterior surface of the parocciptal process, and not extending

1276 dorsally onto the squamosal and supraoccipital. Holmesina floridanus, H. septentrionalis (UF

1277 234224), and Vassallia (FMNH P14424) all have a groove for the occipital artery extending

1278 dorsally from the posttemporal foramen across the squamosal and onto the supraoccipital. This

1279 condition was also described in Euphractus by Wible and Gaudin (2004), and is optimized as a

1280 cingulate synapomorphy by Gaudin and Wible (2006).

1281

1282 Ectotympanic, Entotympanic, Ear ossicles

1283 To our knowledge, no remnant of the ectotympanic or ear ossicles has ever been

1284 recovered in any pampathere, and our specimens, well-preserved though they are, have proven

1285 no exception [Guth (1961) described partial stapes elements in several glyptodonts, but not any

1286 portion of the ectotympanic or other ossicles]. There appear to be facets for the attachment of

1287 the anterior and posterior crura of the ectotympanic preserved in UF 248500 , on the

1288 ventromedial surface of the squamosal's entoglenoid process, and on the anterior surface of the

1289 tympanohyal and the portion of the petrosal forming the anterior wall of the stylomastoid

1290 foramen, respectively. This suggests that the ectotympanic formed a loosely attached, dorsally

1291 incomplete ring. There is also no indication of the presence of an entotympanic element -

1292 indeed, none has ever been described in any pampathere or glyptodont, despite its occurrence in

1293 Euphractus (Wible and Gaudin 2004) and many other cingulates (Patterson et al. 1989; Wible

1294 2010). 
1296 Vomer

1297 The vomer of H. floridanus is only partially visible in two places. It can be seen

1298 anteriorly through the external narial opening of UF 248500, as an elongate ridge extending

1299 dorsally from the roof of the maxillary palatine processes into the nasal cavity. Here it is $\mathrm{Y}$ -

1300 shaped in cross section, with the base in the midsagittal plane and the dorsal arms of the "Y"

1301 supporting the ossified portion of the median nasal septum. It appears to come to an abrupt

1302 anterior termination well behind the internal openings of the incisive foramina, therefore it likely

1303 did not contact the premaxilla, in contrast to Vassallia, Propalaehoplophorus and most other

1304 cingulates (Gaudin and Wible 2006). The vomer is also visible looking posteriorly through the

1305 choanae of UF 191448, as a pair of nearly vertical alae extending along the lateral edge of the

1306 presphenoid, converging anteriorly until they meet in the midline, perhaps covering the

1307 anteriormost tip of the presphenoid ventrally. Much of the posterior and ventral reaches of these

1308 alae are broken, but they likely contacted the maxilla and perhaps the palatine ventrally along the

1309 lateral walls of the nasal passage.

1310

1311 Presphenoid/Orbitosphenoid

1312 There is a clear suture between the presphenoid and basisphenoid in UF 248500, and the

1313 posterior portion of the presphenoid is visible in ventral view extending a short distance posterior

1314 to the choanae, although most of the anterior presphenoid is missing (Figures 6, 7). The entire

1315 presphenoid is preserved in UF 191448, though it is fused into the surrounding elements, so that

1316 its precise boundaries are no longer evident (Figure 9B). Nevertheless, it can be inferred from

1317 the two specimens that the presphenoid takes the form of a narrow, elongate triangle that tapers 
1318 anteriorly until disappearing beneath the vomer within the nasal cavity. As noted above, the

1319 anterior presphenoid connects laterally with the vomerine alae inside the nasal cavity, and likely

1320 contacts the palatine and pterygoid posterolaterally, although UF 248500 has ventrolateral

1321 flanges of the basisphenoid that extend lateral to the posteriormost parts of the presphenoid, and

1322 could preclude contact with the pterygoid. The presphenoid has a very similar form in other

1323 cingulates. In Vassallia, there is a ventrolateral projection of the basisphenoid that extends

1324 forward to preclude pterygoid/presphenoid contact, as in H. floridanus.

1325 The lateral portions of the orbitosphenoid, i.e., the areas where it would normally be

1326 exposed at the surface along the medial orbital wall, are badly damaged in UF 248500 . There is

1327 also some damage in this area in UF 191448, and the orbital sutures are all closed in this

1328 specimen, making it difficult to assess orbitosphenoid anatomy. However, two additional

1329 specimens of $H$. floridanus, UF121742 and UF 223813, provide better insight. The former is an

1330 exquisitely preserved display specimen and shows the surface exposure in the orbital wall, the

1331 latter a fragmentary specimen that preserves the endocranial portion of the orbitosphenoid

1332 (which can also be glimpsed though breaks in UF 248500). The specimens taken together show

1333 that the optic nerve (c.n. II) is completely enclosed in a canal formed by the orbitosphenoid bone

1334 (Figure 8), as is typical for placental mammals (Novacek 1993). The lateral wall of this canal

1335 forms the medial wall of a combined sphenorbital fissure (transmitting c.n. III, IV, $\mathrm{V}_{1}$, and VI, as

1336 well various orbital blood vessels) and foramen rotundum (transmitting c.n. $\mathrm{V}_{2}$ ). In nearly all

1337 cingulates, these two openings are fused.

1338 The endocranial surface of the presphenoid/orbitosphenoid (Figure 12A) is marked by a

1339 strong, continuous orbitosphenoid crest surmounting the internal apertures of the left and right

1340 optic canals, but the jugulum sphenoidale (i.e., the surface of the presphenoid/orbitosphenoid 
1341 rostral to the orbitosphenoid crest - using terminology of Evans and Christiansen 1979; Wible

1342 2008) is only weakly convex in the midline. In many cingulates, including Euphractus, there is a

1343 strong midline crest in this area (Gaudin and Wible 2006 - note Euphractus is coded as lacking

1344 this feature, but should be coded as variably present, because a sharp crest is present in UTCM

1345 1491, and a weaker, rounded crest is present in UTCM 1500). As in Holmesina, the midline crest

1346 itself is only weakly developed in Vassallia, but the entire jugulum singulare is swollen and

1347 convex, quite unlike the condition in Holmesina.

1348 The surface exposure of the orbitosphenoid in the medial orbital wall is relatively small

1349 and ovate or rectangular in UF 121742, and elongated along a posteroventral to anterodorsal axis

1350 (Figure 8). It contacts the frontal anteriorly and dorsally, the maxilla and alisphenoid ventrally,

1351 and is separated by a gap from the lateral wall of the common opening for the optic foramen and

1352 sphenorbital fissure. The orbitosphenoid forms the medial wall of this common opening. In

1353 contrast to Euphractus (Wible and Gaudin 2004) and Proeutatus (Gaudin and Wible 2006: fig.

1354 6.6a), there does not appear to be contact between the palatine and orbitosphenoid, although it is

1355 possible that there is a connection at the base of the medial wall for the common fossa that holds

1356 the optic foramen/ sphenorbital fissure and sphenopalatine canal. The optic foramen transmitted

1357 the optic nerve (c.n. II), whereas the sphenorbital fissure likely accommodated the oculomotor

1358 (c.n. III), trochlear (c.n. IV), abducens (C.N. VI), and first and second branches of the trigeminal

1359 nerve (c.n. $\mathrm{V}_{1}$, the ophthalmic, and c.n. $\mathrm{V}_{2}$, the maxillary), along with a variety of vessels (Wible 1360 and Gaudin 2004).

1361 The orbitosphenoid does not participate in the rim of either the sphenopalatine foramen

1362 or the ethmoid foramen in UF 121742. Both conditions are known to occur at least variably in

1363 euphractine armadillos (Gaudin and Wible 2006), but Gaudin and Wible (2006) code both as 
1364 absent in Vassallia, as they are in Holmesina. Like Vassallia, Propalaehoplophorus, and

1365 Proeutatus (Gaudin and Wible 2006 - an unambiguous synapomorphy of Node 7), the optic

1366 foramen (i.e., the lateral opening of the optic canal) is hidden in lateral view by the lateral wall of

1367 the fossa housing the combined optic foramen/sphenorbital fissure, unlike Euphractus and most

1368 other extant armadillos (Gaudin and Wible 2006), in which the optic foramen is visible laterally.

1369 The small opening to the pterygoid canal lies on the suture between the orbitosphenoid and

1370 alisphenoid, just anterior to the optic foramen/sphenorbital fissure common opening, and at the

1371 base of a bony bridge that connects the alisphenoid and maxilla and forms a partial lateral wall to

1372 the common fossa for the sphenopalatine canal and the optic foramen/sphenorbital fissure

1373 (Figure 8). The position of the pterygoid canal foramen is similar in Vassallia, Proeutatus, and

1374 Euphractus (Wible and Gaudin 2004; Gaudin and Wible 2006), whereas in

1375 Propalaehoplophorus, this foramen lies within the common fossa for the optic foramen and

1376 sphenorbital fissure (Gaudin and Wible 2006). The lateral surface of the orbitosphenoid is

1377 marked by a rounded, anterodorsally directed ridge in UF 121742 . This ridge lies ventral to a

1378 groove emerging from the optic foramen; a similar ridge is formed by the frontal bone above this

1379 groove, separating it from the ethmoid foramen.

1380

\section{Alisphenoid}

1382 The alisphenoid is apparently quite large in H. floridanus, with a shallow bowl-like

1383 surface contour (Figure 8). It has sutural connections dorsally with the orbitosphenoid, frontal,

1384 and squamosal, the first being the shortest, most anterior, and roughly horizontal. The middle

1385 section is positioned more dorsally, and travels posterodorsally, meeting at a point with the

1386 squamosal suture, which sweeps posteriorly and ventrally in a great semicircular curve, crossing 
1387 the entoglenoid process at its posteriormost extremity, so that the alisphenoid forms roughly the

1388 anterior third of this process. The alisphenoid has a generally horizontal suture ventrally with the

1389 pterygoid, taking part in the dorsalmost lateral rugosities of this element. As noted above, it

1390 contacts either a thin sliver of palatine or the maxilla anteriorly, and forms the posterior half of

1391 the rim for the sphenopalatine foramen. There is no contact between alisphenoid and parietal, as

1392 noted above.

1393 The large foramen ovale (for the mandibular branch of the trigeminal nerve, c.n. $\mathrm{V}_{3}$;

1394 Wible and Gaudin 2004) is housed completely within the alisphenoid, as in most cingulates

1395 (Gaudin et al. 1996), though the squamosal does closely approach its dorsal margin (Figure 8).

1396 There is a small transverse canal foramen (for a vein from the cavernous sinus - see Wible and

1397 Gaudin 2004) anteroventral to the foramen ovale in UF 121742, and on the left side of UF

1398 191448. On the right side of UF 191448, and in UF 275496, there are two small foramina in this

1399 position, whereas the foramen appears to be absent in UF 248500. This feature is present in

1400 most cingulates (it is an ambiguous synapomorphy of Node 3 in Gaudin and Wible 2006). There

1401 is no separate foramen rotundum in H. floridanus. As in all known cingulates except

1402 Stegotherium, this opening has become confluent with the sphenorbital fissure (Gaudin and

1403 Wible 2006). The alisphenoid also likely forms at least the lateralmost parts of the piriform

1404 fenestra's anterior edge (Figure 10), though it is difficult to be certain of the contribution because

1405 of fusion between the alisphenoid and basisphenoid posteromedially.

1406 The alisphenoid has a prominent, rounded posterior edge that forms the terminus for the

1407 lateral wall of the nasopharynx. Just below its suture with the frontal, it is traversed by a sharp

1408 crest that originates on the anteromedial corner of the glenoid articular surface and extends

1409 anteriorly across the squamosal and alisphenoid. This is a posterior section of the infratemporal 
1410 crest (Figure 8). It terminates anteriorly at a large boss, where it joins the anterior portion of the

1411 infratemporal crest described above in connection with the frontal bone. This boss likely serves

1412 as the site of origin for most of the extrinsic eye muscles, and would therefore be homologous

1413 with the ossified ala hypochiasmatica described by Wible and Gaudin (2004) in Euphractus,

1414 though it is carried by the alisphenoid rather than the orbitosphenoid. The anatomy of these

1415 crests is very similar to H. floridanus in H. septentrionalis (UF 234224), Vassallia (FMNH

1416 P14424), and Propalaehoplophorus (YPM VPPU 15007). The alisphenoid terminates anteriorly

1417 in a thin, freestanding crest that marks the lateral margin of the fossa housing the optic

1418 foramen/sphenorbital fissure and the sphenopalatine canal. As noted above, it also forms a bony

1419 bridge lateral to this fossa that connects anteriorly with the maxilla. The entoglenoid portion of

1420 the alisphenoid in UF 248500 bears a shallow groove that runs anteroventromedially towards the 1421 foramen ovale, which likely accommodated the chorda tympani nerve.

1423 Basisphenoid

1424 The basisphenoid and basioccipital are fused in all the $H$. floridanus specimens available 1425 to us, so we cannot determine the boundary between the two with certainty. In other cingulates

1426 for which the suture is known (Gilette and Ray 1981; Patterson et al. 1989; Wible and Gaudin

1427 2004; Wible 2010), the boundary lies anterior to the basioccipital tubera, roughly at the level of

1428 the carotid foramina. We will assume a similarly positioned boundary here (Figure 7).

1429 The main body of the basisphenoid has a flat ventral surface contour and is trapezoidal in

1430 outline, tapering anteriorly. It contacts the presphenoid anteriorly and the basioccipital

1431 posteriorly. Along its lateral margins, it bears a prominent, ventrally curving flange. In UF

1432 248500, this flange has a sutural outline anteriorly, although, due to damage in this area it is 
1433 unclear if the bone to which it is sutured is palatine, pterygoid, or perhaps even alisphenoid.

1434 More posteriorly, this flange, if present, is fused to the alisphenoid - there are vague indications

1435 of a basisphenoid/alisphenoid contact emerging from the piriform fenestra, crossing the

1436 anteriormost region of the entoglenoid process and extending anteriorly onto the nasopharyngeal

1437 wall in UF 121742. The ventral basisphenoid flange is visible in UF 275496 (a juvenile

1438 specimen), but is not visible in UF 191448 due to sutural fusion. The ventral flange is also

1439 present in Vassallia (FMNH P14424). In both Holmesina and Vassallia this flange has a

1440 triangular anterior extension that reaches forward beyond the level of the

$1441 \mathrm{presphenoid/basisphenoid} \mathrm{suture,} \mathrm{presumably} \mathrm{separating} \mathrm{the} \mathrm{vomerine} \mathrm{alae} \mathrm{from} \mathrm{the} \mathrm{palatine}$

1442 and/or pterygoid. Although it is not illustrated by Wible and Gaudin (2004), at least three

1443 specimens of Euphractus (UTCM 1486, 1491, and 1500) examined for this study have a small

1444 ventral flange of the basisphenoid. It is much smaller than in pampatheres, restricted anteriorly

1445 and triangular in shape. It extends laterally between the nasopharyngeal exposures of the

1446 pterygoid and palatine.

1447 The posterolateral corner of the basisphenoid bears a concave, semicircular indentation

1448 for the carotid foramen (Figures 6, 7, 9, 10), the opening transmitting the internal carotid artery

1449 into the braincase (Wible and Gaudin 2004). As noted in our description of the alisphenoid,

1450 these two sphenoid elements also form the anterior margin of the piriform fenestra (along with

1451 the entoglenoid process of the squamosal), though their relative contributions are unclear due to

1452 sutural fusion in this area. A short distance anterior to this indentation, a narrow longitudinal

1453 groove forms in both UF 248500 and UF 191448. It travels anteriorly across the basisphenoid,

1454 beginning near the junction of its ventral flange and body, but shortly thereafter curving ventrally

1455 and then traveling straight for the remainder of its course across the ventral flange. This is the 
1456 groove for the vidian nerve (Figure 10). Its anterior terminus is missing in UF 248500, but in UF

1457191448 it terminates at the medial opening for the pterygoid canal, located at the junction of the

1458 ventral basisphenoid flange and the perpendicular plate of the palatine. This open groove for the

1459 vidian nerve is nearly identical in form in Vassallia (FMNH P14424), and an open groove of

1460 somewhat different form is preserved in Proeutatus, whereas in some cingulates, like

1461 Euphractus, the nerve is partially enclosed by a canal, and in others, e.g., Propalaehoplophorus,

1462 it is fully enclosed by a canal (Gaudin and Wible 2006).

1463 The dorsal surface of the basisphenoid is exposed in UF 223813. It is marked by a large,

1464 deep, circular hypophyseal fossa, flanked laterally by prominent grooves for the internal carotid

1465 arteries (Figure 12A). In the roof of the internal carotid sulci are bilaterally symmetrical

1466 openings - small breaks in the basisphenoid show that these are connected to a canal within the

1467 tuberculum sellae (i.e., the eminence in front of the hypophyseal fossa), and are likely part of the

1468 cavernous sinus system, accommodating the veins that open at the transverse canal foramen

1469 anteroventral to the foramen ovale.

\section{Basioccipital}

1472 The basioccipital forms the remainder of the basicranial surface, accounting for over half

1473 its length (if we are reconstructing the position of the basisphenoid/basioccipital suture

1474 correctly). It has straight lateral margins that converge only slightly anteriorly in $H$. floridanus

1475 (Figure 7). The basioccipital is considerably shorter and wider in H. septentrionalis (UF

1476 234224) and H. occidentalis (ROM 3881), with lateral margins that are more steeply inclined,

1477 whereas the proportions of the basioccipital in Vassallia (De Iuliis and Edmund 2002),

1478 Propalaehoplophorus (Scott 1903-4), and Proeutatus (Patterson et al. 1989) are more like those 
1479 of $H$. floridanus. The basioccipital lateral margins are largely separate from the petrosal in $H$.

1480 floridanus, although, as noted above, there is an articulation between the two bones, with a knob

1481 forming on the dorsal edge of the basioccipital's lateral margin, fitting into a depression in the

1482 medial flange of the petrosal and interrupting the otherwise open basicochlear commissure. At

1483 its posterior limit, the lateral margin of the basioccipital curves laterally, forming the anterior

1484 half of the notch for the jugular foramen. The jugular foramen provides passage outside the

1485 cranium to the glossopharyngeal (c.n. IX), vagus (c.n. X), and accessory (c.n. XI) nerves and the

1486 sigmoid sinus, but likely lies too far medially to be involved with the occipital artery as it is in

1487 Euphractus (Wible and Gaudin 2004). UF 248500 retains the suture between the exoccipital and

1488 basioccipital, showing it as a nearly horizontal contact that extends from the medial margin of

1489 the jugular foramen to the anterior portion of the ventral rim of the foramen magnum (Figure 6).

1490 In Euphractus (Wible and Gaudin 2004), this suture runs more diagonally, contacting the rim of

1491 the jugular foramen further anteriorly and the foramen magnum further posteriorly.

1492 The ventral surface of the basioccipital is convex transversely and highly irregular,

1493 marked by several prominent elevations and depressions. The anteriormost of these include two

1494 prominent lateral tubercles flanking an even taller median crest (Figures 6, 7, 9). These represent

1495 the basioccipital tubera and pharyngeal tubercle, respectively [based on comparison with Canis

1496 (Evans and Christiansen, 1979) and Homo (Clemente 1985)], the former serving as the site of

1497 attachment for the m. longus capitis. Behind the basioccipital tubera are large, shallow

1498 depressions, elongated along a posterolateral to anteromedial axis that accommodated the

1499 insertion of the m. rectus capitis ventralis. In H. septentrionalis (UF 234224) and H. occidentalis

1500 (ROM 3881), the pharyngeal tubercle and rectus capitis fossae are less well-developed, whereas

1501 only the latter is reduced in Vassallia (Gaudin and Wible 2006). Proeutatus resembles the 
1502 morphology in H. floridanus, but the basioccipital tubera are more elongated along an oblique

1503 axis, whereas the basioccipital surface relief is much reduced in both Propalaehoplophorus and

1504 Euphractus (Wible and Gaudin 2004; Gaudin and Wible 2006).

1505

1506 Exoccipital/Supraoccipital

1507 The occiput is a single fused plate in UF 191448, as is typical among adult mammals, but 1508 in the subadult UF 248500 the demarcations among its constituent elements are still visible,

1509 including the contact between just described basioccipital and the exoccipital elements on the

1510 skull base, as well as the junction between the exoccipitals and supraoccipital on the posterior

1511 surface of the skull.

1512 The paired exoccipitals have two primary sections: a horizontal moiety on the skull base;

1513 and a vertical portion that forms part of the occipital surface. The former joins the basioccipital

1514 at its anteroventral extremity, at a suture that passes medially from the jugular foramen. It is not

1515 clear if the suture enters the rim of the foramen magnum, or meets its opposite anterior to the rim

1516 of the foramen magnum. Damage to the medial portions of both the left and right exoccipitals of

1517 UF 248500 leaves a sizable gap in this area (Figure 6B). The posterior, vertical segment of the

1518 exoccipital shares a lateral suture with the mastoid part of the petrosal. This suture extends from

1519 the base of the paracondylar process dorsally to the base of the supraoccipital. Any connection

1520 between the occipital exposure of the squamosal and the exoccipital is precluded by a dorsal

1521 contact between the mastoid petrosal and the supraoccipital (Figure 13). The crack that we

1522 interpret as the exoccipital/supraoccipital suture in UF 248500 is not perfectly symmetrical, and

1523 so may not represent the actual suture, but it occupies almost an identical position as that of the

1524 extant armadillo Euphractus (Wible and Gaudin 2004: fig. 5), extending ventromedially from the 
1525 supraoccipital/mastoid suture to the dorsal rim of the foramen magnum. A specimen of

1526 Propalaehoplophorus, YPM VPPU 15007, has a nearly identical suture on the left side only.

1527 Lastly, there is an asymmetrical crack in roughly the same area of the occiput in Vassallia

1528 (FMNH P14424), though it is oriented at a shallower angle and so does not appear to enter the

1529 dorsal rim of the foramen magnum, which would then be formed entirely by the exoccipital.

1530 The lateral edge of the exoccipital's basicranial segment is marked by a distinct concavity

1531 that represents the jugular notch, i.e., the medial edge of the jugular foramen. As noted above,

1532 the anterior portion of the jugular notch is formed by the basioccipital. Extending more laterally

1533 than posteriorly from this notch is a sutural contact between exoccipital and mastoid. This suture

1534 is broadly open in both UF 191448 and UF 248500 (Figure 10), but this is presumably due to

1535 postmortem displacement of the petrosal. At the lateral extremity of this contact surface, the

1536 exoccipital bears a strong, free-standing ventral projection, the paracondylar process

1537 (=paroccipital process of Patterson et al. 1989; Gaudin 1995; =jugular process of Wible and

1538 Gaudin 2004). In posterior view, the paracondylar process has a convex lateral border and a

1539 concave medial border, giving it a hooked appearance, and it is separated by a distinct notch

1540 from the lateral edge of the occipital condyle (Figures 6, 7, 10, 13). This morphology is

1541 apparently a general feature of pampatheres, because it is also present in H. septentrionalis (UF

1542 234224), H. occidentalis (ROM 3881), H. paulacoutoi (Cartelle and Bohórquez 1985), Vassallia

1543 (FMNH P14424), and Pampatherium (Bordas 1939; Guth 1961). In Propalaehoplophorus

1544 (YPM VPPU 15007) the paracondylar process is well developed, but more blunt, and neither

1545 hooked medially nor separated by a notch from the occipital condyle. The process is

1546 dramatically reduced by comparison in both Proeutatus (FMNH P13197) and Euphractus (Wible

1547 and Gaudin 2004). Just medial to the jugular notch is a strong fossa that houses the hypoglossal 
1548 foramen at its base. In UF 248500, there are two hypoglossal foramina, each connecting to a

1549 corresponding opening just inside the foramen magnum within the cranial cavity, and providing

1550 passage for the hypoglossal nerve (c.n. XII) and vein (Wible and Gaudin 2004). In UF 191448,

1551 there appears to be a single hypoglossal foramen. This mirrors the variation noted for

1552 Euphractus by Wible and Gaudin (2004), whereas Gaudin and Wible (2006, char. 153) record

1553 only a single hypoglossal foramen in Vassallia, Propalaehoplophorus, and Proeutatus.

1554 The hypoglossal fossa of $H$. floridanus sits at the medial edge of a second, broader and

1555 shallower fossa that lies just anterior to the occipital condyle, the ventral condyloid fossa of

1556 Wible and Gaudin (2004). Medial to these two depressions, the ventral surface of the exoccipital

1557 is transversely convex, and terminates at a strong, rounded ridge, which is the lateral edge of the

1558 foramen magnum. The transverse convexity of the exoccipital's basicranial exposure is another

1559 general feature of pampatheres, present in H. septentrionalis (UF 234224), H. occidentalis

1560 (ROM 3881), and Vassallia (FMNH P14424); but not in Propalaehoplophorus (YPM VPPU

1561 15007), Proeutatus (FMNH P13197) or Euphractus (Wible and Gaudin 2004), where the

1562 basicranial portion of the exoccipital is flat.

1563 Prominent occipital condyles join the vertical and horizontal segments of the exoccipital

1564 (Figures 6, 7, 13). The condyles are cylindrical (="roughly rectangular" in ventral view, char.

1565 155[1] in Gaudin and Wible 2006) in shape, an unambiguous synapomorphy of Cingulata

1566 according to Gaudin and Wible (2006). The lateral edge bears a distinct indentation that is

1567 present in all cingulates except Peltephilus (Node 2 of Gaudin and Wible 2006). The portion of

1568 the condyle anterior and ventral to this indentation extends much further laterally than the more

1569 dorsal and posterior portion. This is also a feature of in $H$. septentrionalis (UF 234224), $H$.

1570 occidentalis (ROM 3881), and Propalaehoplophorus (YPM VPPU 15007), whereas in 
1571 Proeutatus (FMNH P13197) and Euphractus (UTCM 1486, 1491, 1500) the condyle is more

1572 symmetrical about this indentation, and in Vassallia (FMNH P14424) the indentation itself is

1573 dramatically reduced. In ventral view, the condyle appears to be somewhat wider transversely in

1574 pampatheres and glyptodonts than in armadillos (as represented by Proeutatus and Euphractus).

1575 The measurements reflect this, with the ratio of width to length greater than or equal to 1.5 in $H$.

1576 floridanus, H. septentrionalis, H. occidentalis, Vassallia, and Propalaehoplophorus, and

1577 substantially less in Proeutatus and Euphractus (Tables 1, 2).

1578 The surface of the exoccipital immediately medial to the condyles is deeply impressed by

1579 a fossa that extends anteromedially almost to the front of the foramen magnum's ventral rim

1580 (Figure 12A). Based on comparison with other placental mammals (see Homo, Clemente 1985;

1581 Canis, Evans and Christiansen 1979; in which the condyles are much smaller and shallower) we

1582 identify this depression as the site of insertion for the alar ligaments extending forward from the

1583 dens of the axis. It is not at all clear why these ligaments would be so large in H. floridanus, but

1584 they appear similarly enlarged in other pampatheres, based on the presence of this fossa in $H$.

1585 septentrionalis (UF 234224), H. occidentalis (ROM 3881), and Vassallia (FMNH P14424). No

1586 such depression is described in Wible and Gaudin (2004), but we have subsequently examined

1587 specimens of Euphractus (UTCM 1486, 1491, 1500) in which a small, circular depression is

1588 present in this area. A similar circular depression is also observed in Proeutatus (FMNH

1589 P13197), whereas Propalaehoplophorus (YPM VPPU 15007) appears to have fossa similar in

1590 size to that of pampatheres, but much shallower.

1591 The vertical portion of the exoccipital bears a strongly marked, transversely elongated

1592 depression immediately dorsal to the occipital condyle (Figure 13). This is the dorsal condyloid

1593 fossa of Wible and Gaudin (2004). Dorsal to this depression, the exoccipital is nearly flat. As 
1594 noted above, the exoccipital forms nearly the entire rim of the foramen magnum, the

1595 supraoccipital only contributing a small exposure on the dorsalmost point of the opening. The

1596 rim is irregularly shaped due to a small convexity located at roughly the midpoint of its height,

1597 the nuchal tubercle. The nuchal tubercle is developed to a similar degree in Proeutatus (FMNH

1598 P13197) or Euphractus (Wible and Gaudin 2004), but is less prominent in Propalaehoplophorus

1599 (YPM VPPU 15007). The latter also has a broader, transversely ovate foramen magnum, in

1600 contrast to the taller, more triangular shaped foramen in Proeutatus and H. floridanus.

1601 The supraoccipital is a broad, hemispherical plate that extends from its ventral contacts

1602 with the squamosal, mastoid and exoccipital to its dorsal termination at the nuchal crest, where it

1603 is presumably fused to the parietal, as in Euphractus (Wible and Gaudin 2004). As in both

1604 Euphractus (Wible and Gaudin 2004) and Proeutatus (Scott 1903-4), the nuchal crest is

1605 posteriorly convex laterally and posteriorly concave in the midline. This shape is broadly shared

1606 among euphractine and eutatine armadillos, pampatheres, and early glyptodonts, extending all

1607 the way back to the oldest known cingulate skull, that of the Eocene taxon Utaetus (Barrancan

1608 SALMA; Simpson 1948; Gaudin and Croft 2015). In H. floridanus, there are prominent, raised

1609 tubercles just behind the most posterior point of curvature on the nuchal crest. Low, broadly

1610 rounded ridges extend ventromedially from the tubercles toward the foramen magnum. The

1611 central region of the supraoccipital between these elevations has a gently concave surface,

1612 interrupted in the midline by a very weakly developed external occipital crest (Figure 13). The

1613 supraoccipital is very similar in Vassallia (FMNH P14424). In H. septentrionalis (UF 234224)

1614 and Propalaehoplophorus (YPM VPPU 15007), the nuchal crest is more rugose, and the external

1615 occipital crest is more prominent, the latter also the case in Euphractus (Wible and Gaudin

1616 2004). Proeutatus lacks the raised tubercles present in the other taxa, it has a large pair of 
1617 mastoid foramina that perforate the supraoccipital, and it has a characteristic nuchal crest that is

1618 very tall to the point of being slightly recurved anteriorly in lateral view (Scott 1903-4; FMHH

1619 P13197).

1620 The overall shape of the occiput in H. floridanus is rather tall and narrow, almost

1621 triangular, width its maximum depth and transverse width (measured at the base of the

1622 supraoccipital) nearly equivalent (Tables 1,2$)$. This is also the case in H. septentrionalis (UF

1623 234224), whereas in Vassallia (FMNH P14424), Propalaehoplophorus (YPM VPPU 15007),

1624 Proeutatus (FMHH P13197), and Euphractus (UTCM 1491), the occiput is lower, broader and

1625 more semicircular in shape, with a width/depth ratio $\geq 1.2$.

1626

1627 Mandible

1628 The mandible of H. floridanus (Figure 14; MML = 182-200 mm; Tables 3, 4) is smaller

1629 than that of H. septentrionalis [both Simpson (1930) and James (1957) report MML of 240mm]

1630 and $H$. occidentalis (MML > 268mm in ROM 4955; Table 3). Proportions are very similar to $H$.

1631 occidentalis, with a very similar relative depth of the horizontal ramus (Table 2), whereas the

1632 horizontal ramus appears slightly deeper in H. septentrionalis (Simpson 1930; James 1957;

1633 Edmund 1985b). Like H. occidentalis (ROM 4955), UF 224450 has two mental foramina that

1634 open on the external surface of the horizontal ramus in the symphyseal region (ventral to mf3

1635 and $\mathrm{mf} 4$, respectively; the mental foramen accommodates the mental nerves and vessels of the

1636 rostral lower jaw area, Evan and Christiansen 1979). Unlike H. occidentalis, both mental

1637 foramina are associated with grooves in the surface of the mandible. The more anterior foramen

1638 empties into two closely set, parallel, anterodorsally directed grooves, and indeed the foramen

1639 itself is partially constricted into an upper and lower opening. The groove emerging from the 
1640 posterior mental foramen travels posteroventrally. For H. septentrionalis, Simpson (1930)

1641 illustrates four foramina of varying sizes in the external surface of the mandible anterior to the

1642 level of $\mathrm{mf} 4$, whereas James (1957) describes a single mental foramen beneath $\mathrm{mf3}$. It is not

1643 clear if all four of Simpson's openings are mental foramina, or if one or more are nutritive

1644 foramina that he chose to illustrate.

1645 The anteroventral edge of the symphysis in H. floridanus forms roughly a $27^{\circ}$ angle with

1646 the toothrow (Figure 14C). This appears to be similar to the angle in H. occidentalis (ROM

1647 4955), but somewhat more acute than in H. septentrionalis [roughly $30^{\circ}$ as measured in Simpson

1648 (1930, fig. 4) and Edmund (1985b, fig. 6)] The posteriormost point of the symphysis extends just

1649 below the ventral edge of the horizontal ramus in medial view, as in other Holmesina, and the

1650 anteriormost point forms a very short triangular extension in front of $\mathrm{mfl}$, marked by two small

1651 foramina on its dorsal surface. The length of this short mandibular spout is a little longer than

1652 the mesiodistal diameter of the $\mathrm{mfl}$ alveolus (spout $=6.3 \mathrm{~mm}, \mathrm{ml}$ alveolus $=6.0 \mathrm{~mm}$ ), whereas in

1653 Edmund's (1985b, fig. 6) illustration of H. septentrionalis the spout is shorter than mf1.

1654 The masseteric fossa of H. floridanus (UF 224450) is broad, its anterior terminus marked

1655 by a low crest that connects the anteriormost edge of the angular process with the ventralmost

1656 edge of the coronoid process (Figure 14A). This crest continues posteriorly across the lateral

1657 surface of the coronoid base. This makes the masseteric fossa of $H$. floridanus deeper than that

1658 of Vassallia, but shallower than that of H. occidentalis (Vizcaíno et al. 1998). There are distinct

1659 depressions on either side of this upper masseteric crest. The depression above the crest covers

1660 most of the lateral surface of the coronoid process, and is bounded anteriorly by the coronoid

1661 crest, i.e., the thickened anterolateral margin of the coronoid process. The coronoid crest is

1662 continuous dorsally with a distinct crest that crosses the lateral surface of the coronoid process 
1663 proximal to its tip, which we are designating the lateral coronoid crest. This lateral coronoid

1664 crest is found in all euphractine and eutatine armadillos, as well as pampatheres (Gaudin and

1665 Wible 2006: char 21[1], an unambiguous synapomorphy of Node A). Because this lateral

1666 coronoid depression lies between the coronoid and lateral coronoid crests, which serve as

1667 insertion points for the temporalis musculature in Euphractus (Smith and Redford 1990; Wible

1668 and Gaudin 2004) and presumably in Holmesina as well (Vizcaíno et al. 1998), and the upper

1669 limit of the masseter, we are labeling this area the "intermuscular fossa." The intermuscular fossa

1670 is very similar in size and shape in H. floridanus and H. occidentalis (ROM 4955), ovate and

1671 elongated along an anteroventral to posterodorsal axis. In H. septentrionalis, it appears to be

1672 narrower anteroposteriorly and more elongated posterodorsally (Cahn 1922; Simpson 1930).

1673 There is also a weak, ovate depression below the upper masseteric crest in UF 224450, its

1674 long axis oriented in an anteroventral to posterodorsal direction, bounded posteriorly by the

1675 lateral coronoid crest. It is unclear if this area serves as part of the attachment for the masseter,

1676 although low ridges crossing its surface suggest that it does, and Smith and Redford (1990) show

1677 that the comparable area in Euphractus is covered by the masseter muscle.

1678 The coronoid process itself is generally triangular in H. floridanus, but varies rather

1679 dramatically in its proportions. The ratio of maximum height to basal anteroposterior length

1680 ranges from 0.85-1.43, easily encompassing $H$. septentrionalis [as illustrated by James (1957)

1681 and Edmund (1985b), the ratio is 1.25 or 1.23 , respectively] within this range. The process

1682 appears to be somewhat more tapered distally in $H$. floridanus than in H. septentrionalis. A

1683 complete coronoid is not preserved in the specimen of $H$. occidentalis illustrated by Vizcaíno et

1684 al. (1998), but the preserved portion is more parallel sided than tapered distally, resembling more

1685 closely the condition in H. septentrionalis. Although the posterior edge of the coronoid process 
1686 is slightly inclined posterodorsally in both H. floridanus and H. septentrionalis, the former taxon

1687 possesses an additional small but distinct posterior hook at its distal terminus (Figure 14), a

1688 feature lacking in the latter species (James 1957; Edmund 1985b). Similar to the lateral coronoid

1689 crest described above, the coronoid process of $H$. floridanus carries a thickened anterior edge on

1690 its medial face, as well (Figure 14C). This medial crest connects to a second crest near the base

1691 of the coronoid. This low crest traces a posteroventrally curved arc, terminating at a point above

1692 the space between the last molariform tooth and the mandibular foramen. Anteroposteriorly, the

1693 medial surface of the coronoid process is gently concave. The base of the coronoid covers the

1694 posterior half of $\mathrm{m} 8$ in lateral view, and hides mf9 entirely, as in other pampatheres (De Iuliis

1695 and Edmund 2002).

1696 When viewed laterally or medially (Figure 14), the condylar process of H. floridanus is

1697 very short and triangular, closely resembling that of H. septentrionalis (Simpson 1930; James

1698 1957; Edmund 1985b) and H. occidentalis (Vizcaíno et al. 1998). As noted above, there is a

1699 single, short condyloid crest on the lateral side of the condylar process. There are two such

1700 crests on the medial side. All are short and extend in an anteroventral direction - the lateral crest

1701 is straight, whereas the medial crests are curved in an anteriorly concave fashion. Edmund

1702 (1985b) illustrates three medial condyloid crests in his specimen of $H$. septentrionalis. The

1703 condyle itself is ovate, very broad transversely, and narrow anteroposteriorly, its width two to

1704 three times its length (Tables 3, 4). Its surface is flat anteroposteriorly, but slightly concave

1705 transversely, and inclined posterodorsally in lateral view, as it is in H. occidentalis (ROM 4955).

1706 At its medial extremity, the condyle of $H$. floridanus hooks sharply anteriorly at nearly a right

1707 angle, forming a tall medial wall to an ovate fossa. This fossa extends nearly to the midpoint of

1708 the condyle, lying anterior to the articular surface. It likely served as the site of insertion for the 
1709 lateral pterygoid muscle, since the muscle attaches to this region in the extant Euphractus (Wible

1710 and Gaudin 2004). The condyle in H. floridanus is strongly elevated, located high above the

1711 level of the toothrow, like it is in H. septentrionalis (Edmund 1985b) and H. occidentalis

1712 (Vizcaíno et al. 1998). Curiously, the condyle of pampatheres is noticeably less elevated than

1713 that of Propalaehoplophorus, Proeutatus, or Euphractus (Table 3).

1714 As in the other Holmesina, the angular process of H. floridanus extends only a short

1715 distance posterior to the base of the condylar process, but forms a very broad, posteroventrally

1716 convex curved structure that reaches anteriorly nearly to the midpoint of the last molariform

1717 tooth (Figure 14). It extends, at its lowest point, slightly below the ventral edge of the horizontal

1718 ramus. The outer surface, part of the very large masseteric fossa, is only slightly convex

1719 anteroposteriorly. Similarly, its inner surface is only slightly concave anteroposteriorly, nearly

1720 flat dorsoventrally, but strongly scalloped near its margin by the insertion of the medial

1721 pterygoid muscle, which attaches to this same region in Euphractus (Wible and Gaudin 2004)

1722 and other placental mammals (e.g., Canis, Evans and Christiansen 1979; Homo, Clemente 1985).

1723 Again, this morphology is virtually identical to that of other Holmesina (Simpson 1930; Edmund

1724 1985b; Vizcaíno et al. 1998). The mandibular foramen, for the inferior alveolar nerves and

1725 vessels (Wible and Gaudin 2004), lies just above the inner medial pterygoid fossa, just behind

1726 and below the level of the last molarifom and positioned directly above the most ventral portion

1727 of the angular process. In Simpson's (1930) illustration of H. septentrionalis, the foramen is

1728 located somewhat more anterior and much further ventrally, but this may be due to postmortem

1729 damage. In Edmund's (1985b) illustration of the same taxon, there appear to be two mandibular

1730 foramina, one in a position like that of Simpson's specimen, the other in roughly the same

1731 position as in $H$. floridanus (UF 224450). 
There is more variation in lower tooth counts than upper tooth counts among crown-

1733 group cingulates (Gaudin and Wible 2006) - e.g., Proeutatus (Scott 1903-4) and Euphractus

1734 (Wible and Gaudin 2004) both have 10 lowers, and Propalaehoplophorus has only eight (Scott

1735 1903-4). Holmesina has nine, as in other pampatheres (Simpson 1930; Edmund and Theodor

1736 1997; DeIulis and Edmund 2002), and this condition is optimized as a synapomorphy of

1737 pampatheres plus glyptodonts in Gaudin and Wible's (2006; Node 8) phylogenetic analysis.

1738 Only three teeth are preserved in UF 224450: mf2, mf6 and mf7 (Figure 14). In addition,

1739 there appears to be a conical, unerupted $\mathrm{m} 4$, but this is likely a pathological condition, as

1740 indicated not only by the shape and position of the tooth itself, but by the spongy bone that

1741 occupies much of the volume of the alveolus. The shape of the remaining teeth can only be

1742 inferred from the outline of their alveoli. There are lower teeth preserved in other FLMNH $H$.

1743 floridanus specimens, though many can only be observed in lateral view because of preservation

1744 and degree of preparation. UF 223813 preserves all nine lower molariforms (Table 4), UF

1745275497 preserves mfl, mf3-7 and mf9, UF 275498 preserves mf1-7, and UF 285000 preserves

$1746 \mathrm{mf}$, mf4-5, and mf7-8. The first three lower molariforms in H. floridanus are ovate

1747 mesiodistally, with their long axis rotated to a slightly mesiolingual to distolabial orientation.

1748 The fourth molarifom is pathological in UF 224450. The alveolus shape indicates a reniform

1749 outline, with a slight labial indentation, but there is no visible external groove on the teeth in the

1750 other $H$. floridanus specimens, where the tooth takes on almost a rectangular shape, or perhaps

1751 weakly bilobate, in contrast to the reniform mf4 (with a lingual groove) of other Holmesina (see

1752 below). The remaining lower teeth in H. floridanus (mf5-9) appear to be strongly bilobate in

1753 outline. The first and last of these (i.e., mf5 and mf9) are substantially shorter mesiodistally than

1754 the intervening three teeth in between. 
1756 Edmund 1985b), although both $\mathrm{mf3}$ and $\mathrm{mf4}$ are clearly reniform (concave lingually) in this

1757 species, in clear contrast to H. floridanus, and even mf2 has a lingual groove as illustrated by

1758 Edmund (1985b). Holmesina occidentalis (Vizcaíno et al. 1998) is even more similar to $H$.

1759 floridanus, lacking the reniform anterior teeth of $H$. septentrionalis, although mf5 in this taxon is

1760 as large as mf6-8, contrasting with its reduced length (relative to m6-8) in other Holmesina.

1761 Simpson (1930) notes that mf4 is bilobate in both Pampatherium and Kraglievichia, and is

1762 clearly more elongated mesiodistally than $\mathrm{mf3}$, both features contrasting with the condition in

1763 Holmesina. De Iuliis and Edmund (2002) describe and illustrate an m4 for Vassallia that

1764 resembles that of Pampatherium and Kraglievichia, whereas Castellanos $(1937,1946)$ attributes

1765 a Holmesina-like morphology to this taxon. De Iuliis and Edmund (2002) suggest the

1766 discrepancy may be due to individual variation, and Edmund and Theodor (1997: p. 230) note

1767 that the shape of mf4 in Scirrotherium varies "from reniform to elongate-elliptical." In both

1768 Pampatherium and Vassallia (Simpson, 1930; Castellanos 1937, 1946), mf5 is reniform rather

1769 than bilobate, as it is in Holmesina. In Scirrotherium, mf5 is described as bilobate but illustrated

1770 as reniform (Edmund and Theodor 1997: fig.14.2). The long axis of mf5-7 in Vassallia is

1771 obtusely V-shaped with a lingual vertex (FMNH P14424; see illustration in De Iuliis and

1772 Edmund, 2002), and is rotated so that the posterior lobe extends further labially than the anterior

1773 lobe. Simpson (1930) illustrates a similar if less well developed condition for mf6, mf7, and mf8

1774 in Kraglievichia, and $\mathrm{mf5}, \mathrm{mf6}$ and $\mathrm{mf8}$ in Pampatherium, whereas in Holmesina and

1775 Scirrotherium (Edmund and Theodor 1997), the long axis of the posterior molariforms is

1776 essentially straight. 
1778 Scott 1903-4) are reminiscent of those in pampatheres in some respects, with the first and second

1779 lower molariforms (likely homologous to $\mathrm{mf} 2$ and $\mathrm{mf} 3$ of pampatheres) ovate or slightly

1780 reniform in outline, and the third ( $=\mathrm{m} 4$ of pampatheres) clearly reniform, but the remaining

1781 lower molariforms show the distinctive trilobate shape characteristic of glyptodonts (Hoffstetter

1782 1958). The lower tooth outlines in Proeutatus (FMNH P13197; Scott 1903-4) also display some

1783 pampathere-like features. The anterior teeth (mf1-3) are ovate, but mf4-8 are vaguely heart

1784 shaped, with a shallow groove followed by a sharp keel on the lingual surface, with a stronger

1785 groove on the labial edge. The long axes of mf4-8 are tilted somewhat posterolabially, as

1786 described above for Vassallia. The mf9 in Proeutatus is weakly bilobate, like that of

1787 pampatheres, but the distal lobe is the broader of the two, whereas the mesial lobe is broader in

1788 pampatheres. The tooth outlines in Euphractus are like those of most other armadillos, i.e.,

1789 uniformly circular or ovate in cross section (Wible and Gaudin 2004; Gaudin and Wible 2006).

1790 As was the case with the upper dentition, the preserved teeth in UF 224450 possess a

1791 raised central region of osteodentine surrounded by more typical orthodentine (Ferigolo 1985;

1792 Kalthoff 2011). In mf2, the osteodentine core takes on the shape of a very narrow oval aligned

1793 with the long axis of tooth's outline. The osteodentine in $\mathrm{mf} 6$ and $\mathrm{mf} 7$ is mostly linear,

1794 expanding into a short "Y" at its mesial and distal ends, as was the case with the posterior upper

1795 molarifoms. The same condition is present in other pampatheres (Simpson 1930; De Iuliis and

1796 Edmund 2002; Kalthoff 2011), whereas in glyptodonts the central osteodentine core bear

1797 multiple lateral branches (Scott 1903-4; Gillette and Ray 1981; Ferigolo 1985; Kalthoff 2011),

1798 and in Proeutatus the osteodentine core takes the form of an obliquely oriented oval (Scott 1903-

1799 4). Euphractus and other cingulates lack this osteodentine core, the central regions of their teeth 
1800 occupied instead by a variably vascularized "modified orthodentine" (Ferigolo 1985; Gaudin and

1801 Wible 2006; Kalthoff 2011).

1802 The occlusal surface of the first three lower molariforms in H. floridanus is quite

1803 variable. In some instances the teeth are nearly flat, contrasting with the more beveled crowns of

1804 the anterior upper molariforms - e.g., in mf1 of UF 223813 and 275497 (L only), and mf2 and

1805 mf3 of UF 275498. Other are beveled (some only weakly, e.g., m2 of UF 224450; Figure 14),

1806 with a small, mesioventrally sloping anterior facet, usually occupying less than $1 / 4$ of the occlusal

1807 surface, and the remaining distal facet sloping distoventrally. As noted above in the description

1808 of the premaxillary teeth, there does not appear to be any obvious correlation between variation

1809 in wear surface morphology of these beveled anterior molariforms and the chronological age of

1810 the specimens. The remaining molariforms (mf4-9) have single, flat occlusal surfaces, as was

1811 the case with the upper posterior teeth. These occlusal surface are not horizontal, but inclined

1812 distoventrally, giving adjacent tooth crowns a stair-step appearance, as described above for the

1813 upper dentition. These occlusal surface patterns are, as far as can be determined, nearly identical

1814 in other pampatheres. Proeutatus also has beveled wear on the anterior teeth and flat surfaces on

1815 the posterior teeth (flat on mf8-10 in FMH P13197; see also Scott 1903-4; Gaudin and Wible,

1816 2006). In glyptodonts, all teeth are worn flat, whereas in Euphractus and other armadillos, all

1817 teeth show beveled wear (Wible and Gaudin 2004; Gaudin and Wible 2006).

1818 The long axis of $\mathrm{mf} 2$ is oriented anteriorly in lateral view in $H$. floridanus, and nearly

1819 vertical or perhaps slightly posteriorly in $\mathrm{mf6}$ and $\mathrm{mf} 7$ (UF 224450). In anterior view, $\mathrm{m} 2$ tilts

1820 somewhat lingually, like the anteriormost upper teeth (although this may be a preservational

1821 artifact, since the anterior alveoli appear to slant labially). Like their counterparts in the upper

1822 dentition, $\mathrm{mf} 6$ and $\mathrm{mf} 7$ are implanted vertically, whereas the alveolus of $\mathrm{mf} 9$ seems to clearly be 
1823 inclined lingually, opposite its counterpart in the upper dentition. The latter condition (i.e.,

1824 posterior lower molariforms inclined lingually) is identified as a xenarthran synapomorphy by

1825 Gaudin (2004).

1826

1827

DISCUSSION

1828 The present study represents the most detailed and extensively illustrated description of a 1829 pampathere skull published to date. This is not to say that everything worthy of note is now

1830 known about the cranial osteology of Holmesina floridanus. As noted in the descriptive text

1831 above, we have yet to identify any ear ossicles, or any ecto- or entotympanic elements, in whole

1832 or in part (if the latter indeed exists in pampatheres, as it does in many other cingulates - see

1833 Patterson et al. 1989). CT-scanning of existing, but still unprepared specimens of H. floridanus

1834 might allow for the digital recovery of these small, often delicate and loosely attached structures.

1835 Such structures are frequently lost through more traditional mechanical preparation techniques,

1836 even if they exist and remain with the skull, either embedded in matrix, or, in the case of the

1837 ossicles, trapped in the vestibule of the inner ear. CT scans might also yield information on

1838 endocranial osteology, e.g., on the delicate and hard-to-prepare nasal turbinate elements and

1839 paranasal sinuses, as has been done for the glyptodont Neosclerocalyptus (Fernicola et al. 2012)

1840 and the extant armadillo Dasypus (Billet et al. 2017). Scanning would also allow for the

1841 reconstruction of soft tissues, especially the brain and associated cranial nerves and endocranial

1842 vasculature, as has recently been done (in part) for the pampathere Pampatherium humboldti

1843 (Tambusso and Fariña 2015). Producing and describing detailed CT scans of the skull in $H$.

1844 floridanus were deemed beyond the scope of the present study, but are planned for the future. In 
1845 addition, there is extensive postcranial and carapace material for this species that was not

1846 considered in this investigation, but will be the subject of planned future work.

1847 It is particularly fortuitous that this description centers on H. floridanus, a taxon

1848 represented by such abundant and well preserved material, including at least 10 complete or

1849 nearly complete skulls from two sites of similar age in central Florida. As noted by Wible and

1850 Gaudin (2004), De Iuliis et al. (2014), and many others, all too often descriptions of fossil

1851 species are based on single (or even incomplete) specimens. Whereas this is often due to the

1852 limitations of the available material, it makes it difficult to account for intraspecific variation, to

1853 distinguish between species level distinctions and sexual dimorphism (e.g., McDonald 2006), or

1854 to assess the reliability of systematic characters based on fossil taxa. The present study, like

1855 other recent detailed analyses of xenarthran skull morphology (e.g., Wible and Gaudin 2004;

1856 Gaudin 2011; McAfee and Naples 2012; Deluliis et al. 2014; Hautier et al. 2014; Gaudin et al.

1857 2015), has revealed substantial variation in a variety of cranial features in H. floridanus. These

1858 features include the number, size and /or position of a variety of cranial foramina (anterior

1859 palatal foramen, maxillary foramen, minor palatine foramina, foramen for frontal diploc vein,

1860 ethmoid foramen, transverse canal foramen, foramina for rami temporalis, suprameatal foramen,

1861 hypoglossal foramen); the presence, size and shape of various processes (anteroventral process

1862 on premaxilla, lacrimal tubercle, ventral zygomatic process, postorbital process of jugal, orbito-

1863 auricularis crest, medial pterygoid process, circular boss on lateral wall of promontorium, medial

1864 shelf of petrosal, coronoid process of mandible) or depressions (digastric fossa, tensor tympani

1865 fossa, fossa incudis); and the shape of other cranial (proportions of nasal bone, shape of anterior

1866 margin of premaxilla, shape of naso-frontal and jugal/squamosal sutures, shape of external nares 
1867 and occipital exposure of mastoid) or dental features (e.g., outline of M4 and M5, shape of wear 1868 facets on M1).

1869 Whereas the present study reveals a significant amount of intraspecific cranial variation 1870 in H. floridanus, it has also produced a long list of features that affirm previously hypothesized 1871 systematic relationships between this and other purportedly related taxa. Among these are

1872 features that are diagnostic of the taxon itself. The only diagnostic feature provided in the 1873 original diagnosis of the species by Robertson (1976) was the shape and orientation of the fourth

1874 upper molariform, and, as noted above, the shape of this tooth is variable among specimens of $H$. 1875 floridanus. Edmund (1987) distinguished this taxon based almost exclusively on size. Hulbert 1876 and Morgan (1993) conducted a more extensive analysis, looking at the taxonomic implications 1877 of size variation but also a series of qualitative postcranial and dental features for Holmesina 1878 specimens from Florida only, but they did not list any cranial characteristics that served to 1879 distinguish $H$. floridanus from the younger $H$. septentrionalis. The present study recognizes at 1880 least 11 distinct, meristic cranial features that may be diagnostic for $H$. floridanus (Table 5), 1881 further affirming its status as a disctinct pampathere species, currently known only from the late 1882 Blancan NALMA of central Florida.

1883 The description has also revealed a large number of characteristics that appear to

1884 distinguish the genus Holmesina from other pampatheres. As noted in the Introduction section

1885 of the present study, Holmesina is not recognized as a separate genus by McKenna and Bell

1886 (1997), and other authors have suggested the genus may be invalid (James 1957; Robertson

1887 1976). Our description identifies more than a dozen potential diagnostic cranial features (Table

1888 5), strongly affirming the monophyly of this genus, which includes species from both North and 1889 South America. 
1891 synapomorphies of pampatheres as a group (Table 5). The pampatheres have long been

1892 recognized as a distinctive group of cingulates, with their flat-topped, bilobate posterior

1893 molariforms that are highly dissimilar to the teeth of other cingulates. However, there is less

1894 agreement on how this morphological uniqueness should be treated taxonomically, with debate

1895 centered on whether pampatheres should be placed in a subfamily Pampatheriinae, a subgroup of

1896 the extinct and extant armadillo family Dasypodidae, as was typically the case in traditional

1897 classifications (e.g., Hoffstetter 1958; Patterson et al. 1989), or considered a family in their own

1898 right, the Pampatheriidae, as they are listed in McKenna and Bell (1997) and in most recent

1899 papers (e.g., De Iuliis and Edmund 2002; Tambusso and Fariña 2015; Góis et al. 2015). It

1900 should be noted here that if pampatheres are placed in their own family, and if we accept their

1901 close relationship to glyptodonts (discussed below), both morphological (Gaudin and Wible

1902 2006; Billet et al. 2011) and molecular phylogenies (Delsuc et al. 2016; Mitchell et al. 2016)

1903 would imply that this clade evolved from within armadillos. This in turn would make the family

1904 Dasypodidae, a taxon still widely employed in the mammalogical literature (e.g., Wilson and

1905 Reeder 2005; Vaughan et al. 2015), a paraphyletic group, necessitating the recognition of

1906 multiple armadillo families within "Dasypodidae." Gibb et al. (2016) propose dividing the

1907 Cingulata into two families, Dasypodidae and Chlamyphoridae, the latter including the

1908 glyptodonts as a subfamily. This arrangement reflects the basal split in Cingulata between these

1909 two clades, but it results in one of the long-recognized subfamilies of armadillos (and indeed the

1910 smallest subfamily in terms of generic level diversity), the Dasypodinae, being accorded family

1911 level status by Gibb et al. (2016). The other three armadillo subfamilies (Euphractinae,

1912 Chlamyphorinae and Tolypeutinae) are lumped together, along with the extinct glyptodonts 
1913 (Glyptodontinae), and presumably their close relatives the pampatheres (now Pampatheriinae),

1914 into a single, very large, taxonomically, morphologically and ecologically diverse family. In our

1915 view, this is a minimalist approach to reordering family level diversity among cingulates that

1916 does not adequately reflect the age, morphological disparity, and taxonomic diversity

1917 encompassed by cingulates in general, and the Chlamyphoridae in particular. Moreover, it

1918 appears inconsistent with the manner in which taxonomic diversity is distributed in the sister

1919 taxon to Cingulata, the Pilosa. It is particularly noteworthy that the Vermilingua, the youngest

1920 and least diverse of the three main xenarthran clades (including only four living species;

1921 McDonald et al. 2008; Gaudin and Croft 2015), is currently divided into two families. The

1922 sloths, which are also a younger radiation than the cingulates (at least as far as they are

1923 documented in the fossil record; Gaudin and Croft 2015) are currently arranged in five families

1924 (Gaudin 2004). We would therefore advocate recognition of all 4 extant subfamilies of

1925 armadillos, as well as the pampatheres and very diverse glyptodonts, respectively, as family level

1926 taxa, so that Cingulata would encompass at least seven families - Dasypodidae (following Gibb

1927 et al. 2016), Chlamyphoridae (following Gibb et al. 2016, but restricted to the members of the

1928 subfamily Chlamyphorinae, i.e., the living fairy armadillos), Euphractidae (for living

1929 euphractines plus their extinct kin), Tolypeutidae, Glyptodontidae, and Pampatheriidae. We

1930 would then group the latter six families into a larger clade Chlamyphoroidea, following the

1931 phylogeny of Gibb et al. (2016 -note this is also consistent with the morphological phylogenies

1932 of Billet et al. 2011 and Gaudin and Wible 2006). We believe this is a better way to arrange

1933 cingulate diversity; however, we recognize that it does not account for all the taxonomic

1934 difficulties posed by the group. For example, it would leave some extinct taxa (e.g., eutatine

1935 armadillos, and perhaps some extinct "euphractines" like Prozaedyus or Macroeuphractus, and 
1936 the peculiar horned armadillo Peltephilus; see Gaudin and Wible 2006; Billet et al. 2011) with an

1937 unresolved family-level status.

1938 The second largest list of putative synapomorphies recognized in this study support the

1939 alliance of pampatheres with the other clade of cingulate herbivores, the much more diverse and

1940 specialized glyptodonts (Table 5). An alliance of these two groups of large bodied herbivores

1941 was most prominently suggested by Bryan Patterson (Patterson and Pascual 1972; Patterson et al.

1942 1989), and was confirmed by the subsequent cladistic phylogenetic studies of Engelmann (1985),

1943 Gaudin and Wible (2006), Porpino et al. (2009, 2010), and Billet et al. (2011). The present study

1944 adds to the already extensive list of derived resemblances among these forms (Table 5). The

1945 studies by Gaudin and Wible (2006) and Billet et al. (2011) also suggest that the Miocene

1946 armadillo Proeutatus (Santacrucian SALMA) is the sister taxon to pampatheres plus glyptodonts.

1947 This armadillo has been hypothesized to share the herbivorous diet characteristic of pampatheres

1948 and glyptodonts (Vizcaíno et al. 2012 and references therein). Table 5 confirms that this

1949 relationship is supported by cranial features not directly related to mastication, e.g., features from

1950 the ear region.

1951 Lastly, it should be noted that the present study identified a number of cranial features

1952 which are shared by some, but not all pampathere genera (e.g., M4 is bilobate in Pampatherium

1953 and Kraglievich but not Holmesina; m5 is reniform in Pampatherium and Vassallia but not

1954 Holmesina) and some features that appear to be apomorphies of pampatheres other than

1955 Holmesina (e.g., postorbital process of zygomatic arch on squamosal rather than the jugal, and

1956 loss of connection between zygomatic arch and nuchal crest in Vassallia). Clearly, and

1957 unsurprisingly, cranial data has much to contribute to our understanding of pampathere

1958 systematics. To our knowledge, no published phylogenetic analysis of pampatheres exists, but 
1959 we felt that such an analysis was beyond the scope of the present study, especially given the fact

1960 that much of the critical material is available only in South American museums. Nevertheless,

1961 such a study clearly needs to be produced in the near future if we are to better understand the

1962 evolution of this distinctive group of large cingulate herbivores, and their place in the history of

1963 Cingulata as a whole. Moreover, given their geographic distribution on both sides of the Isthmus

1964 of Panama (Scillato-Yané et al. 2005), a better understanding of pampathere internal

1965 relationships might also yield insights into their role in the so-called Great American Biotic

1966 Interchange (GABI), the extensive exchange of taxa between North and South America that

1967 plays such a central role in the evolution of the mammalian fauna of these two continents.

1968

1969

\section{CONCLUSION}

1970 The present study represents the first detailed, extensively illustrated, bone-by-bone description

1971 of pampathere cranial osteology, including reconstructions of sutural patterns and the position

1972 and content of the major cranial foramina. Due to the abundance of fossil material available for

1973 this late Pliocene - early Pleistocene species from Florida, we have been able to document

1974 extensive intraspecific variation in a variety of cranial features. We have also identified a series

1975 of new cranial characteristics which appear to be diagnostic for Holmesina floridanus. Though

1976 the systematics of pampatheres is controversial, our study affirms the monophyly of the genus

1977 Holmesina, and provides additional characters that support the monophyly of pampatheres as a

1978 whole. We advocate the recognition of pampatheres as a distinct family Pampatheriidae within

1979 the large clade Cingulata. We also advocate for the recognition of their sister taxon, the

1980 glyptodonts, as a family level grouping Glyptodontidae, and for similar family level recognition

1981 for the extant cingulate clades historically assigned subfamily status, i.e, the Dasypodidae, 
1982 Chlamyphoridae, Euphractidae, and Tolypeutidae. Lastly, this analysis highlights the need for

1983 further studies of pampatheres in general and Holmesina floridanus in particular, including

1984 phylogenetic analyses of pampathere interrelationships, studies of $H$. floridanus postcrania and

1985 carapaces, and further studies of $H$. floridanus cranial anatomy using CT-scans.

1986

1987

\section{ACKNOWLEDGMENTS}

1988 First and foremost, we thank Richard Hulbert and Jon Bloch of the Florida Museum of Natural

1989 History (University of Florida, Gainesville, FL), for all of their help in accessing the wonderful

1990 material of Holmesina floridanus on which this report is based. For access to other fossil and

1991 extant skeletal material used in this study, we thank B. Simpson, J. Flynn and K. Angielczyk of

1992 the Field Museum of Natural History (Chicago, IL), J. Wible of the Carnegie Museum of Natural

1993 History (Pittsburgh, PA), and W. Joyce and D. Brinkman of the Peabody Museum at Yale

1994 University (New Haven, CT). For the exceptional illustrations accompanying this paper, we

1995 thank the ever-talented Julia Morgan Scott, and we thank S. Chatzimanolis of the University of

1996 Tennessee at Chattanooga for his help in making the stereophotographs in Figure 8. We thank

1997 our anonymous reviewers for their insightful reviews of this manuscript.

1998

1999

\section{LITERATURE CITED}

2000

Abba AM, GH Cassini GH, Valverde G, Tilak M-K, Vizcaíno SF, M. Superina M, Delsuc F. 2015. Systematics of hairy armadillos and the taxonomic status of the Andean hairy armadillo (Chaetophractus nationi). Journal of Mammalogy, 96(4):673-689.

2003 DOI:10.1093/jmammal/gyv082 
2004 Aguiar JM, Da Fonseca AB. 2008. Conservation status of the Xenarthra. In: Loughry WJ, 2005 Vizcaíno SF, eds. Biology of the Xenarthra. Gainesville: University of Florida Press, 2152006231.

2007 Babot J, García-López DA, Gaudin TJ. 2012. The most ancient xenarthran petrosal: morphology and evolutionary significance. Journal of Vertebrate Paleontology, 32(5): 1186-1197.

2010

2011

2012

2013

2014

2015

2016

2017

2018

2019

2020

2021

2022

2023

2024

2025

2026

Billet G, Hautier L, de Muizon C, Valentin X. 2011. Oldest cingulate skulls provide congruence between morphological and molecular scenarios of armadillo evolution. Proceedings of the Royal Society of London, B. Biological Sciences, 278:2791-2797. DOI: $10.1098 / \mathrm{rspb} .2010 .2443$

Billet G, Hautier L, Lebrun R. 2015. Morphological diversity of the bony labyrinth (inner ear) in extant xenarthrans and its relation to phylogeny. Journal of Mammalogy, special feature, 96(4):658-672. DOI:10.1093/jmammal/gyv074

Billet G, Hautier L, de Thoisy B, Delsuc F. 2017. The hidden anatomy of paranasal sinuses reveals biogeographically distinct morphotypes in the nine-banded armadillo (Dasypus novemcinctus). PeerJ, 5:e3593. DOI 10.7717/peerj.3593

Bugge J. 1979. Cephalic arterial pattern in New World edentates and Old World pangolins with special reference to their phylogenetic relationships and taxonomy. Acta Anatomica, 105(1):37-46.

Cahn AR. 1922. Chlamytherium septentrionalis, a fossil edentate new to the fauna of Texas. Journal of Mammalogy, 3:22-24.

Cartelle C, Bohórquez GA. 1985. Pampatherium paulcoutoi, uma nova espécie de tatu gigante da Bahia, Brasil (Edentata, Dasypodidae). Revista Brasileira de Zoología, 2(4):229-254. 
2027 Castellanos A. 1937. Anotaciones sobre las líneas filogenéticas de los clamiterios. Publicaciones 2028 del Instituto Fisiografia y Geología, Universidad Nacional del Litoral, Rosario 2029 Argentina. Serie Técnica y Científica, 8:1 -35.

2030 Castellanos, A. 1946. Una nueva especie de clamiterio, Vassallia maxima n. sp. Publicaciones 2031 del Instituto de Fisiografia y Geología, Universidad Nacional del Litoral, Rosario 2032 Argentina. Serie Técnica y Cientifica, 26:1 -47.

2033 Clemente CD. 1985. Gray's Anatomy. Philadelphia: Lea and Febiger.

2034 Croft DA. 2016. Horned Armadillos and Rafting Monkeys. The Fascinating Fossil Mammals of 2035 South America. Bloomington: Indiana University Press.

2036 De Iuliis G, Edmund AG. 2002. Vassallia maxima Castellanos, 1946 (Mammalia: Xenarthra:

2037 Pampatheriidae), from Puerta del Corral Quemado (late Miocene to early Pliocene), 2038 Catarca Province, Argentina. Pp. 49-64 in R. J. Emry (ed.), Cenozoic Mammals of Land 2039 and Sea: Tributes to the Career of Clayton E. Ray. Smithsonian Contributions to $2040 \quad$ Paleobiology 93, 372 pp.

2041 De Iuliis G, Bargo MS, Vizcaíno SF. 2000. Variation in skull morphology and mastication in the 2042 fossil giant armadillos Pampatherium spp. and allied genera (Mammalia: Xenarthra:

2043 Pampatheriidae), with comments on their systematics and distribution. Journal of 2044 Vertebrate Paleontology, 20(4):743-754.

2045 De Iuliis G, Gaudin TJ, Vicars MP. 2011. A new genus and species of nothrotheriid sloth 2046 (Xenathra, Tardigrada, Nothrotheriidae) from the late Miocene (Huayquerian) of Peru. 2047 Palaeontology, 54:171-205. DOI: 10.1111/j.1475-4983.2010.01001.x

2048 De Iuliis G, Pujos F, Toledo N, Bargo MS, Vizcaíno SF. 2014. Eucholoeops Ameghino, 1887 2049 (Xenarthra, Tardigrada, Megalonychidae) from the Santa Cruz Formation, Argentine 
Patagonia: implications for the systematics of Santacrucian sloths. Geodiversitas, 36:

2051 209-255. DOI: $10.5252 / \mathrm{g} 2014 \mathrm{n} 2 \mathrm{a} 2$

2052 Delsuc F, Gibb GC, Kuch M, Billet G, Hautier L, Southon J, Rouillard JM, Fernicola JC, 2053 Vizcaíno SF, MacPhee RD, Poinar HN. 2016. The phylogenetic affinities of the extinct 2054 glyptodonts. Current Biology, 26(4): R155-R156. DOI: 10.1016/j.cub.2016.01.039

2055 2056 2057 2058 2059 2060 2061 2062 2063 2064 2065 2066 2067 2068

Edmund G. 1985b. The fossil giant armadillos of North America (Pampatheriinae, Xenarthra Edentata). In: Montgomery GG, ed. The Ecology and Evolution of Armadillos, Sloths, and Vermilinguas. Washington, DC: Smithsonian Institution Press, 83-93.Edmund AG. 1987. Evolution of the genus Holmesina (Pampatheriidae, Mammalia) in Florida, with remarks on taxonomy and distribution. Pearce-Sellards Series, Texas Memorial Museum, 45:1-20.

Edmund AG, Theodor JM. 1997. A giant new pampatheriid armadillo. In: Kay RF, Madden RH, Cifelli RL, Flynn JJ, eds. Vertebrate Paleontology in the Neotropics: The Miocene Fauna of La Venta, Colombia. Washington, DC: Smithsonian Institution Press, 227-332.

Engelmann G. 1985. The phylogeny of the Xenathra. In: Montgomery GG, ed. The Ecology and Evolution of Armadillos, Sloths, and Vermilinguas. Washington, DC: Smithsonian Institution Press, 51-63

Evans HE, Christiansen GC. 1979. Miller's Anatomy of the Dog, 2nd edition. Philadelphia: W.B. Saunders.

Feijó A, Cordeiro-Estrela P. 2016. Taxonomic revision of the Dasypus kappleri complex, with revalidations of Dasypus pastasae (Thomas, 1901) and Dasypus beniensis Lönnberg, 
2073

2074

2075

2076

2077

2078

2079

2080

2081

2082

2083

2084

2085

2086

2087

2088

2089

2090

2091

2092

2093

1942 (Cingulata, Dasypodidae). Zootaxa, 4170(2):271-297. DOI:

10.11646/zootaxa.4170.2.3

Ferigolo J. 1985. Evolutionary trends of the histological pattern in the teeth of Edentata (Xenarthra). Archives of Oral Biology, 30(1):71-82.

Fernicola JC, Toledo N, Bargo MS, Vizcaíno SF. 2012. A neomorphic ossification of the nasal cartilages and the structure of paranasal sinus system of the glyptodont Neosclerocalyptus Paula Couto 1957 (Mammalia, Xenarthra). Palaeontologia Electronica, 15(3):27A, 22p. palaeo-electronica.org/content/2012-issue-3-articles/305-glyptodont-nasal-anatomy.

Fernicola JC, Vizcaíno SF, Fariña RA. 2008. The evolution of armored xenarthrans and a phylogeny of glyptodonts. In: Loughry WJ, Vizcaíno SF, eds. Biology of the Xenarthra. Gainesville: University of Florida Press, 79-85.

Frost DR, Wozencraft WC, Hoffmann RS. 1991. Phylogenetic relationships of hedgehogs and gymnures (Mammalia: Insectivora: Erinaceidae). Smithsonian Contributions to Zoology, 518: $1-69$.

Gaudin TJ. 1995. The ear region of edentates and the phylogeny of the Tardigrada (Mammalia, Xenarthra). Journal of Vertebrate Paleontology, 15(3): 672-705.

Gaudin TJ. 2004. Phylogenetic relationships among sloths (Mammalia, Xenarthra, Tardigrada): the craniodental evidence. Zoological Journal of the Linnean Society, 140(2): 255-305.

Gaudin TJ. 2011. On the osteology of the auditory region and orbital wall in the extinct West Indian sloth genus Neocnus (Megalonychidae, Xenarthra, Placentalia). Annals of the Carnegie Museum of Natural History, 80(1):5-28. 
2094 Gaudin TJ, Croft DA. 2015. Paleogene Xenarthra and the evolution of South American

2095

2096

2097

2098

2099

2100

2101

2102

2103

2104

2105

2106

2107

2108

2109

2110

2111

2112

2113

2114

2115

2116

mammals. Journal of Mammalogy, special feature, 96(4):622-634.

DOI:10.1093/jmammal/gyv073

Gaudin TJ, McDonald HG. 2008. Morphology-based investigations of the phylogenetic relationships among extant and fossil Xenarthrans. In: Loughry WJ, Vizcaíno SF, eds. Biology of the Xenarthra. Gainesville: University of Florida Press, 24-36.

Gaudin TJ, Wible JR. 2006. Chapter 6. The phylogeny of living and extinct armadillos (Mammalia, Xenarthra, Cingulata): a craniodental analysis. In: Carrano MT, Gaudin TJ, Blob, RW, Wible, JR, eds. Amniote Paleobiology: Perspectives on the Evolution of Mammals, Birds, and Reptiles. Chicago:University of Chicago Press, 153-198.

Gaudin TJ, DeIuliis G, Toledo N, Pujos F. 2015. The basicranium and orbital region of the early Miocene Eucholoeops ingens Ameghino, 1887 (Xenarthra, Pilosa, Megalonychidae). Ameghiniana, 52:226-240. DOI: 10.5710/AMGH.04.12.2014.2755

Gaudin TJ, Emry RJ, Morris J. 2016. Description of the skeletal anatomy of the North American pangolin Patriomanis americana (Mammalia, Pholidota) from the latest Eocene of Wyoming (USA). Smithsonian Contributions to Paleobiology, 98:1-103.

Gaudin TJ, Wible JR, Hopson JA, Turnbull WD. 1996. Reexamination of the morphological evidence for the Cohort Epitheria (Mammalia, Eutheria). Journal of Mammalian Evolution, 3(1): 31-79.

Gibb GC, Condamine FL, Kuch M., Enk J, Moraes-Barros N, Superina M, Poinar HN, Delsuc F. (2016). Shotgun mitogenomics provides a reference phylogenetic framework and timescale for living xenarthrans. Molecular Biology \& Evolution, 33(3):621-642. DOI:10.1093/molbev/msv250. 
2117 Gillette DD, Ray CE. 1981. Glyptodonts of North America. Smithsonian Contributions to

2118 Paleobiology, 40:1-255.

2119 Góis, F. Scillato-Yané, G.J., Carlini, A.A., Ubilla, M. 2012. Una nueva especie de Holmesina

2120 Simpson (Xenarthra, Cingulata, Pampatheriidae) del Pleistoceno de Rondonia, Sudoeste

2121 de la Amazonia, Brasil. Revista Brasileira de Paleontologia, 15(2): 211-227.

2122 Góis, F., Scillato-Yané, G.J., Carlini, A.A., Guilherme, E. 2013. A new species of Scirrotherium

2123 Edmund \& Theodor, 1997 (Xenarthra, Cinculata, Pampatheriidae) from the late Miocene 2124 of South America. Alcheringa, 37: 177-188.

2125 Góis F, González Ruiz LR, Scillato-Yané GJ, Soibelzon E. 2015. A peculiar new Pampatheriidae 2126 (Mammalia: Xenarthra: Cingulata) from the Pleistocene of Argentina and comments on 2127 Pampatheriidae diversity. PLoS ONE, 10(6): e0128296.

2128 DOI:10.1371/journal.pone.0128296

2129 González-Ruiz LR, Ciancio RM, Martin GM, Zurita AE. 2015. First record of supernumerary 2130 teeth in Glyptodontidae (Mammalia, Xenarthra, Cingulata). Journal of Vertebrate $2131 \quad$ Paleontology, 35(1): e885033.

2132 Guth C. 1961. La région temporale des Édentés. D. Phil. Thesis, L’Université de Paris.

2133 Hautier L, Billet G, Eastwood B, Lane J. 2014. Patterns of morphological variation of extant 2134 sloth skulls and their implication for future conservation efforts. The Anatomical Record, 2135 297:979-1008. DOI: $10.1002 / \operatorname{ar} .22916$

2136 Hautier L, Billet G, de Thoisy B, Delsuc F. 2017. Beyond the carapace: skull shape variation and 2137 morphological systematics of long-nosed armadillos (genus Dasypus). PeerJ, 5:e3650.

$2138 \quad$ DOI $10.7717 /$ peerj. 3650 
2139 Hoffstetter R. 1958. Xenarthra. In: Piveteau P, ed. Traité de Paléontologie, Vol. 2, no. 6,

2140 Mammifères Évolution. Paris: Masson et Cie, 535- 636.

2141 Hulbert RC, Morgan GS. 1993. Quantitative and qualitative evolution in the giant armadillo

2142 Holmesina (Edentata: Pampatheriidae) in Florida. In: Martin RA, Barnosky AD, eds.

2143 Morphological Change in Quaternary Mammals of North America. New York: Columbia

$2144 \quad$ University Press, 134-177.

2145 Hulbert RC, Webb SD. 2001. Chapter 10 - Mammalia 2, Xenarthrans. In: Hulbert RC, ed. The

2146 Fossil Vertebrates of Florida. Gainesville: University Press of Florida, 175-187.

2147 James G. 1957. An edentate from the Pleistocene of Texas. Journal of Paleontology, 31(4):796-

$2148 \quad 808$.

2149 Kalthoff DC. 2011. Microstructure of dental hard tissues in fossil and recent Xenarthrans

2150 (Mammalia: Folivora and Cingulata). Journal of Morphology, 272:641-661. DOI:

$2151 \quad 10.1002 /$ jmor.10937

2152 MacIntyre GT. 1972. The trisulcate petrosal pattern of mammals. Evolutionary Biology, 6:275$2153 \quad 303$.

2154 McAfee RK, Naples VL. 2012. Notice on the occurrence of supernumerary teeth in the two-toed

2155 sloths Choloepus didactylus and C. hoffmanni. Mastozoología Neotropical, 19: 339-344.

2156 McDonald HG. 2006. Sexual dimorphism in the skull of Harlan's ground sloth. Contributions in

2157 Science, Natural History Museum of Los Angeles County, 510: 1-9.

2158 McDonald HG., Vizcaíno SF, Bargo MS. 2008. Skeletal anatomy and the fossil history of the

2159 Vermilingua. In: Loughry WJ, Vizcaíno SF, eds. Biology of the Xenarthra. Gainesville:

2160 University of Florida Press, 64-78. 
2161 McDonough, C. M., and W. J. Loughry. 2008. Behavioral ecology of armadillos. In: Loughry 2162 WJ, Vizcaíno SF, eds. Biology of the Xenarthra. Gainesville: University of Florida Press, $2163 \quad 281-293$.

2164 McKenna MC, Bell SK. 1997. Classification of Mammals Above the Species Level. New York: 2165 Columbia University Press.

2166 Mitchell KJ., Scanferla A, Soibelzon E, Bonini R, Ochoa J, Cooper A. 2016. Ancient DNA from 2167 the extinct South American giant glyptodont Doedicurus sp. (Xenarthra: Glyptodontidae) 2168 reveals that glyptodonts evolved from Eocene armadillos. Molecular Ecology, 25(14): 3499-3508. DOI: $10.1111 / \mathrm{mec} .13695$

2170 Novacek MJ. 1986. The skull of leptictid insectivorans and the higher-level classification of 2171 eutherian mammals. Bulletin of the American Museum of Natural History, 183:1-112.

2172 Novacek MJ. 1993. Patterns of diversity in the mammalian skull. In: Hanken J, Hall BK, eds.). The Skull, Volume 2, Patterns of Structural and Systematic Diversity. Chicago: University of Chicago Press, 438-545.

Novacek MJ, Wyss AR. 1986. Higher-level relationships of the recent eutherian orders:

2177 O’Leary MA, Bloch JI, Flynn JJ, Gaudin TJ, Giallombardo A, Giannini NP, Goldberg SL, 2178 Kraatz BP, Luo Z-X, Meng J, Ni X, Novacek MJ, Perini FA, Randall Z, Rougier GW, 2179 Sargis EJ, Silcox MT, Simmons NB, Spaulding M, Velazco PM, Weksler M, Wible JR, 2180 Cirranello AL. 2013. The placental mammal ancestor and the post-KPg radiation of 2181 placentals. Science, 339:662-667. DOI: 10.1126/science.1229237 
2182 Patterson B, Pascual R. 1972. The fossil mammal fauna of South America. In: Keast A, Erk FC,

2183 Glass B, eds. Evolution, Mammals and the Southern Continents. Albany: State University

2184 of New York Press, 247-309.

2185 Patterson B, Segall W, Turnbull WD. 1989. The ear region in xenarthrans (= Edentata,

2186 Mammalia). Part I. Cingulates. Fieldiana, Geology, n.s., 18:1-46.

2187 Patterson B, Segall W, Turnbull WD, Gaudin TJ. 1992. The ear region in xenarthrans (=

2188 Edentata, Mammalia). Part II. Pilosa (sloths, anteaters), palaeanodonts, and a miscellany.

2189 Fieldiana, Geology, n.s., 24:1-79.

2190 Porpino K, Fernicola JC, Bergqvist LP. 2009. A new cingulate (Mammalia, Xenarthra),

$2191 \quad$ Pachyarmatherium brasiliense sp. nov., from the late Pleistocene of Northeastern Brazil.

2192 Journal of Vertebrate Paleontology, 29(3): 881-893.

2193 Porpino KO, Fernicola JC, Bergqvist LP. 2010. Revisiting the intertropical Brazilian species

2194 Hoplophorus euphractus (Cingulata, Glyptodontoidea) and the phylogenetic affinities of

2195 Hoplophorus. Journal of Vertebrate Paleontology, 30(3):911-927.

2196 Robertson JS. 1976. Latest Pliocene mammals from Haile XV A, Alachua County, Florida.

2197 Bulletin of the Florida State Museum, Biological Sciences, 20(3):111-186.

2198 Rose KD, Emry RJ. 1993. Relationships of Xenarthra, Pholidota, and fossil 'Edentates': the

2199 morphological evidence. In: Szalay FS, Novacek MJ, McKenna MC, eds. Mammal

$2200 \quad$ Phylogeny. Volume 2: Placentals. New York: Springer-Verlag, 81-102.

2201 Scillato-Yané GJ, Carlini AA, Tonni EP, Noriega JI. 2005. Palaeobiogeography of the late

2202 Pleistocene pampatheres of South America. Journal of South American Earth Sciences,

$2203 \quad 20(1 / 2): 131-138$. 
2204 Scott WB. 1903-1904. Mammalia of the Santa Cruz Beds. Part 1: Edentata. Reports of the 2205 Princeton Expeditions to Patagonia, 5:1-364.

2206 Simpson GG. 1930. Holmesina septentrionalis, extinct giant armadillo of Florida. American 2207 Museum Novitates, 442:1-10.

2208 Simpson GG. 1948. The beginning of the age of mammals in South America. Part 1.

2209 Introduction. Systematics: Marsupialia, Edentata, Condylarthra, Litopterna, and $2210 \quad$ Notioprogonia. Bulletin of the American Museum of Natural History, 91:1-227.

2211 Sinclair WJ. 1909. Mammalia of the Santa Cruz Beds. Volume VI, Paleontology. Part I, 2212 Typotheria; pp. 1-110 in W. B. Scott (ed.), Reports of the Princeton University 2213 Expeditions to Patagonia, 1896-1899. Princeton University, E. Schweizerbart'sche $2214 \quad$ Verlagshandlung (E. Nägele), Stuttgart.

2215 Smith KK, Redford KH. 1990. The anatomy and function of the feeding apparatus in two 2216 armadillos (Dasypoda): anatomy is not destiny. Journal of Zoology, 222:27-47.

2217 Stock C. 1925. Cenozoic gravigrade edentates of western North America. Carnegie Institute of $2218 \quad$ Washington Publications, 331:1-206.

2219 Tambusso PS, Fariña RA. 2015. Digital endocranial cast of Pampatherium humboldtii 2220 (Xenarthra, Cingulata) from the Late Pleistocene of Uruguay. Swiss Journal of 2221 Palaeontology, 134(1):109-116. DOI: 10.1007/s13358-015-0070-5

2222 Vaughan TA, Ryan JM, Czaplewski NJ. 2015. Mammalogy. 6th ed. Burlington, MA: Jones and $2223 \quad$ Bartlett Publishers.

2224 Vizcaíno SF, De Iuliis G, Bargo MS. 1998. Skull shape, masticatory apparatus and diet of 2225 Vassallia and Holmesina (Mammalia: Xenarthra: Pampatheriidae): when anatomy 2226 constrains destiny. Journal of Mammalian Evolution, 5(4):291-322. 
2227 Vizcaíno SF, Fariña RA. 1997. Diet and locomotion of the armadillo Peltephilus: a new view. $2228 \quad$ Lethaia, 30: 79-86.

2229 Vizcaíno SF, Fernicola JC, Bargo MS. 2012. Paleobiology of Santacrucian glyptodonts and 2230 armadillos. In: Vizcaíno SF, Kay RF, Bargo MS, eds. Early Miocene Paleobiology in 2231 Patagonia. Cambridge: Cambridge University Press, 194-215.

2232 Wible JR. 1990. Petrosals of Late Cretaceous marsupials from North America, and a cladistic 2233 analysis of the petrosal in therian mammals. Journal of Vertebrate Paleontology, 10(2):183-205.

2235

2236

2237

2238

2239

2240

2241

2242

2243

Wible JR. 2003. On the osteology of the short-tailed opossum Monodelphis brevicaudata (Didelphidae, Marsupialia). Annals of the Carnegie Museum, 72:137-202.

Wible JR. 2008. On the cranial osteology of the Hispaniolan solenodon, Solenodon paradoxus Brandt, 1833 (Mammalia, Lipotyphla, Solenodontidae). Annals of the Carnegie Museum, 70(3):321-402.

Wible JR. 2010. Petrosal anatomy of the nine-banded armadillo, Dasypus novemcinctus Linnaeus, 1758 (Placentalia: Xenarthra: Dasypodidae). Annals of Carnegie Museum, $79: 1-28$.

Wible JR. 2011. On the treeshrew skull (Mammalia, Placentalia, Scandentia). Annals of Carnegie Museum, 79: 149-230.

Wible JR, Gaudin TJ. 2004. On the cranial osteology of the yellow armadillo Euphractus sexcinctus (Dasypodidae, Xenarthra, Placentalia). Annals of Carnegie Museum, 73(3):117-196. 
2248 Wible JR, Novacek MJ, Rougier GW. 2004. New data on the skull and dentition in the 2249 Mongolian Late Cretaceous mammal Zalambdalestes. Bulletin of the American Museum of Natural History, 281:1-144.

2251 Wible JR, Rougier GW, Novacek MJ, Asher RJ. 2009. The eutherian mammal Maelestes 2252 gobiensis from the Late Cretaceous of Mongolia and the phylogeny of Cretaceous Eutheria. Bulletin of the American Museum of Natural History, 327:1-123.

2254 Wilson RW, Reeder DM. 2005. Mammal Species of the World: A Taxonomic and Geographic 2255 Reference. Baltimore: Johns Hopkins University Press.

2256

2257 
2260 Figure 1. Photographs of skulls of Holmesina floridanus. Skull of UF 248500: A, ventral view; B, dorsal view; C, right lateral view. Skull of UF 191448: D. ventral view; E, dorsal view, $F$, right lateral view. Scale bars $=5 \mathrm{~cm}$.

2263

2264

Figure 2. Skull of Holmesina floridanus in dorsal view. A, UF 191448; B, UF 248500. Scale bar 2265 $=5 \mathrm{~cm}$.

2266

2267 Figure 3. Reconstruction of the skull of Holmesina floridanus in dorsal view. Abbreviations: $\mathbf{f}$, frontal; frt, foramina for rami temporalis; j, jugal; l, lacrimal; lf, lacrimal foramen; mx, maxilla; n, nasal; nc, nuchal crest; p, parietal; pm, premaxilla; pop, paroccipital process of petrosal (= mastoid process of Patterson et al. 1989); popf, postorbital process of frontal; popj, postorbital process of jugal; sq, squamosal; tl, temporal lines; zp,

2272 zygomatic process of squamosal.

2273

2274 Figure 4. Skull of Holmesina floridanus in lateral view. A, UF 191448 in right lateral view; B, 2275 UF 248500 in right lateral view; C, UF 248500 in left lateral view. Scale bar $=5 \mathrm{~cm}$. 2276

Figure 5. Reconstruction of the skull of Holmesina floridanus in right lateral view. Abbreviations: aof, antorbital fossa; as, alisphenoid; bo, basioccipital; bs, basisphenoid; $\mathbf{d p j}$, two projections forming descending process of jugal; $\mathbf{f}$, frontal; fdv, foramen for frontal diploic vein; fo, foramen ovale; frt, foramina for rami temporalis; iof, infraorbital 
2281

2282

2283

2284

2285

2286

2287

2288

2289

2290

2291

2292

2293

2294

2295

2296

2297

2298

2299

2300

2301

2302

foramen; j, jugal; 1, lacrimal; lf, lacrimal foramen; lt, lacrimal tubercle; Mf1, first upper molariform tooth; Mf9, ninth upper molariform tooth; mr, maxillary ridge, i.e., ridge on facial process of maxilla; mx, maxilla; n, nasal; nc, nuchal crest; oc, occipital; occ, occipital condyle; $\mathbf{p}$, parietal; pm, premaxilla; pop, paroccipital process of petrosal (= mastoid process of Patterson et al. 1989); pt, pterygoid; smf, suprameatal foramen; sq, squamosal; zp, zygomatic process of squamosal.

Figure 6. Skull of Holmesina floridanus in ventral view. A, UF 191448; B, UF 248500. Scale bar $=5 \mathrm{~cm}$.

Figure 7. Reconstruction of the skull of Holmesina floridanus in ventral view. Abbreviations: apf, anterior palatal foramen; as, alisphenoid; bcc, basicochlear commissure; bo, basioccipital; bs, basisphenoid; cf, carotid foramen; dpj, two projections forming descending process of jugal; eo, exoccipital; fdv, foramen for frontal diploic vein; fm, foramen magnum; fo, foramen ovale; gf, glenoid fossa; hf, hypoglossal foramen; if, incisive foramen; iof, infraorbital foramen; jf, jugular foramen; mapf, major palatine foramen; Mf1, first upper molariform tooth; Mf9, ninth upper molariform tooth; mx, maxilla; n, nasal; oc, occipital; occ, occipital condyle; pal, palatine; pcp, paracondylar process of exoccipital (=paroccipital process of Patterson et al. 1989); pf, piriform fenestra; pgf, postglenoid foramen; pgp, postglenoid process; pm, premaxilla; pop, paroccipital process of petrosal (= mastoid process of Patterson et al. 1989); popf, postorbital process of frontal; popj, postorbital process of jugal; pr, promontorium of 
2303

2304

2305

2306

2307

2308

2309

2310

2311

2312

2313

2314

2315

2316

2317

2318

2319

2320

2321

2322

2323

2324

2325

petrosal; prs, presphenoid; pt, pterygoid; rcf, rectus capitis fossa; zp, zygomatic process of squamosal; zpm, zygomatic process of maxilla.

Figure 8. Reconstruction of right orbital wall of Holmesina floridanus in lateral view. Crosshatched surfaces indicate where zygomatic arch is "cut.". Abbreviations: as, alisphenoid; bo, basioccipital; bs, basisphenoid; cf, carotid foramen; cpf, caudal palatine foramen; ef, ethmoid foramen; f, frontal; fdv, foramen for frontal diploic vein; fo, foramen ovale; fr/sof, fused foramen rotundum and sphenorbital fissure; frt, foramina for rami temporalis; fv, fenestra vestibuli; iof, infraorbital foramen; itc, infratemporal crest; $\mathbf{j}$, jugal; l, lacrimal; If, lacrimal foramen; lfe, lacrimal fenestra; lopc, lateral opening of pterygoid canal; It, lacrimal tubercle; Mf9, ninth upper molariform tooth; mx, maxilla; mxf, maxillary foramen; n, nasal; of, optic foramen; os, orbitosphenoid; p, parietal; pgf, postglenoid foramen; pgp, postglenoid process; pop, paroccipital process of petrosal (= mastoid process of Patterson et al. 1989); pr, promontorium of petrosal; pt, pterygoid; ptp, post-tympanic process of squamosal; spf, sphenopalatine foramen; sq, squamosal; tcf, transverse canal foramen; zp, zygomatic process of squamosal.

Figure 9. Posterior palate, pterygoid processes, and choanae of Holmesina floridanus in ventral view. A, UF 121742 (exhibit skull); B, UF 191448. Abbreviations: bot, basioccipital tuber; bs, basisphenoid; $\mathbf{c f} / \mathbf{p f} / \mathbf{b c c}$, confluent carotid foramen, piriform fenestra and basicochlear commissure; epp, entopterygoid process (=hamulus or pterygoid process of other cingulates); fo, foramen ovale; mapf, major palatine foramina; Mf9, ninth upper molariform tooth or alveolus; mipf, minor palatine foramen; mipn, notch for minor 
2326

2327

2328

2329

2330 Figure 10. Stereophotographs of right auditory region of Holmesina floridanus (UF 248500) in

palatine nerve and vessels; mpp?, neomorphic medial pterygoid process; pal, palatine; ppm, pneumatized mass of bone that may pertain to the pterygoid; prs, presphenoid, rcf; rectus capitits fossa. ventral view. Abbreviations: abX, groove for auricular branch of vagus nerve (c.n. X); aptt, anteroventral process of tegmen tympani (= processus crista facialis); as, alisphenoid; bb, bony bridge between tympanohyal and crista interfenestralis; bcc, basicochlear commissure; bo, basioccipital; bs, basisphenoid; cf, carotid foramen; ci, crista interfenestralis; cp, crista parotica; ctpp, caudal tympanic process of petrosal; eam, external auditory meatus; egp, entoglenoid process; eo, exoccipital; er, epitympanic recess; fc, fenestra cochleae; fi, ridge immediately ventral to fossa incudis; $\mathbf{f m}$, foramen magnum; fo, foramen ovale; fs, facial sulcus; gf, glenoid fossa; gvn, groove for vidian nerve; hf, hypoglossal foramen; jf, jugular foramen; occ, occipital condyle; og, groove for occipital artery; pcp, paracondylar process of exoccipital (=paroccipital process of Patterson et al. 1989); pe, petrosal; pf, piriform fenestra; pgf, postglenoid foramen; pgp, postglenoid process; pop, paroccipital process of petrosal (= mastoid process of Patterson et al. 1989); pr, promontorium of petrosal; sq, squamosal; stmf, stylomastoid foramen; th, tympanohyal; ttf, tensor tympani fossa on epitympanic wing of petrosal; zp, zygomatic process of squamosal. Scale bar $=1 \mathrm{~cm}$. Photos by S. Chatzimanolis and T. Gaudin. 
2348 Figure 11. Isolated left petrosal of Holmesina floridanus (UF 248500) in A, B, ventrolateral; C,

2349 D, ventral; E, F, lateral; and G, H, medial views. Abbreviations: aptt, anteroventral

2350 process of tegmen tympani (= processus crista facialis); av, aqueductus vestibuli; bof,

2351 basioccipital facet; $\mathbf{c b}$, circular boss on ventrolateral surface of promontorium; ci, crista

2352 interfenestralis; coc, cochlear canaliculus; $\mathbf{c p}$, crista parotica; crp, crista petrosal; ctpp,

2353 caudal tympanic process of petrosal; er, epitympanic recess; ew, epitympanic wing; fc,

2354 fenestra cochleae; fs, facial sulcus; fsi, foramen singulare; fv, fenestra vestibuli; $\mathbf{g p s ,}$

2355 sulcus for greater petrosal nerve; iam, internal acoustic meatus; ips; fossa/groove for

2356 inferior petrosal sinus; iva, inferior vestibular area; $\mathbf{p f c}$, prefacial commissure; pff,

2357 primary facial foramen; pop, paroccipital process of petrosal (= mastoid process of

2358 Patterson et al. 1989); pr, promontorium of petrosal; rpp, rostral process of petrosal; saf,

2359 subarcuate fossa; set, spiral cribriform tract; sf, stapedius fossa; stmn, stylomastoid

2360 notch; sps, groove for superior petrosal sinus; sva, superior vestibular area; tc, transverse

2361 crest; th, tympanohyal; ts, triangular shelf (=roof of post-promontorial sinus. Scale bar =

$2362 \quad 1 \mathrm{~cm}$.

2363

2364 Figure 12. Isolated right petrosal, left occipital condyle, and basicranium of Holmesina

2365 floridanus, UF 223813. A, petrosal, basicranium and condyle in dorsal view; B, petrosal

2366 in posterior view. Abbreviations: alf, fossa for alar ligament of atlas; av, aqueductus

$2367 \quad$ vestibuli; bs, basisphenoid; coc, cochlear canaliculus; $\mathbf{c s , ~ c a r o t i d ~ s u l c u s ~ f o r ~ i n t e r n a l ~}$

2368 carotid artery; ew, epitympanic wing; fc, fenestra cochleae; hfo, hypophyseal fossa; iam,

2369 internal acoustic meatus; js, jugulum sphenoidale; occ, occipital condyle; opc, internal

2370 openings of optic canals; osc, orbitosphenoid crest; pe, petrosal; pr, promontorium of 
2371

2372

2373

2374

2375 Figure 13. Skull of Holmesina floridanus in posterior view. A, UF 191448; B, Reconstruction.

petrosal; rpp, rostral process of petrosal; tc, opening accommodating veins that connect to transverse canal foramen; ts, tuberculum sellae. Upper scale bar $(\mathrm{A})=2 \mathrm{~cm}$. Lower scale bar $(B)=1 \mathrm{~cm}$.
2376

2377

2378

2379

2380

2381

2382

2383

2384

2385

2386

2387

2388

2389

2390

2391
Abbreviations: bo, basioccipital; def, dorsal condyloid fossa; dgf, digastric fossa; eo, exoccipital; eoc, external occipital crest; eocc, exoccipital crest; fm, foramen magnum; Ici; lateral condyle indentation, i.e., indentation on lateral edge of occipital condyle; nc, nuchal crest; oc, occipital; occ, occipital condyle; og, groove for occipital artery; me, mastoid exposure of petrosal; pcp, paracondylar process of exoccipital (=paroccipital process of Patterson et al. 1989); ptc, posttemporal canal; so, supraoccipital; sq, squamosal. Scale bar $=5 \mathrm{~cm}$.

Figure 14. Left mandible of Holmesina floridanus (UF 224450) in A, lateral; B, occlusal; and, C, medial views. Abbreviations: ap, angular process; cnc, condyloid crest; cop, coronoid process; crc, coronoid crest; hr, horizontal ramus of mandible; imf, intermuscular fossa; Icc, lateral coronoid crest; m1, first lower molariform tooth; m6, sixth lower molariform tooth; m7, seventh lower molariform tooth; maf, masseteric fossa; mco, mandibular condyle; mf, mental foramen; mnf, mandibular foramen; ms, mandibular symphysis. Scale $\mathrm{bar}=5 \mathrm{~cm}$. 


\section{Table 1 (on next page)}

Skull measurements for Holmesina floridanus and related taxa.

All measurements reported in millimeters $(\mathrm{mm})$; those reported to the nearest tenth of a millimeter are direct measurements, those rounded to the nearest integer are taken from literature sources or from photographs taken by TJG. Numbers in square brackets are scaled to Greatest Skull Length (GSL) 
Table 1. Skull measurements for Holmesina floridanus and related taxa. All measurements reported in millimeters (mm); those

reported to the nearest tenth of a millimeter are direct measurements, those rounded to the nearest integer are taken from literature

sources or from photographs taken by TJG. Numbers in square brackets are scaled to Greatest Skull Length (GSL).

\begin{tabular}{|c|c|c|c|c|c|c|c|}
\hline $\begin{array}{l}\text { Measurement } \\
\text { Description }\end{array}$ & $\begin{array}{l}\text { Holmesina } \\
\text { floridanus } \\
\text { UF } 248500\end{array}$ & $\begin{array}{l}\text { Holmesina } \\
\text { floridanus } \\
\text { UF } 191448\end{array}$ & $\begin{array}{l}\text { Holmesina } \\
\text { septentrio- } \\
\text { nalis } \\
\text { UF } 234224 \\
\end{array}$ & $\begin{array}{l}\text { Vassalia } \\
\text { maxima } \\
\text { FMNH P14424 }\end{array}$ & $\begin{array}{l}\text { Propalaeo- } \\
\text { hoplophorus } \\
\text { australis } \\
\text { YPMPU } 15007 \\
\end{array}$ & $\begin{array}{l}\text { Proeutatus } \\
\text { oenophorus } \\
\text { FMNH P13197 }\end{array}$ & $\begin{array}{l}\text { Euphractus } \\
\text { sexcinctus } \\
\text { UTCM } 1491\end{array}$ \\
\hline Maximum nasal ln & $89.9[0.39]$ & $107.9[0.43]$ & $134.0[0.46]$ & $117.0[0.47]$ & $45^{c}[0.28]$ & $47.9[0.41]$ & $42.6[0.36]$ \\
\hline Nasal wd at midpoint & 35.6 & 34.9 & 38 & 41 & $23^{c}$ & 10.6 & 15.4 \\
\hline $\begin{array}{l}\text { Premaxilla/nasal suture } \\
\ln \end{array}$ & $19.2[0.08]$ & $21.1[0.08]$ & - & - & $6.2^{c}[0.04]$ & $13.1[0.11]$ & $17.6[0.15]$ \\
\hline $\begin{array}{c}\text { Mesiodistal } \ln / \max \text { wd } \\
\text { of upper molariforms: } \\
\text { M1 }\end{array}$ & $7.0 / 5.5$ & - & $10 / 6$ & $6.8 / 4.5^{b}$ & $\mathrm{n}$ & $2.9 / 1.8$ & $4.4 / 2.3$ \\
\hline M4 & $10.7 / 7.1$ & $10.3 / 6.8$ & $16 / 8$ & $14.5 / 6.6^{b}$ & $9 / 4^{d}$ & $5.5 / 3.4$ & $5.4 / 3.4$ \\
\hline M5 & $15.9 / 8.3$ & $16.7 / 8.6$ & $18 / 10$ & $18.5 / 8.0^{b}$ & $11 / 4.5^{d}$ & $5.3 / 4.7$ & $5.7 / 3.9$ \\
\hline M6 & $16.8 / 8.7$ & - & $22 / 10$ & $19.0 / 8.6^{b}$ & $12 / 6^{d}$ & $5.2 / 5.0$ & $6.0 / 4.5$ \\
\hline M7 & $15.3 / 8.1$ & $15.0 / 7.8$ & $23 / 11$ & $17.5 / 8.5^{b}$ & $12.5 / 7^{d}$ & $4.9 / 4.6$ & $5.6 / 4.5$ \\
\hline M8 & $13.3 / 7.7$ & - & $21 / 9^{a}$ & $16.7 / 7.5^{b}$ & $12.5 / 7^{d}$ & $4.3 / 4.7$ & $5.3 / 4.0$ \\
\hline M9 & $9.8 / 5.8$ & - & $20 / 8^{a}$ & $13.7 / 7.0^{b}$ & $10.5 / 7^{d}$ & $3.2 / 3.6$ & $4.8 / 2.9$ \\
\hline Mean ratio of upper & 1.61 & - & 1.99 & 1.92 & 1.75 & 1.28 & 1.56 \\
\hline
\end{tabular}


molariform $\ln / \mathrm{wd}$

Palatal ln (in midline)

Min interpterygoid wd

Max zygomatic wd

Min interorbital wd

Min postorbital wd

Max wd of glenoid

fossa in ventral view

(measured along

glenoid's long axis)

Max anteroposterior ln

of glenoid in ventral

view

Ratio of glenoid wd to ln

Postglenoid skull ln

Max wd of occipital

condyles in ventral view

(measured along

condyle's long axis)

Max anteroposterior ln

of condyles in ventral

view

Ratio of occipital condyle

wd to $\ln$

$\begin{array}{ccccccc}143.6[0.63] & 163.0[0.65] & - & 146[0.59] & 104^{\mathrm{d}}[0.65] & 64.0[0.54] & 68.0[0.57] \\ 16.7[0.07] & 17.8[0.07] & - & 12[0.05] & 14[0.09] & 8.1[0.07] & 8.1[0.07] \\ 121.1[0.53] & 122.9[0.49] & - & 138^{\mathrm{b}}[0.56] & 118[0.74] & 70.2[0.60] & 65.6[0.55] \\ 65.6[0.29] & 76.2[0.31] & 89[0.30] & 79^{\mathrm{b}}[0.32] & 54[0.34] & 42.5[0.36] & 38.5[0.32] \\ 38.7[0.17] & 44.3[0.18] & 56[0.19] & 52^{\mathrm{b}}[0.21] & 28[0.09] & 27.6[0.23] & 27.5[0.23]\end{array}$
23.4
23.3
32
$31^{\mathrm{e}}$
8.4
9.8

$\begin{array}{ccccccc}14.9 & 11.1 & 17 & 12 & 11^{\mathrm{e}} & 8.0 & 9.8 \\ 1.57 & 2.10 & - & 2.7 & 2.82 & 1.05 & 1.00 \\ 43.5[0.19] & 35.8[0.14] & 47[0.16] & 57[0.23] & 14[0.09] & 17.1[0.15] & 20.5[0.17]\end{array}$

Wd of occiput

(measured at base of supraoccipital)

Max dp of occiput in midline (including ventral edge of foramen magnum)

Ratio of wd to dp

$\begin{array}{lllllll}21.7 & 24 & 24 & 25 & 61 & 11.4 & 9.6\end{array}$

21.7

13.

13.0

14.2

16

15

1.5

1.67

$97^{b}$

67

1.44

1.04

83

$\begin{array}{ll} & 53 \\ & \\ 44 & 1.19\end{array}$

1.19

9.5

1.2

52.1

45.6

72.5

1.04

(1.04

1.44


6 Abbreviations: “ $-“=$ data unavailable; $\mathrm{dp}=$ dorsoventral depth; $\ln =$ anteroposterior length, Max = maximum; Min = minimum; $\mathrm{n}=$ 7 data not applicable; $w d=$ transverse width.

8 *Estimated due to skull breakage; ${ }^{a}$ Data from UF 889, multiplied by 0.96 to account for size difference between UF 889 and UF 9 234224; ${ }^{\mathrm{b}}$ Data from De Iuliis and Edmund (2002); ${ }^{\mathrm{c}}$ Data from YPMPU 15291; ${ }^{\mathrm{d}}$ Data from Scott (1903-4), who measured YPMPU 10 15212; ${ }^{\mathrm{e}}$ Data from FMNH P13205. 


\section{Table 2 (on next page)}

Skull measurements for additional specimens of Holmesina floridanus.

All measurements reported in millimeters $(\mathrm{mm})$. Numbers in square brackets are scaled to Greatest Skull Length (GSL). 
2 Numbers in square brackets are scaled to Greatest Skull Length (GSL).

\begin{tabular}{|c|c|c|c|c|c|c|}
\hline $\begin{array}{c}\text { Measurement } \\
\text { Description }\end{array}$ & $\begin{array}{c}\text { Holmesina } \\
\text { floridanus } \\
\text { UF } 223813\end{array}$ & UF 275496 & UF 275497 & UF 275498 & UF 285000 & UF 293000 \\
\hline $\begin{array}{l}\text { Greatest Skull Length } \\
\text { (GSL) }\end{array}$ & $256 *$ & 237.8 & - & $223^{*}$ & 239.5 & - \\
\hline Maximum nasal ln & $81[0.32]$ & $85.4[0.36]$ & 69.7 & $70.0[0.34]$ & $85.1[0.36]$ & 88.0 \\
\hline Nasal wd at midpoint & 34.4 & 35.0 & 33.8 & 34.2 & 37.8 & 35.0 \\
\hline Ratio nasal width to length & 0.42 & 0.41 & 0.48 & 0.49 & 0.44 & 0.40 \\
\hline $\begin{array}{l}\text { Rostrum } \ln \text { (measured } \\
\text { from anterior orbital } \\
\text { rim) }\end{array}$ & $122[0.48]$ & $111[0.47]$ & 106 & $103[0.46]$ & $113[0.47]$ & 104 \\
\hline $\begin{array}{l}\text { Premaxilla/nasal suture } \\
\ln \end{array}$ & - & $18.0[0.08]$ & 19.8 & $22.3[0.10]$ & $17.9[0.07]$ & 17.4 \\
\hline $\begin{array}{c}\text { Mesiodistal } \ln / \max \mathrm{wd} \\
\text { of upper molariforms: } \\
\text { M1 }\end{array}$ & $7.1 / 5.4$ & $6.0 / 5.7$ & - & $6.8 / 5.5$ & $5.9 / 5.8$ & $6.9 / 4.3$ \\
\hline M2 & $8.2 / 5.8$ & - & - & $7.9 / 5.6$ & $7.9 / 6.1$ & $8.0 / 4.8$ \\
\hline M3 & $9.5 / 6.1$ & $9.7 / 6.1$ & - & $10.4 / 6.3$ & $9.8 / 6.1$ & $10.2 / 5.4$ \\
\hline M4 & $11.7 / 7.0$ & $11.3 / 7.2$ & - & $11.5 / 7.1$ & $12.3 / 6.7$ & $11.7 / 6.0$ \\
\hline M5 & $16.0 / 9.1$ & $15.6 / 8.7$ & $13 *$ & $16.6 / 8.8$ & $15.1 / 8.4$ & $16.6 / 8.0$ \\
\hline M6 & $16.8 / 8.5$ & $16.9 / 8.9$ & $15.7 / 7.6$ & $18.7 / 9.0$ & $17.2 / 8.3$ & $17.9 / 7.9$ \\
\hline M7 & $15.4 / 8.0$ & $15.5 / 8.4$ & $14.9 / 7.0$ & - & $16.6 / 8.2$ & $16.1 / 7.0$ \\
\hline M8 & $13.5 / 7.5$ & $13.7 / 7.9$ & - & - & $14.1 / 8.0$ & $15.7 / 6.6$ \\
\hline M9 & $10.3 / 6.0$ & $8.6 / 6.1$ & $9.3 / 6.0$ & - & - & $10.2 / 5.8$ \\
\hline $\begin{array}{l}\text { Mean ratio of upper } \\
\text { molariform } \ln / \text { wd }\end{array}$ & 1.68 & - & & - & - & 1.99 \\
\hline Palatal ln (in midline) & $156 *[0.61]$ & $145 *[0.61]$ & - & - & $149[0.62]$ & 155 \\
\hline Min interpterygoid wd & - & - & - & - & - & - \\
\hline
\end{tabular}




\begin{tabular}{|c|c|c|c|c|c|c|}
\hline Max zygomatic wd & - & - & - & - & - & - \\
\hline Min interorbital wd & - & $57[0.24]$ & - & $60[0.27]$ & - & 55 \\
\hline Min postorbital wd & - & - & - & 42 [0.19] & - & - \\
\hline $\begin{array}{l}\text { Max wd of glenoid } \\
\text { fossa in ventral view } \\
\text { (measured along } \\
\text { glenoid's long axis) }\end{array}$ & - & - & - & - & - & 29 \\
\hline $\begin{array}{l}\text { Max anteroposterior ln } \\
\text { of glenoid in ventral } \\
\text { view }\end{array}$ & $12.6[0.05]$ & - & 13.6 & $14.5[0.07]$ & $14.3[0.06]$ & 12.7 \\
\hline Ratio of glenoid wd to ln & - & - & - & - & - & 2.28 \\
\hline Postglenoid skull ln & $46^{*}[0.18]$ & $44[0.19]$ & - & $42[0.19]$ & $40[0.17]$ & - \\
\hline $\begin{array}{l}\text { Max wd of occipital } \\
\text { condyles in ventral view } \\
\text { (measured along } \\
\text { condyle's long axis) }\end{array}$ & 22.2 & 22.7 & 20.8 & 21.3 & - & 24.2 \\
\hline $\begin{array}{l}\text { Max anteroposterior ln } \\
\text { of condyles in ventral } \\
\text { view }\end{array}$ & 13.5 & 13.3 & 12.7 & 14.0 & - & 14.0 \\
\hline $\begin{array}{l}\text { Ratio of occipital condyle } \\
\text { wd to } \ln \end{array}$ & 1.64 & 1.71 & 1.64 & 1.52 & - & 1.73 \\
\hline $\begin{array}{l}\text { Wd of occiput } \\
\text { (measured at base of } \\
\text { supraoccipital) }\end{array}$ & 69.8 & 73.7 & - & 66.7 & 70.6 & 68 \\
\hline $\begin{array}{l}\text { Max dp of occiput in } \\
\text { midline (including } \\
\text { ventral edge of foramen } \\
\text { magnum) }\end{array}$ & - & $77^{*}$ & - & 64.0 & - & 64.7 \\
\hline Ratio of wd to $\mathrm{dp}$ & - & 0.96 & - & 1.04 & - & 1.05 \\
\hline
\end{tabular}

Abbreviations: " - " = data unavailable; $\mathrm{dp}=$ dorsoventral depth; $\ln =$ anteroposterior length, Max = maximum; Min = minimum; wd $=$ transverse width.

*Estimated due to skull breakage. 


\section{Table 3(on next page)}

Mandibular measurements for Holmesina floridanus and related taxa.

All measurements reported in millimeters $(\mathrm{mm})$; those reported to the nearest tenth of a millimeter are direct measurements, those rounded to the nearest millimeter are taken from literature sources or from photographs taken by TJG. Numbers in square brackets are scaled to Maximum Mandibular Length (MML). 
Table 3. Mandibular measurements for Holmesina floridanus and related taxa. All measurements reported in millimeters (mm); those

reported to the nearest tenth of a millimeter are direct measurements, those rounded to the nearest millimeter are taken from literature

\begin{tabular}{|c|c|c|c|c|c|c|}
\hline $\begin{array}{l}\text { Measurement } \\
\text { Description }\end{array}$ & $\begin{array}{l}\text { Holmesina } \\
\text { floridanus } \\
\text { UF } 224450\end{array}$ & $\begin{array}{l}\text { Holmesina } \\
\text { occidentalis } \\
\text { ROM } 4955\end{array}$ & $\begin{array}{l}\text { Vassalia } \\
\text { maxima } \\
\text { FMNH P14424a }\end{array}$ & $\begin{array}{l}\text { Propalaeo- } \\
\text { hoplophorus } \\
\text { australis } \\
\text { MLP } 16-15^{\mathrm{b}}\end{array}$ & $\begin{array}{l}\text { Proeutatus } \\
\text { oenophorus } \\
\text { FMNH P13197 }\end{array}$ & $\begin{array}{l}\text { Euphractus } \\
\text { sexcinctus } \\
\text { UTCM } 1491\end{array}$ \\
\hline $\begin{array}{l}\text { Maximum } \\
\text { Mandibular Length } \\
\text { (MML) }\end{array}$ & 200.5 & $268 *$ & $180 *$ & 139 & 98.3 & 93.0 \\
\hline $\begin{array}{l}\text { Max dp of horizontal } \\
\text { ramus }\end{array}$ & $40.0[0.20]$ & 52 [0.19] & $47.5^{\mathrm{a}}[0.26]$ & $37[0.27]$ & $16.1[0.16]$ & $13.5[0.15]$ \\
\hline $\begin{array}{l}\text { Max dp of ascending } \\
\text { ramus }\end{array}$ & $120.5[0.60]$ & $155[0.58]$ & $132.0^{\mathrm{a}}[0.73]$ & $98[0.71]$ & $53.8[0.55]$ & $49.5[0.53]$ \\
\hline Condyle, max wd & 23.4 & - & $31.2^{\mathrm{a}}$ & - & 9.0 & 9.9 \\
\hline Condyle, max ln & 7.0 & - & $11.0^{\mathrm{a}}$ & - & 4.7 & 5.9 \\
\hline Ratio of condyle wd to $\ln$ & 3.34 & - & 2.84 & - & 1.91 & 1.68 \\
\hline $\begin{array}{l}\text { Height of condyle } \\
\text { above toothrow }\end{array}$ & $39.3[0.20]$ & $84[0.31]$ & $60[0.33]$ & $59[0.42]$ & $37.3[0.38]$ & $41.7[0.45]$ \\
\hline Symphysis ln & $59.0[0.29]$ & $79 *[0.29]$ & $54.0^{\mathrm{a}}[0.30]$ & $41[0.29]$ & $23.5[0.24]$ & $25.7[0.28]$ \\
\hline $\begin{array}{l}\text { Coronoid process, } \\
\text { anteroposterior ln at } \\
\text { base }\end{array}$ & 31.0 & 40 & 33 & 31 & 12.4 & 9.8 \\
\hline $\begin{array}{l}\text { Coronoid process, } \\
\text { maximum dp }\end{array}$ & 42.0 & - & 50 & 31 & 16.2 & 15.5 \\
\hline $\begin{array}{l}\text { Ratio of coronoid process dp } \\
\text { to } \ln \end{array}$ & 1.35 & - & 1.52 & 1.0 & 1.31 & 1.58 \\
\hline $\begin{array}{l}\text { Mesiodistal } \ln / \max \text { wd } \\
\text { of lower molariforms in } \\
\text { Holmesina floridanus }\end{array}$ & $\begin{array}{l}\mathrm{m} 1: 5.8 / 5.1^{* *} \\
\mathrm{~m} 8: 16.7 / 8.5^{* *}\end{array}$ & $\begin{array}{l}2: 7.5 / 5.6 \mathrm{~m} 3: 1 \\
\mathrm{~m} 9: 12.3 / 7.6^{* *}\end{array}$ & $\begin{array}{l}7 / 7.1^{* *} \mathrm{~m} 4: 14.9 \\
\text { ean ratio of lower }\end{array}$ & $\begin{array}{l}7.7^{* *} \mathrm{~m} 5: 17 \\
\text { molariform } \ln /\end{array}$ & $\begin{array}{l}9.3^{* *} \mathrm{~m} 6: 16.9 / \\
1.72]\end{array}$ & $m 7: 16.2 / 8.0$ \\
\hline
\end{tabular}


UF 224450

6 Abbreviations: “ - “ = data unavailable; $\mathrm{dp}=$ dorsoventral depth; $\mathrm{ln}=$ anteroposterior length, Max = maximum; Min = minimum; $\mathrm{n}=$ 7 data not applicable; $w d=$ transverse width.

8 *Estimated due to breakage; **Estimated from alveolus diameter.

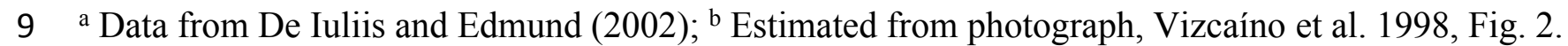




\section{Table 4(on next page)}

Mandibular measurements for additional specimens of Holmesina floridanus.

All measurements reported in millimeters $(\mathrm{mm})$. Numbers in square brackets are scaled to Maximum Mandibular Length (MML). 
Table 4. Mandibular measurements for additional specimens of Holmesina floridanus. All measurements reported in millimeters

2 (mm). Numbers in square brackets are scaled to Maximum Mandibular Length (MML).

\begin{tabular}{|c|c|c|c|c|c|}
\hline $\begin{array}{l}\text { Measurement } \\
\text { Description }\end{array}$ & $\begin{array}{l}\text { Holmesina } \\
\text { floridanus } \\
\text { UF } 223813\end{array}$ & UF 275497 & UF 275498 & UF 285000 & UF 293000 \\
\hline $\begin{array}{l}\text { Maximum } \\
\text { Mandibular Length } \\
\text { (MML) }\end{array}$ & 182.2 & $187^{*}$ & $191 *$ & - & $185^{*}$ \\
\hline $\begin{array}{l}\text { Max dp of horizontal } \\
\text { ramus }\end{array}$ & $38 *[0.21]$ & $41.0[0.22]$ & $40.4[0.21]$ & 44 & $39.3[0.21]$ \\
\hline $\begin{array}{l}\text { Max dp of ascending } \\
\text { ramus }\end{array}$ & $106.5[0.58]$ & $120.3[0.64]$ & - & - & $113 *[0.61]$ \\
\hline Condyle, max wd & 24.0 & 21.4 & 18.3 & 23.0 & 23.8 \\
\hline Condyle, max $\ln$ & 7.4 & 9.5 & 7.5 & 10.0 & 9.1 \\
\hline Ratio of condyle wd to $\ln$ & 3.24 & 2.25 & 2.44 & 2.30 & 2.62 \\
\hline $\begin{array}{l}\text { Height of condyle } \\
\text { above toothrow }\end{array}$ & $45.6[0.25]$ & $43.0[0.23]$ & - & 30.0 & $37.0[0.20]$ \\
\hline Symphysis $\ln$ & $54.3[0.30]$ & - & $50.3[0.26]$ & - & $58.4[0.32]$ \\
\hline $\begin{array}{l}\text { Coronoid process, } \\
\text { anteroposterior ln at } \\
\text { base }\end{array}$ & 31.2 & 33.3 & - & - & 31.7 \\
\hline $\begin{array}{l}\text { Coronoid process, } \\
\text { maximum dp }\end{array}$ & 26.6 & 47.7 & - & - & 36.0 \\
\hline $\begin{array}{l}\text { Ratio of coronoid process } \mathrm{dp} \\
\text { to } \ln \end{array}$ & 0.85 & 1.43 & - & - & 1.14 \\
\hline $\begin{array}{l}\text { Mesiodistal } \mathrm{ln} / \max \mathrm{wd} \\
\text { of lower molariforms in } \\
\text { Holmesina floridanus } \\
\text { UF } 223813\end{array}$ & \multicolumn{5}{|c|}{$\begin{array}{l}\mathrm{m} 1: 5.0 / 4.8 \mathrm{~m} 2: 7.2 / 5.7 \mathrm{~m} 3: 8.2 / 6.0 \mathrm{~m} 4: 11.5 / 6.8 \mathrm{~m} 5: 16.0 / 8.6 \mathrm{~m} 6: 17.0 / 8.4 \mathrm{m7}: 15.2 / \\
\text { 8.0 m8: } 13.6 / 7.0 \mathrm{~m} 9: 10.7 / 5.9 \text { [Mean ratio of lower molariform } \ln / \mathrm{wd}: 1.65 \text { ] }\end{array}$} \\
\hline
\end{tabular}


5 Abbreviations: “ - " = data unavailable; $\mathrm{dp}=$ dorsoventral depth; ln = anteroposterior length, Max = maximum; Min = minimum; wd $6=$ transverse width.

7 *Estimated due to breakage.

8 


\section{Table 5 (on next page)}

Listing of cranial features with potential systematic value (i.e., diagnostic features or putative synapomorphies) identified in the description from the present study. 
Table 5. Listing of cranial features with potential systematic value (i.e., diagnostic features or putative synapomorphies) identified in

the description from the present study.

Holmesina floridanus: 1) ovate shape of M3; 2) absence of vomer/premaxilla contact within nasal cavity; 3) lacrimal foramen situated on the antorbital ridge; 4) medial pterygoid exposure that fails to reach nasopharyngeal roof; 5) inflated pterygoid; 6) presence of a bony bridge connecting the tympanohyal and crista interfenestralis; 7) presence of a raised circular boss on the lateral surface of the promontorium; 8) elongate, narrow basioccipital; presence of well-developed rectus capitis fossae and pharyngeal tubercle on basioccipital; 9) distinct grooves emerging anteriorly from mental foramina; and 10) mandibular spout with anteroposterior $\ln >\mathrm{m} 1$; 11) rectangular shape of $\mathrm{m} 4$.

Genus Holmesina: 1) nasals become narrower posteriorly; 2) maxillary/premaxillary suture M-shaped in ventral view; 3) maxillary/palatine suture U-shaped in ventral view; 4) presence of prominent lateral maxillary ridge and deep antorbital fossa; 5) reniform M4 and bilobate m5; 6) lack of orbital exposure of palatine; 7) ethmoid foramen entirely within frontal, lacking orbitosphenoid participation in rim; 8) no orbitosphenoid participation in rim of sphenopalatine foramen; 9) fenestra cochleae very low and wide, ratio of $\mathrm{wd} / \mathrm{dp}>3$; 10) triangular stylohyal fossa with distally expanded tympanohyal; 11) strong medial flange of petrosal marked by pits and ridges; 12) low stapedial ratio $(<1.4)$; and 13) ventrally displaced internal acoustic meatus.

Pampatheres: 1) nasal $\ln >45 \%$ of GSL; 2) presence of median anteroventral processes on premaxilla; 3 ) incisive foramina open ventrally into single, deeply recessed, midline fossa; 4) infraorbital canal elongate, extending from level of M6-M8; 5) reniform anterior molariforms and bilobate posterior molariforms; 6) posterior molariforms with linear, unbranched core of 
osteodentine; 7) partially closed (anteriorly) upper toothrows; 8) teeth wear in stairstep fashion in lateral view; 9) triangular facial process of lacrimal; 10) triangular glenoid fossa (apex lateral); 11) no horizontal portion of jugal/squamosal suture; 12) ridged, anteroposteriorly expanded ventral zygomatic process formed by maxilla and anterior jugal [mostly the latter]; 13) zygomatic process of squamosal increases in dp anteriorly; 14) reduced midline crest on endocranial exposure of orbitosphenoid; 15) ventral flange of basisphenoid forms portion of the lateral wall of the nasopharynx; 16) Elongate groove on petrosal for greater petrosal nerve; 17) broad crista interfenestralis of petrosal; 18) enormously enlarged paroccipital process of petrosal; 19) caudal tympanic process of petrosal forms posterior wall to stapedial fossa; 20) large epitympanic wing of petrosal (as in Euphractus), forms shelf above rostral process of promontorium; 21) Groove for auricular branch of vagus nerve between caudal tympanic process and triangular shelf [= roof of postpromontorial sinus]; 22) Sharp, narrow transverse crest within internal acoustic meatus; 23) low rounded ridges subdivide subarcuate fossa; 24) prefacial commissure enlarged, bulbous; 25) crista petrosa rounded, divided by groove into medial and lateral parts; 26) paracondylar process of exoccpital hooked medially; 27) ventral surface of exoccipital convex transversely; 28) mandibular condyle less elevated above toothrow than glyptodonts, Proeutatus, Euphractus; and 29) coronoid process covers m9 and part of m8 in lateral view.

Pampatheres plus glyptodonts: 1) presence of semicircular notch in anterolateral edge of premaxilla; 2) dp of external nares $\geq$ wd; 3) teeth with essentially linear core of osteodentine; 4) anterior molariforms slanted lingually in posterior view, posterior molariforms slanted labially; 5) narrow, U-shaped postpalatal margin (also in Gaudin and Wible 2006); 6) pterygoid processes form thickened, rugose bosses (also in Gaudin and Wible 2006); 7) pterygoid participation in hard palate; 8) lacrimal formaen positioned on facial process of lacrimal; 9) lacrimal foramen situated within distinct fossa; 10) presence of an enlarge ventral zygomatic process near anterior terminus of zygomatic arch; 11) sphenopalatine foramen in common fossa with sphenorbital fissure (also in Gaudin and Wible 2006); 12) raised ridge along squamosal/parietal suture; 13) posterior zygomatic root directed laterally (also in Gaudin and Wible 2006); 14) postglenoid foramen visible in ventral view (also in Gaudin and Wible 
2006); 15) broad triangular shelf [= roof of postpromontorial sinus]; 16 \& 17) enlarged paroccipital process of petrosal and paracondylar process of exoccipital; 18) well-developed external occipital crest; 19) anterior portion of occipital condyle extends lateral to dorsal portion in ventral view; 20) nine lower molariforms present; 21) ratio between maximum depth of mandibular horizontal ramus vs. MML > 0.2 (also in Gaudin and Wible 2006); and 22) maximum wd of mandibular condyle $\geq$ $3 x$ its $\ln$ (also in Gaudin and Wible 2006).

Pampatheres plus glyptodonts plus Proeutatus: 1) nasal $\ln >35 \%$ of GSL (also in Gaudin and Wible 2006); 2) presence of osteodentine core in molariforms (also in Gaudin and Wible 2006); 3) beveled wear on anterior molariforms, posterior molariforms worn flat (also in Gaudin and Wible 2006); 4) lateral portion of frontal/parietal suture even with anterior edge of the glenoid; 5) optic foramen hidden in lateral view (also in Gaudin and Wible 2006); 6) dorsal edge of zygomatic process of squamosal connected to nuchal crest posteriorly; 7) middle of infratemporal crest marked by large boss, the ossified ala hypochiasmata; 8) open groove for vidian nerve in roof of nasopharynx; 9) large entoglenoid process of squamosal; 10) groove for greater petrosal nerve uncovered by anteroventral process of tegmen tympani [=processus crista facialis]; 11) anteroventral process of tegmen tympani reduced in size, only contacts squamosal; 12) tensor tympanic muscle originates on anteroventral promontorium; 13) caudal tympanic process of petrosal lacks contact for ectotympanic; 13) Rostral process of petrosal enlarged, promontorium elongated anteromedially; 14) presence of epitympanic recess [as opposed to a sinus]; and 15) triangular shelf of petrosal with raised posterolateral corner

Abbreviations: GSL = greatest skull length; $\mathrm{dp}=$ dorsoventral depth; $1 \mathrm{l}=$ anteroposterior length; M1 ...9= upper molariform teeth; $\mathrm{MML}=$ maximum mandibular length; $\mathrm{wd}=$ transverse width. 


\section{Figure 1}

Photographs of skulls of Holmesina floridanus

Skull of UF 248500: A, ventral view; B, dorsal view; C, right lateral view. Skull of UF 191448:

D. ventral view; $E$, dorsal view, $F$, right lateral view. Scale bars $=5 \mathrm{~cm}$.

A

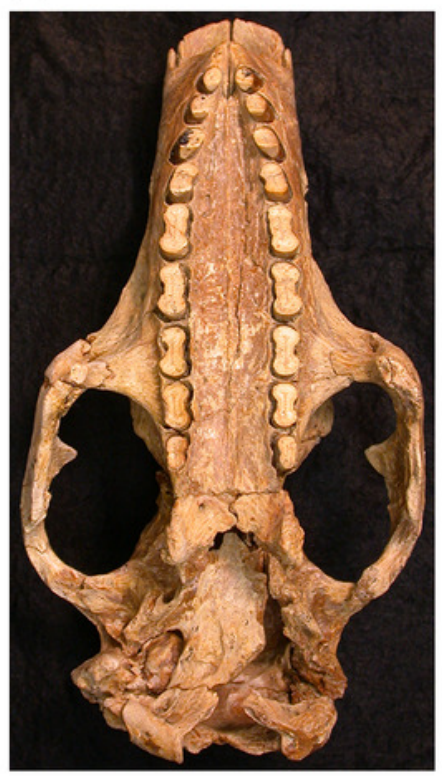

C
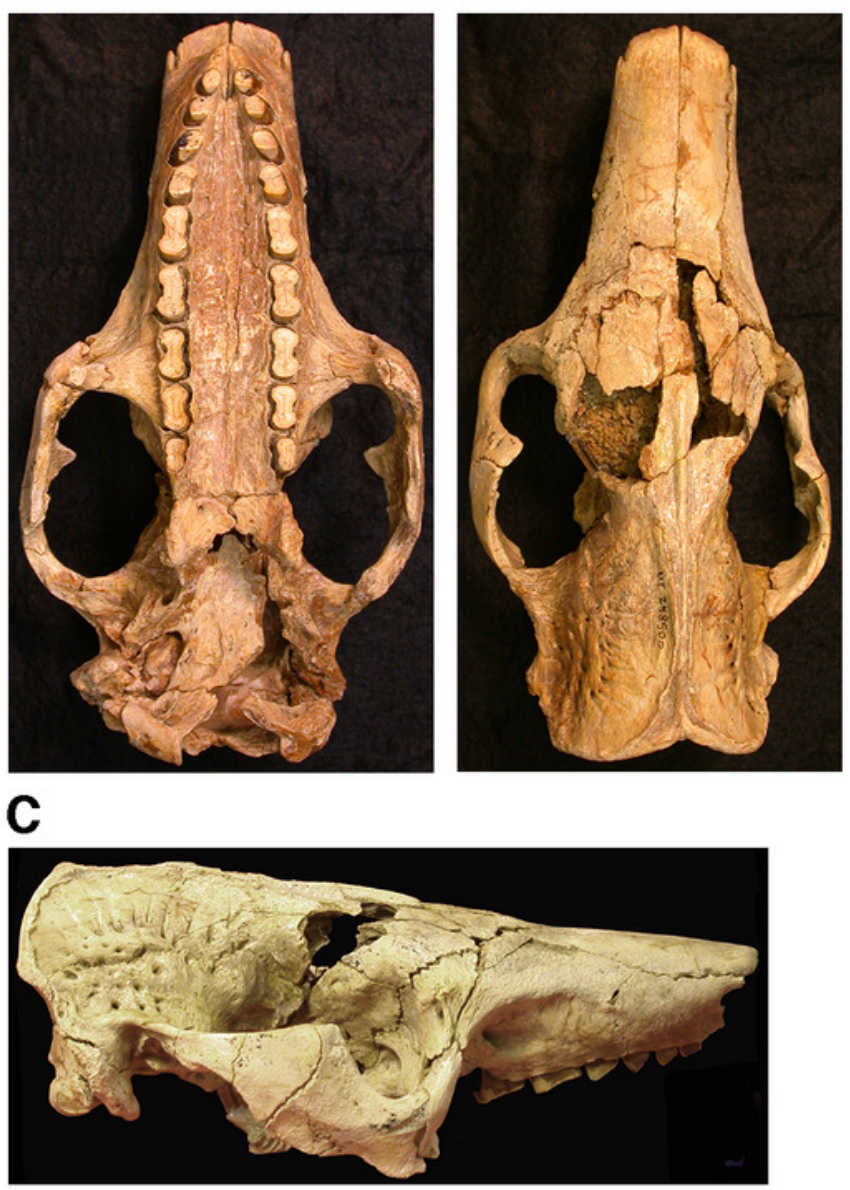

D

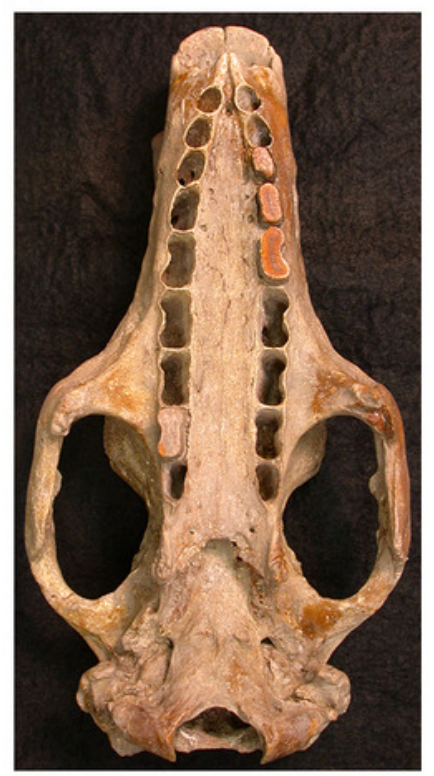

$\mathbf{F}$

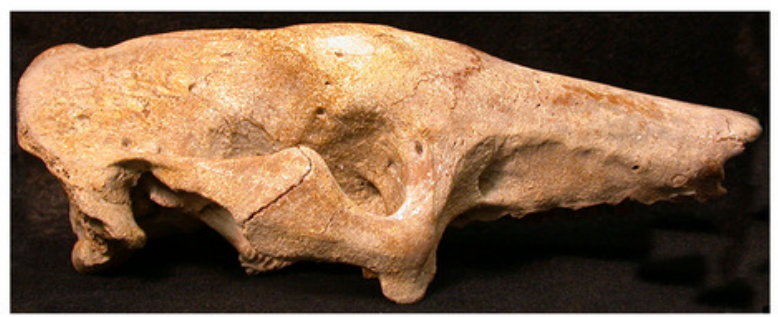

E

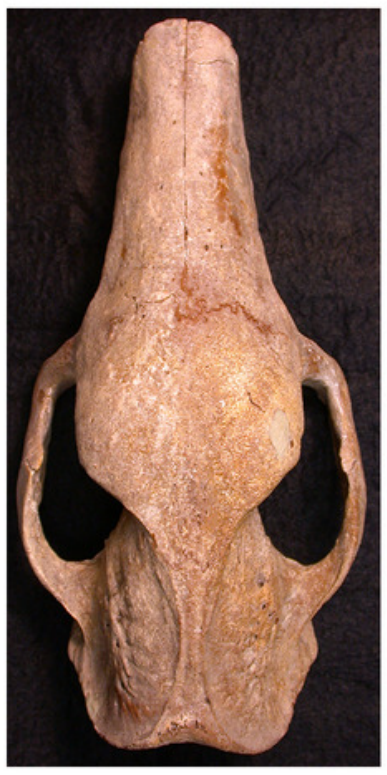

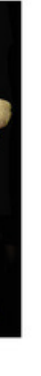

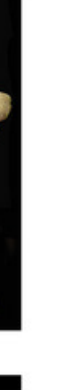


Figure 2

Skull of Holmesina floridanus in dorsal view

A, UF 191448; B, UF 248500. Scale bar $=5 \mathrm{~cm}$.
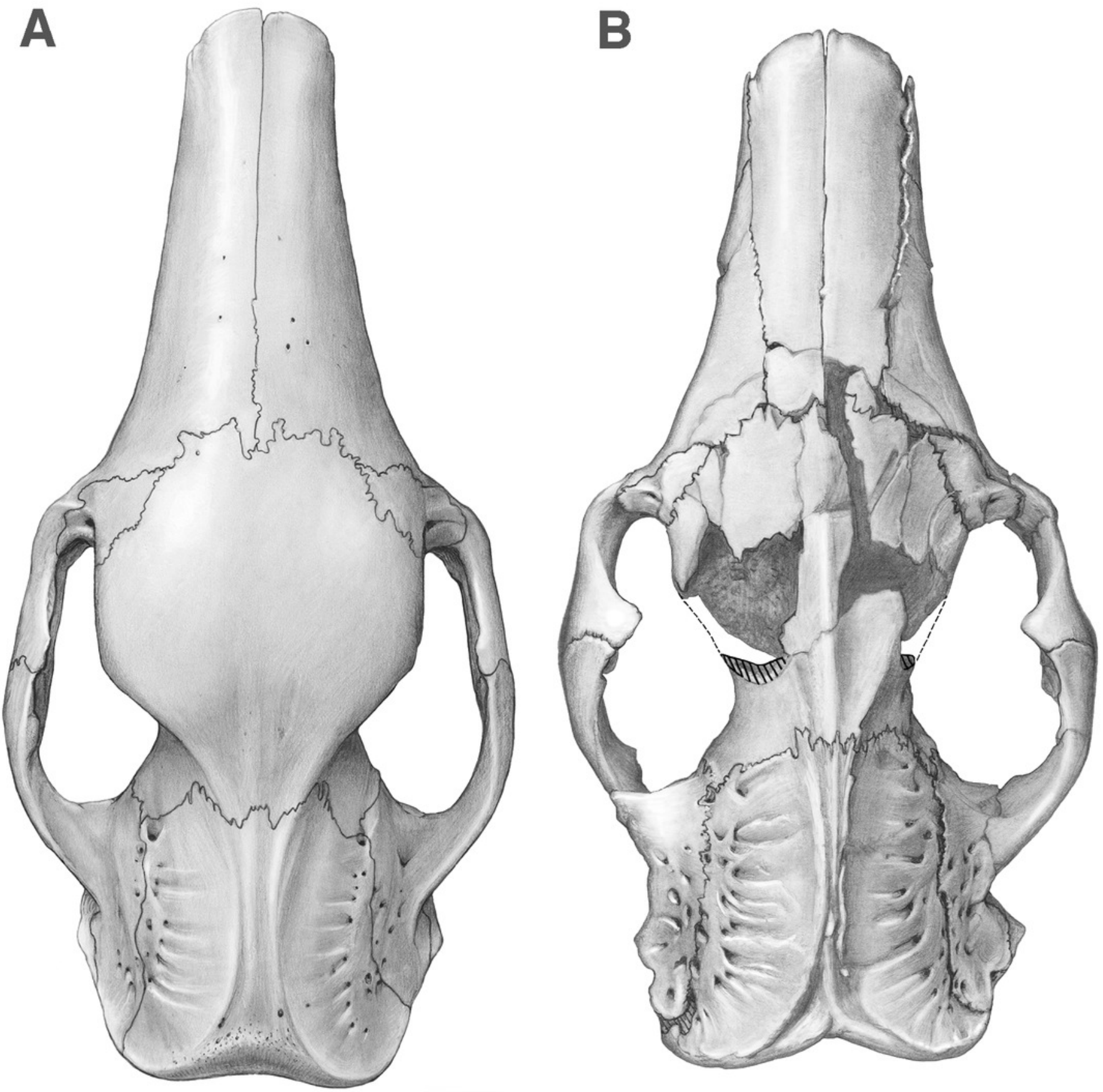


\section{Figure 3}

Reconstruction of the skull of Holmesina floridanus in dorsal view

Abbreviations: f, frontal; frt, foramina for rami temporalis; j, jugal; I, lacrimal; If, lacrimal

foramen; $\mathbf{m x}$, maxilla; $\mathbf{n}$, nasal; nc, nuchal crest; $\mathbf{p}$, parietal; pm, premaxilla; pop, paroccipital process of petrosal (= mastoid process of Patterson et al. 1989); popf, postorbital process of frontal; popj, postorbital process of jugal; sq, squamosal; tl, temporal lines; zp, zygomatic process of squamosal. 


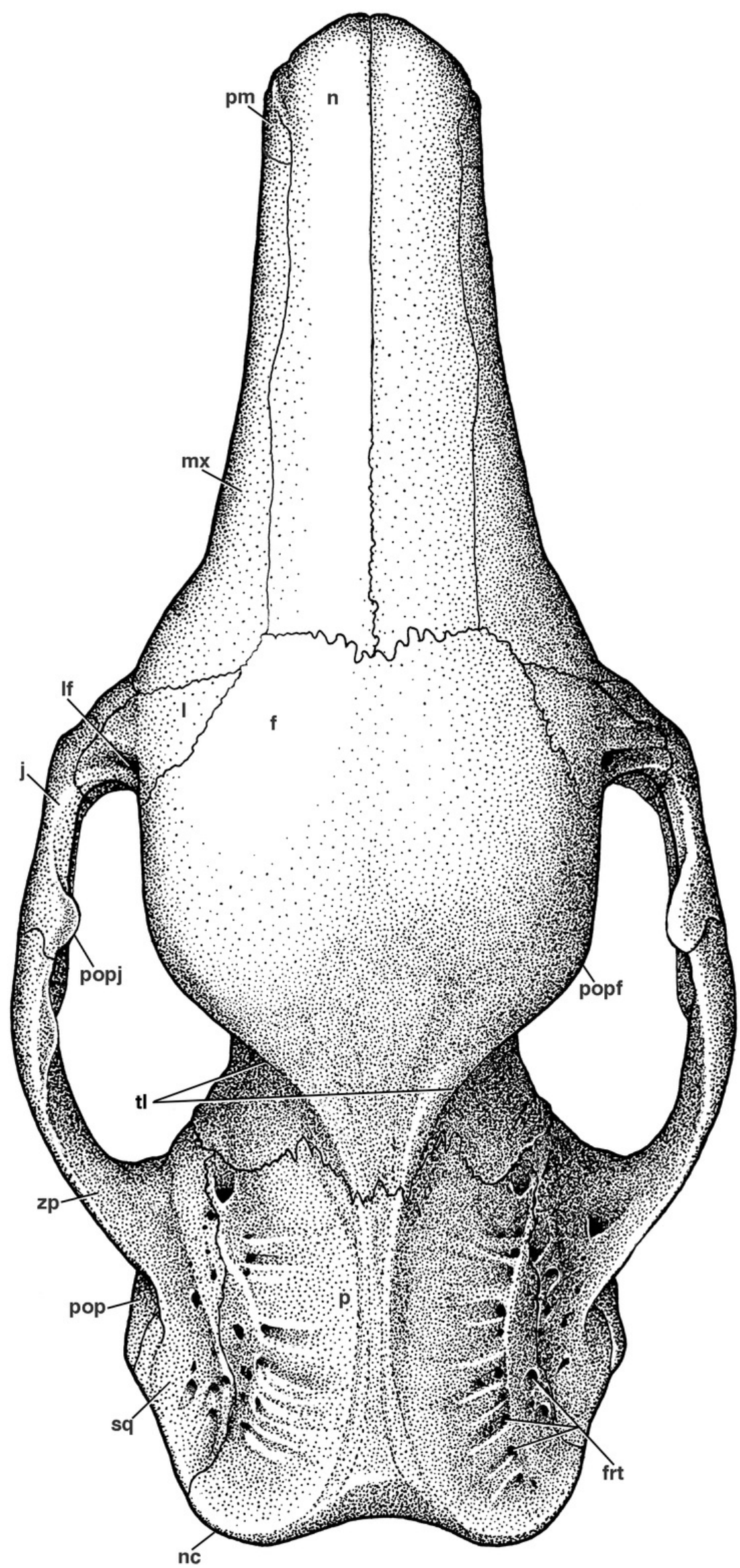

PeerJ reviewing PDF | (2017:08:19901:1:0:CHECK 20 Oct 2017) 
Figure 4

Skull of Holmesina floridanus in lateral view

A, UF 191448 in right lateral view; B, UF 248500 in right lateral view; C, UF 248500 in left lateral view. Scale bar $=5 \mathrm{~cm}$. 
A

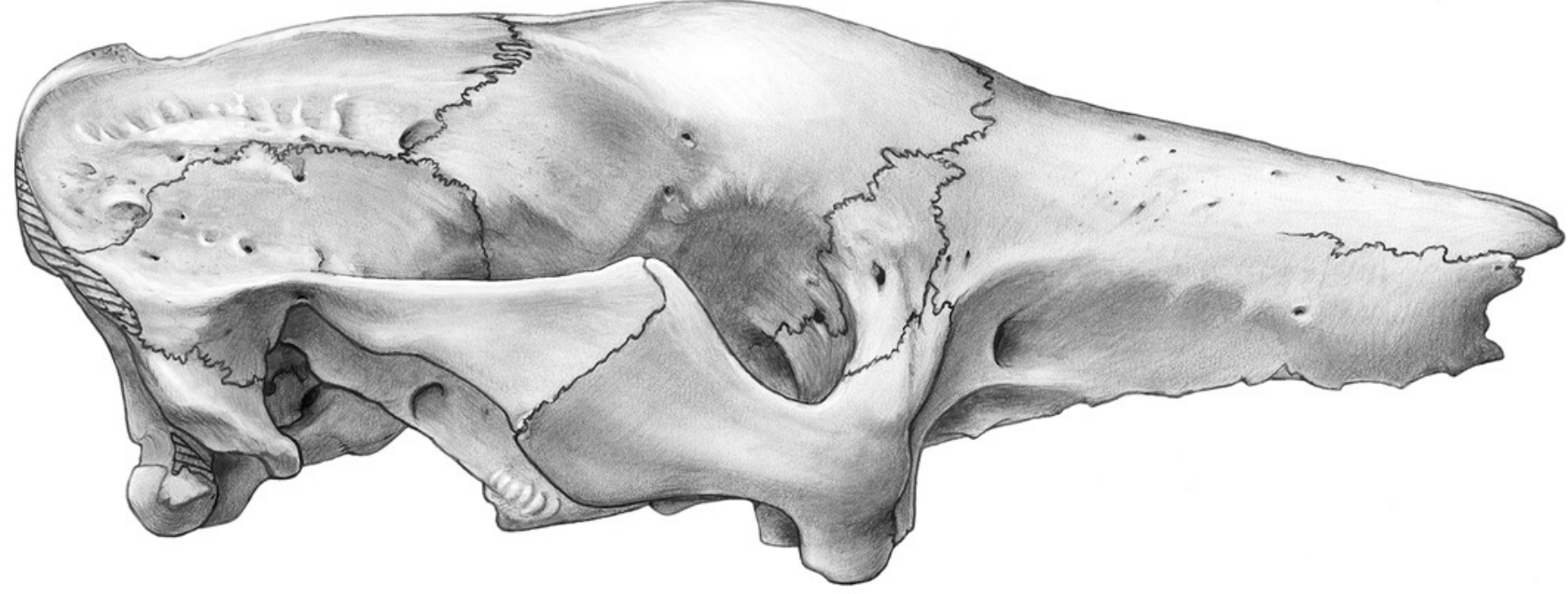

B
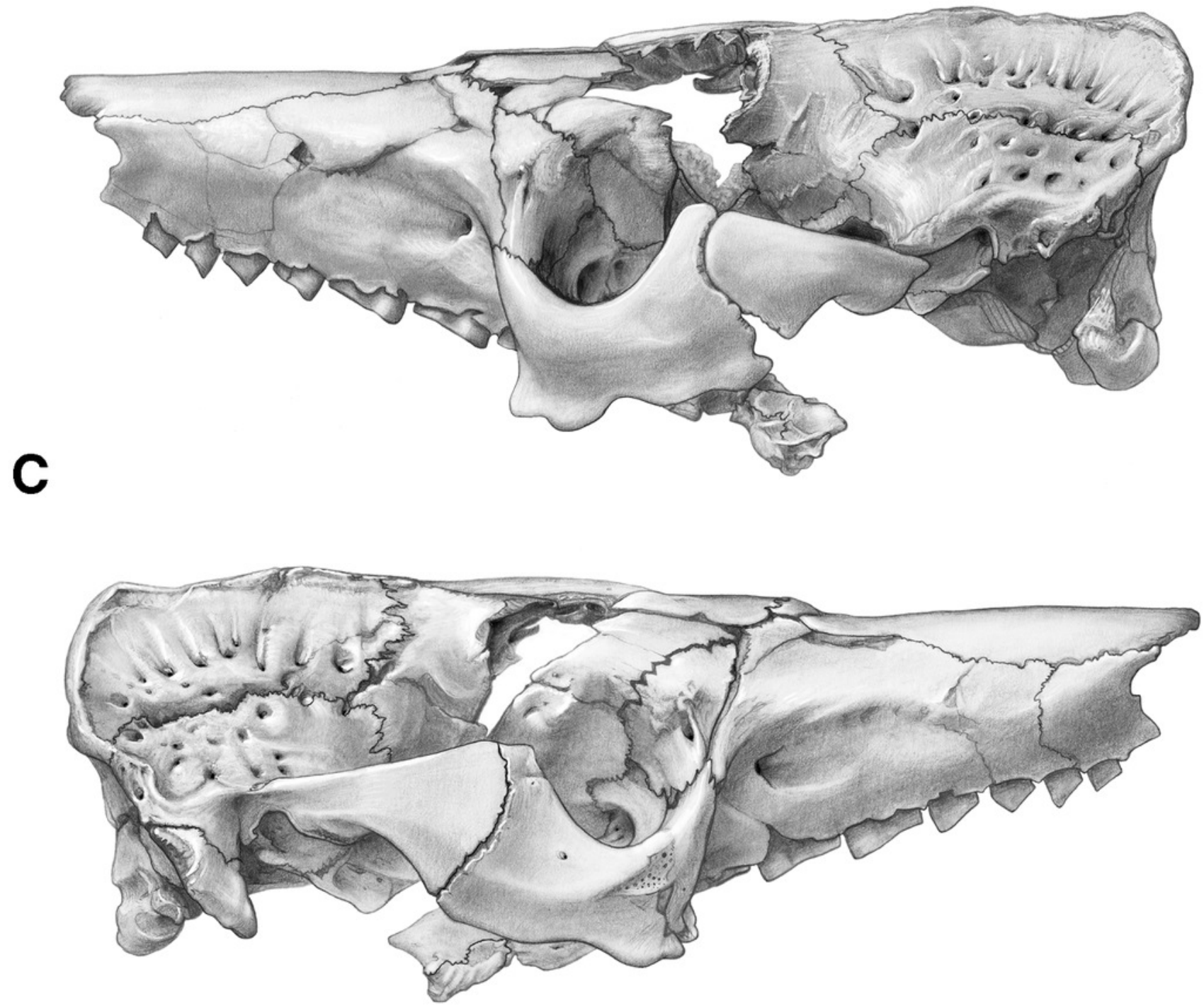


\section{Figure 5}

Reconstruction of the skull of Holmesina floridanus in right lateral view

Abbreviations: aof, antorbital fossa; as, alisphenoid; bo, basioccipital; bs, basisphenoid;

$\mathbf{d p j}$, two projections forming descending process of jugal; $\mathbf{f}$, frontal; fdv, foramen for frontal diploic vein; fo, foramen ovale; frt, foramina for rami temporalis; iof, infraorbital foramen; $\mathbf{j}$, jugal; I, lacrimal; If, lacrimal foramen; It, lacrimal tubercle; Mf1, first upper molariform tooth; Mf9, ninth upper molariform tooth; $\mathbf{m r}$, maxillary ridge, i.e., ridge on facial process of maxilla; mx, maxilla; $\mathbf{n}$, nasal; nc, nuchal crest; oc, occipital; occ, occipital condyle; p, parietal; pm, premaxilla; pop, paroccipital process of petrosal (= mastoid process of Patterson et al. 1989); pt, pterygoid; smf, suprameatal foramen; sq, squamosal; zp, zygomatic process of squamosal.

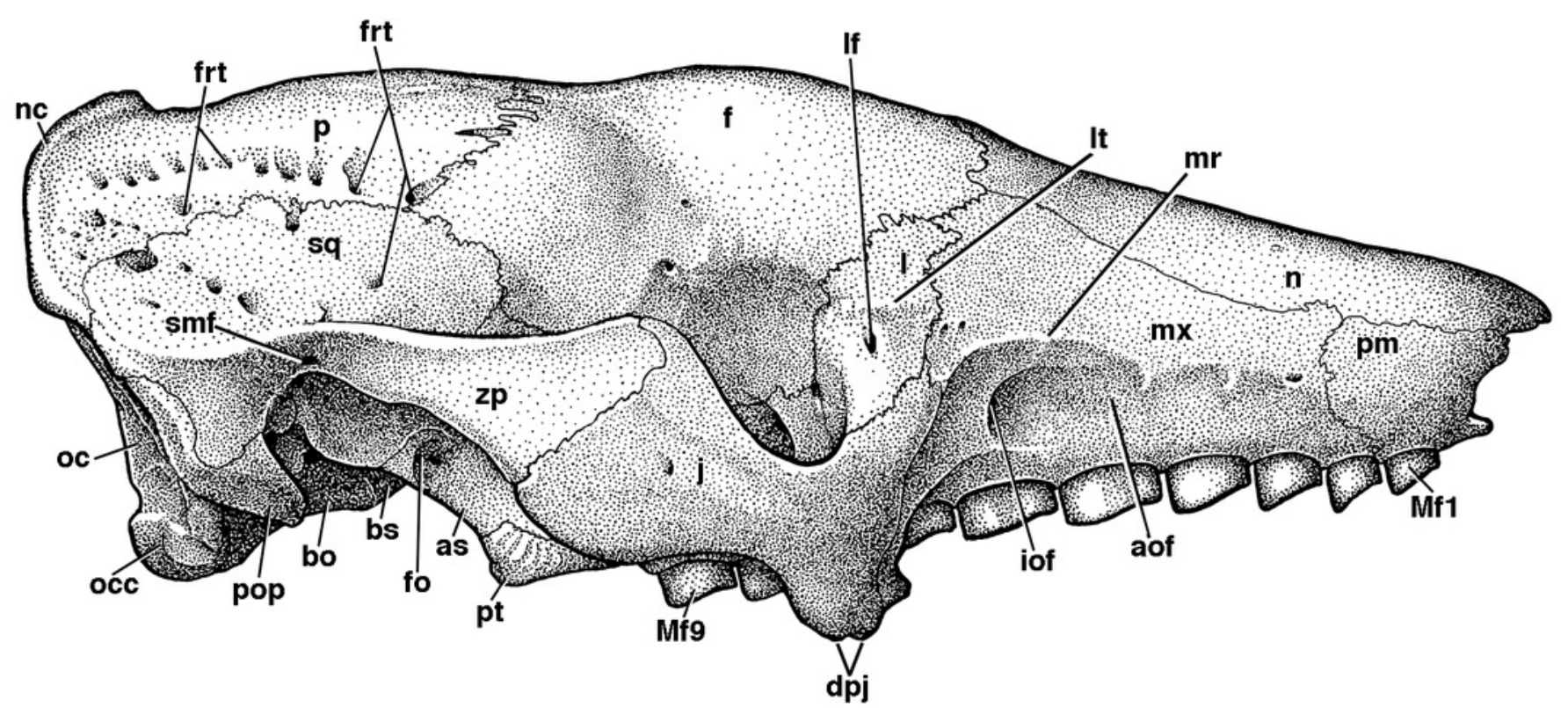


Figure 6

Skull of Holmesina floridanus in ventral view

A, UF 191448; B, UF 248500. Scale bar $=5 \mathrm{~cm}$.
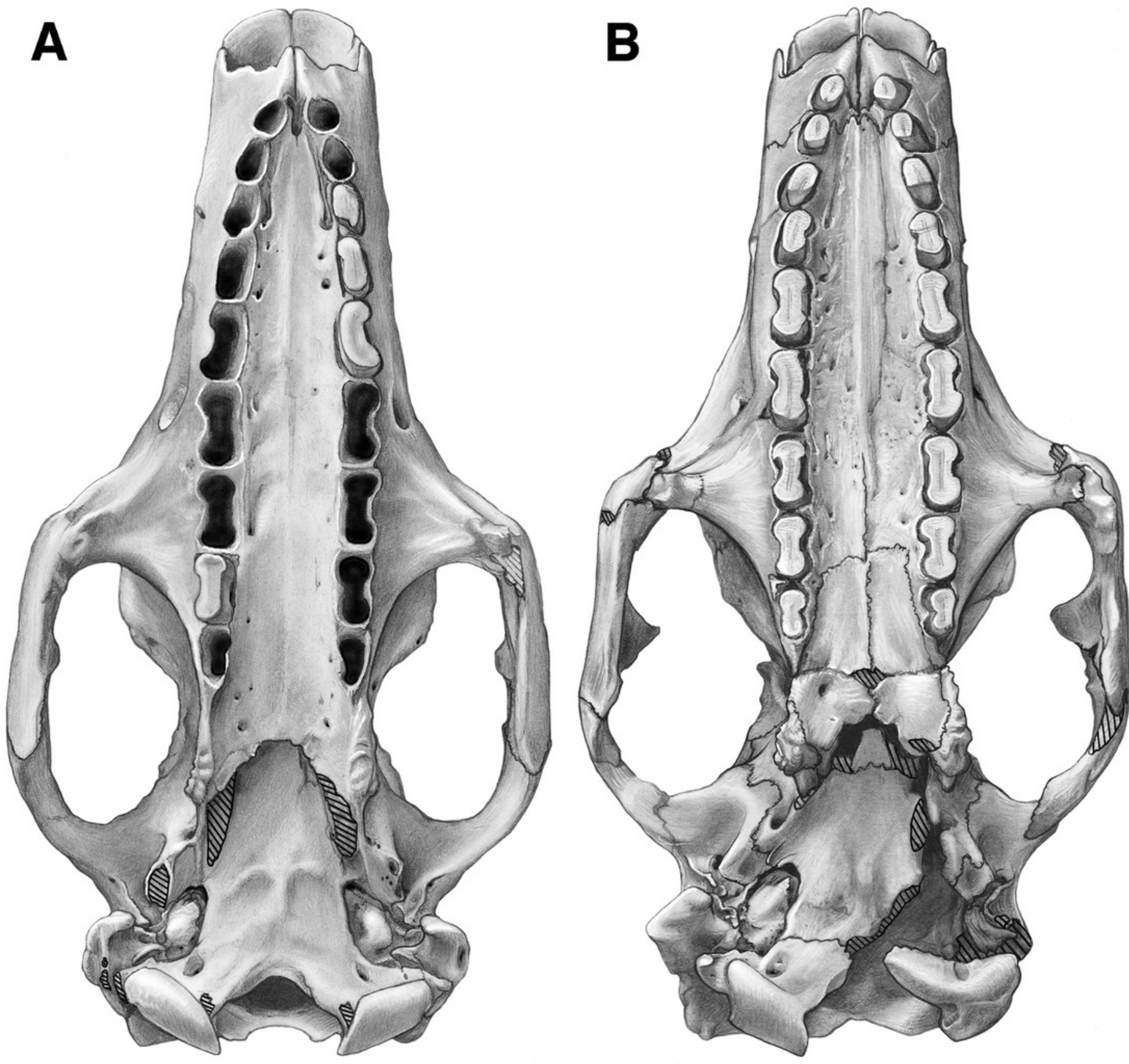


\section{Figure 7}

Reconstruction of the skull of Holmesina floridanus in ventral view

Abbreviations: apf, anterior palatal foramen; as, alisphenoid; bcc, basicochlear commissure;

bo, basioccipital; bs, basisphenoid; cf, carotid foramen; dpj, two projections forming descending process of jugal; eo, exoccipital; fdv, foramen for frontal diploic vein; fm, foramen magnum; fo, foramen ovale; gf, glenoid fossa; $\mathbf{h f}$, hypoglossal foramen; if, incisive foramen; iof, infraorbital foramen; jf, jugular foramen; mapf, major palatine foramen; Mf1, first upper molariform tooth; Mf9, ninth upper molariform tooth; $\mathbf{m x}$, maxilla; $\mathbf{n}$, nasal; oc, occipital; occ, occipital condyle; pal, palatine; pcp, paracondylar process of exoccipital (=paroccipital process of Patterson et al. 1989); pf, piriform fenestra; pgf, postglenoid foramen; pgp, postglenoid process; $\mathbf{p m}$, premaxilla; pop, paroccipital process of petrosal (= mastoid process of Patterson et al. 1989); popf, postorbital process of frontal; popj, postorbital process of jugal; pr, promontorium of petrosal; prs, presphenoid; pt, pterygoid; rcf, rectus capitis fossa; $\mathbf{z p}$, zygomatic process of squamosal; zpm, zygomatic process of maxilla. 


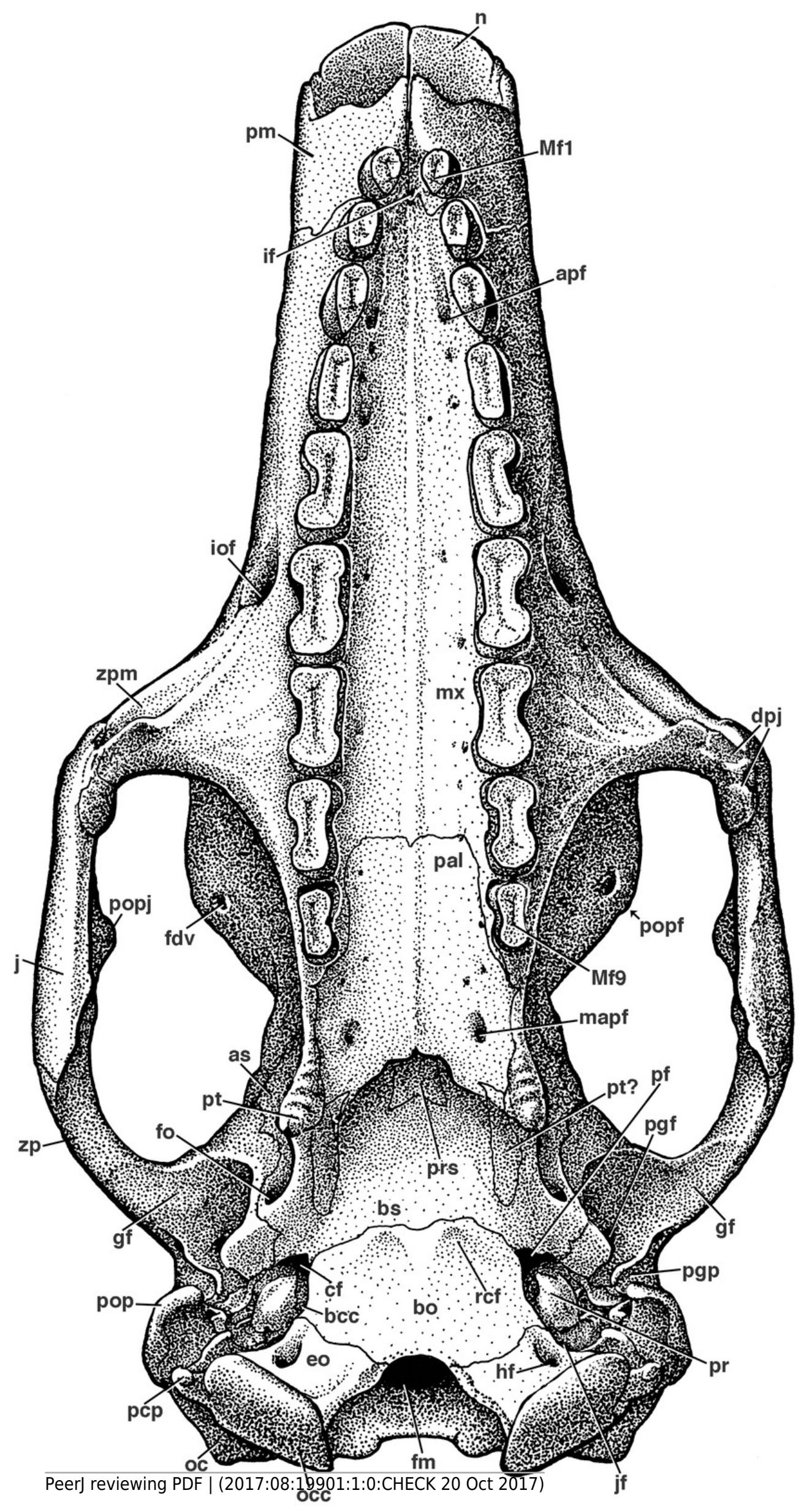




\section{Figure 8}

Reconstruction of right orbital wall of Holmesina floridanus in lateral view

Cross-hatched surfaces indicate where zygomatic arch is "cut.". Abbreviations: as, alisphenoid; bo, basioccipital; bs, basisphenoid; cf, carotid foramen; cpf, caudal palatine foramen; ef, ethmoid foramen; $\mathbf{f}$, frontal; fdv, foramen for frontal diploic vein; fo, foramen ovale; fr/sof, fused foramen rotundum and sphenorbital fissure; frt, foramina for rami temporalis; fv, fenestra vestibuli; iof, infraorbital foramen; itc, infratemporal crest; j, jugal; I, lacrimal; If, lacrimal foramen; Ife, lacrimal fenestra; lopc, lateral opening of pterygoid canal; It, lacrimal tubercle; $\mathbf{M f 9}$, ninth upper molariform tooth; $\mathbf{m x}$, maxilla; $\mathbf{m x f}$, maxillary foramen; $\mathbf{n}$, nasal; of, optic foramen; os, orbitosphenoid; p, parietal; pgf, postglenoid foramen; pgp, postglenoid process; pop, paroccipital process of petrosal (= mastoid process of Patterson et al. 1989); pr, promontorium of petrosal; pt, pterygoid; ptp, post-tympanic process of squamosal; spf, sphenopalatine foramen; sq, squamosal; tcf, transverse canal foramen; zp, zygomatic process of squamosal. 


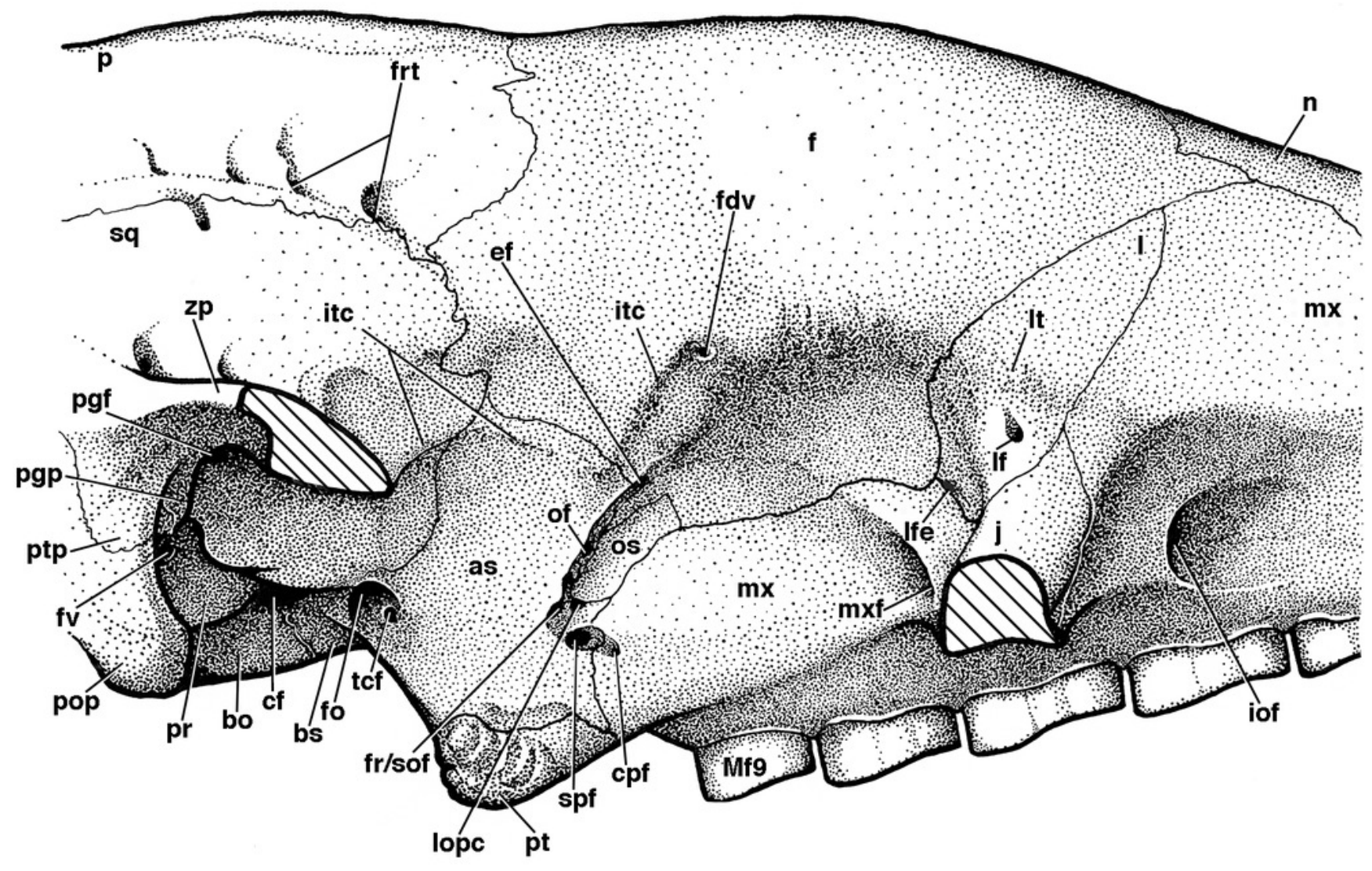




\section{Figure 9}

Posterior palate, pterygoid processes, and choanae of Holmesina floridanus in ventral view

A, UF 121742 (exhibit skull); B, UF 191448. Abbreviations: bot, basioccipital tuber; bs, basisphenoid; cf/pf/bcc, confluent carotid foramen, piriform fenestra and basicochlear commissure; epp, entopterygoid process (=hamulus or pterygoid process of other cingulates); fo, foramen ovale; mapf, major palatine foramina; Mf9, ninth upper molariform tooth or alveolus; mipf, minor palatine foramen; mipn, notch for minor palatine nerve and vessels; mpp?, neomorphic medial pterygoid process; pal, palatine; ppm, pneumatized mass of bone that may pertain to the pterygoid; prs, presphenoid, rcf; rectus capitits fossa.
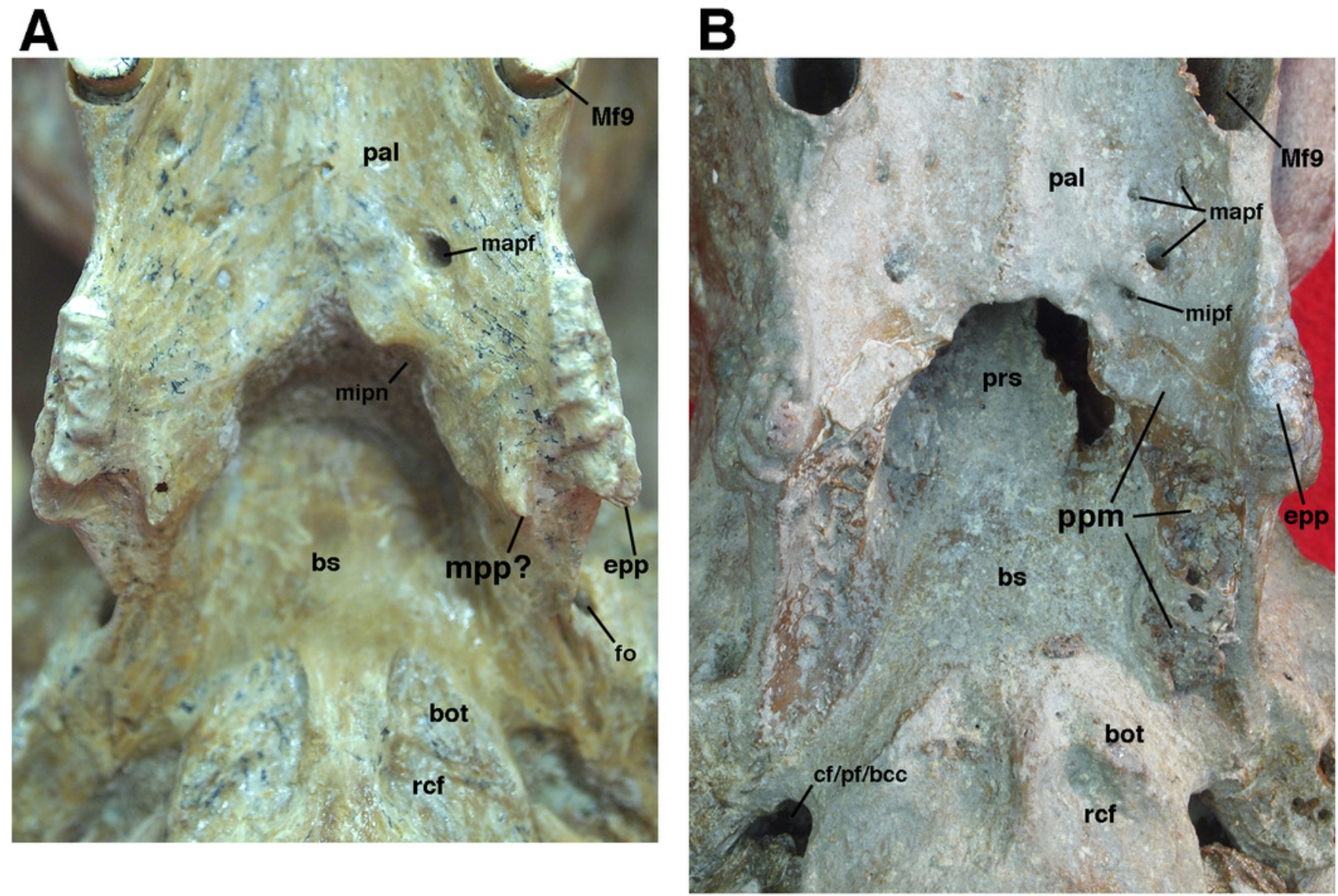


\section{Figure 10}

Stereophotographs of right auditory region of Holmesina floridanus (UF 248500) in ventral view

Abbreviations: abX, groove for auricular branch of vagus nerve (c.n. X); aptt, anteroventral process of tegmen tympani (= processus crista facialis); as, alisphenoid; bb, bony bridge between tympanohyal and crista interfenestralis; bcc, basicochlear commissure; bo, basioccipital; bs, basisphenoid; cf, carotid foramen; ci, crista interfenestralis; $\mathbf{c p}$, crista parotica; ctpp, caudal tympanic process of petrosal; eam, external auditory meatus; egp, entoglenoid process; eo, exoccipital; er, epitympanic recess; fc, fenestra cochleae; fi, ridge immediately ventral to fossa incudis; $\mathbf{f m}$, foramen magnum; fo, foramen ovale; $\mathbf{f s}$, facial sulcus; gf, glenoid fossa; gvn, groove for vidian nerve; hf, hypoglossal foramen; jf, jugular foramen; occ, occipital condyle; og, groove for occipital artery; pcp, paracondylar process of exoccipital (=paroccipital process of Patterson et al. 1989); pe, petrosal; pf, piriform fenestra; pgf, postglenoid foramen; pgp, postglenoid process; pop, paroccipital process of petrosal (= mastoid process of Patterson et al. 1989); pr, promontorium of petrosal; sq, squamosal; stmf, stylomastoid foramen; th, tympanohyal; ttf, tensor tympani fossa on epitympanic wing of petrosal; zp, zygomatic process of squamosal. Scale bar $=1 \mathrm{~cm}$. Photos by S. Chatzimanolis and T. Gaudin. 

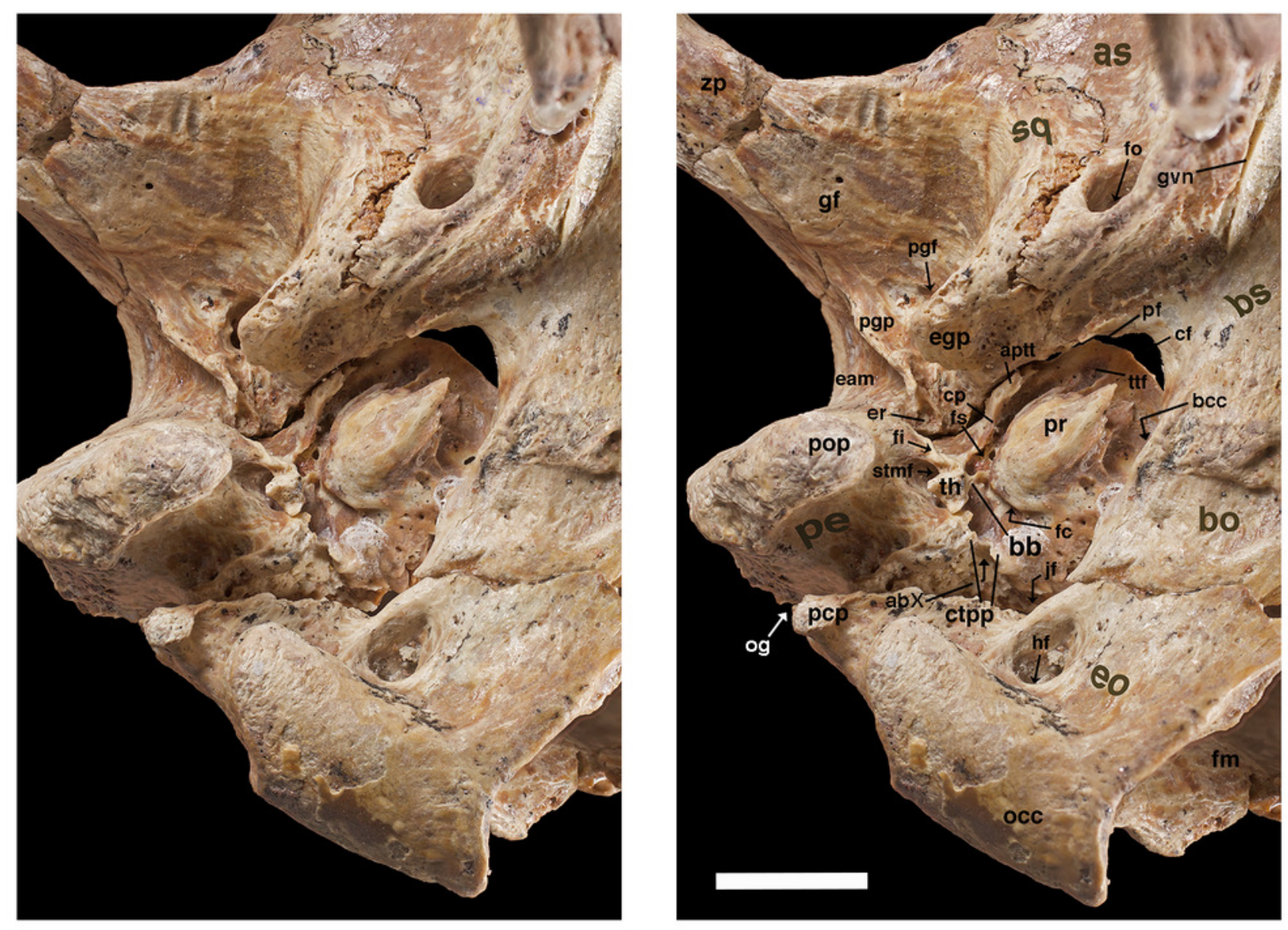


\section{Figure 11 (on next page)}

Isolated left petrosal of Holmesina floridanus (UF 248500)

A, B, ventrolateral; C, D, ventral; E, F, lateral; and G, H, medial views. Abbreviations: aptt, anteroventral process of tegmen tympani (= processus crista facialis); av, aqueductus vestibuli; bof, basioccipital facet; cb, circular boss on ventrolateral surface of promontorium; ci, crista interfenestralis; coc, cochlear canaliculus; cp, crista parotica; crp, crista petrosal; ctpp, caudal tympanic process of petrosal; er, epitympanic recess; ew, epitympanic wing; fc, fenestra cochleae; fs, facial sulcus; fsi, foramen singulare; fv, fenestra vestibuli; gps, sulcus for greater petrosal nerve; iam, internal acoustic meatus; ips; fossa/groove for inferior petrosal sinus; iva, inferior vestibular area; pfc, prefacial commissure; pff, primary facial foramen; pop, paroccipital process of petrosal (= mastoid process of Patterson et al. 1989); pr, promontorium of petrosal; rpp, rostral process of petrosal; saf, subarcuate fossa; sct, spiral cribriform tract; sf, stapedius fossa; stmn, stylomastoid notch; sps, groove for superior petrosal sinus; sva, superior vestibular area; tc, transverse crest; th, tympanohyal; ts, triangular shelf (=roof of post-promontorial sinus. Scale bar $=1 \mathrm{~cm}$. 
A
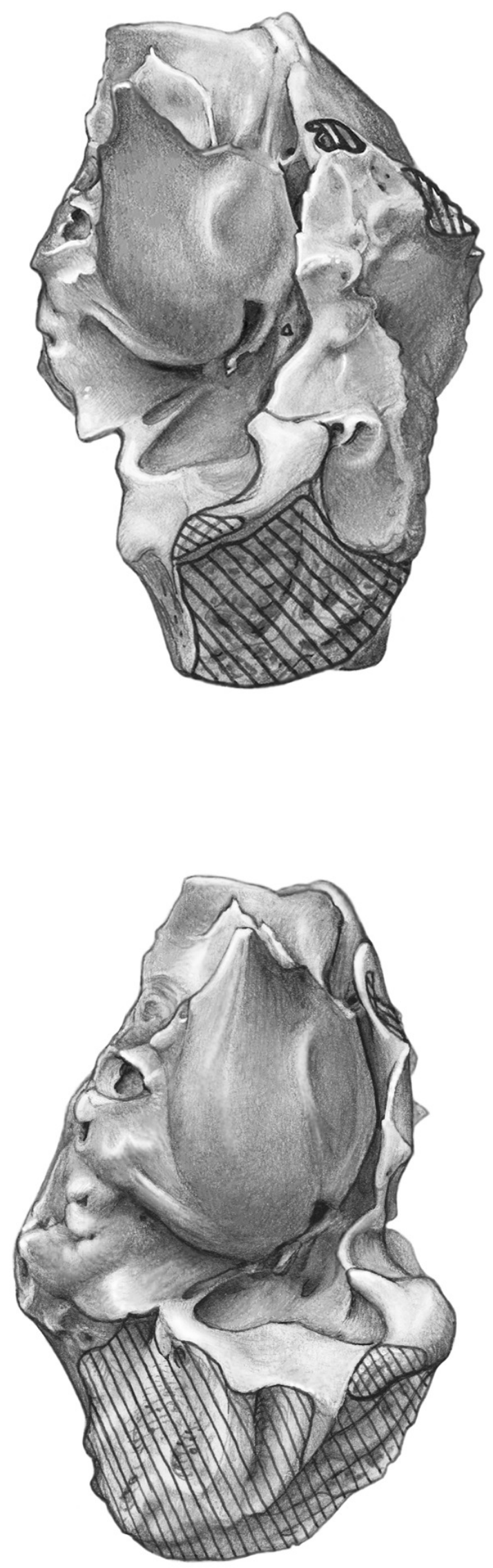

B

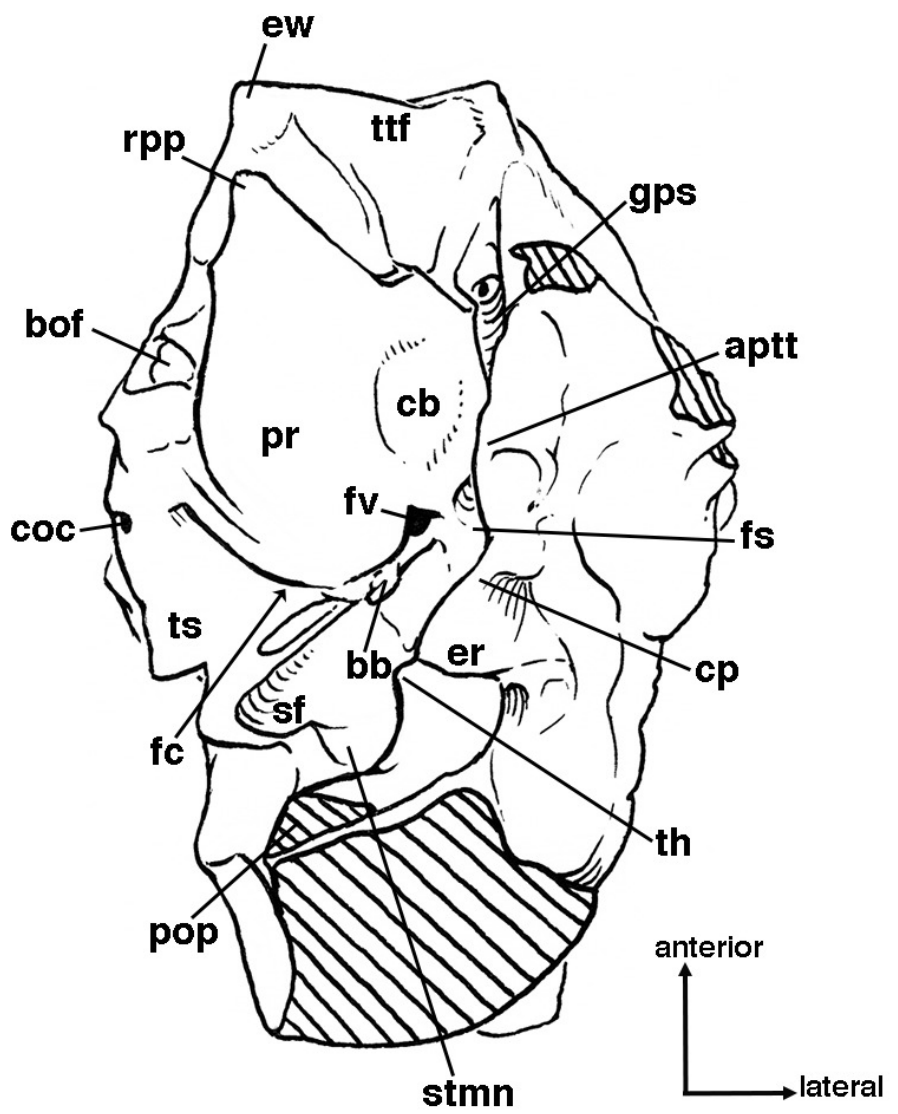

D

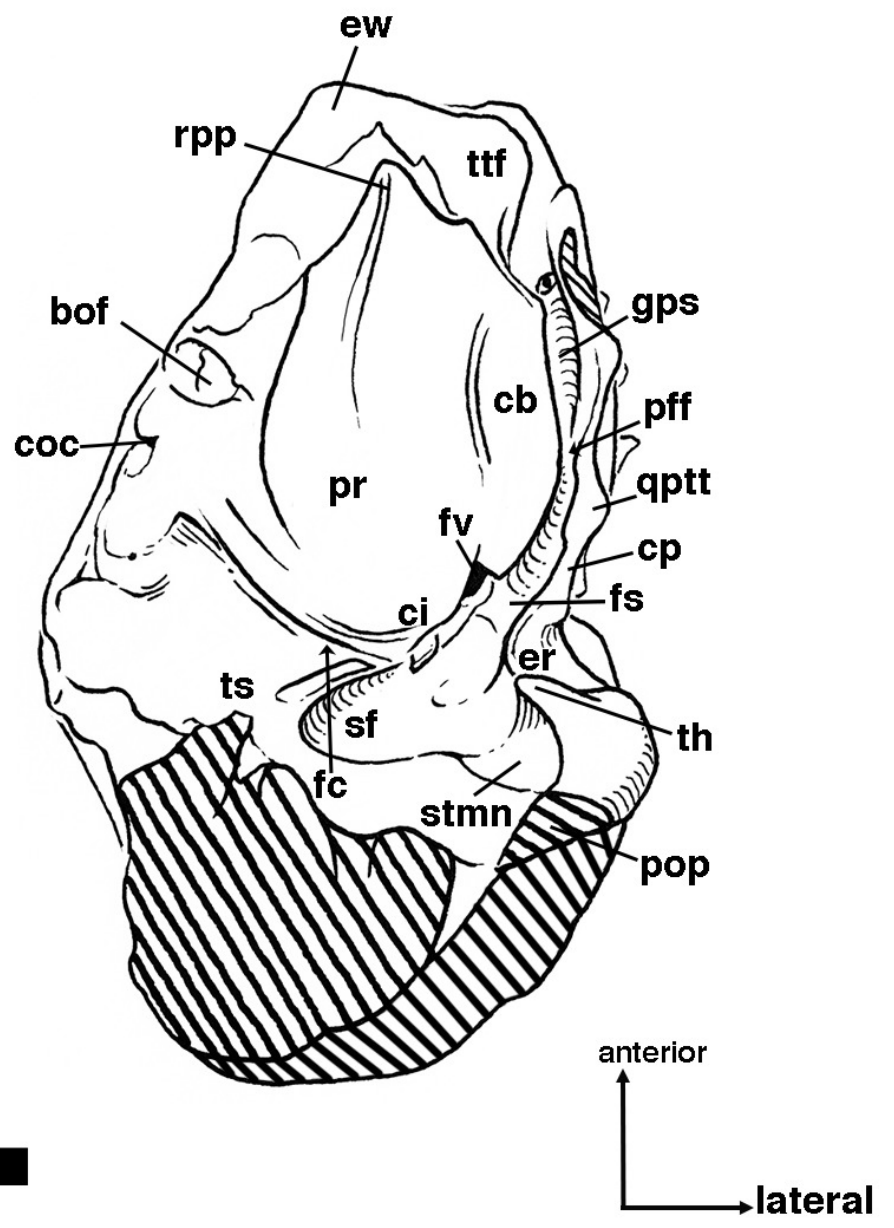


$\mathbf{E}$

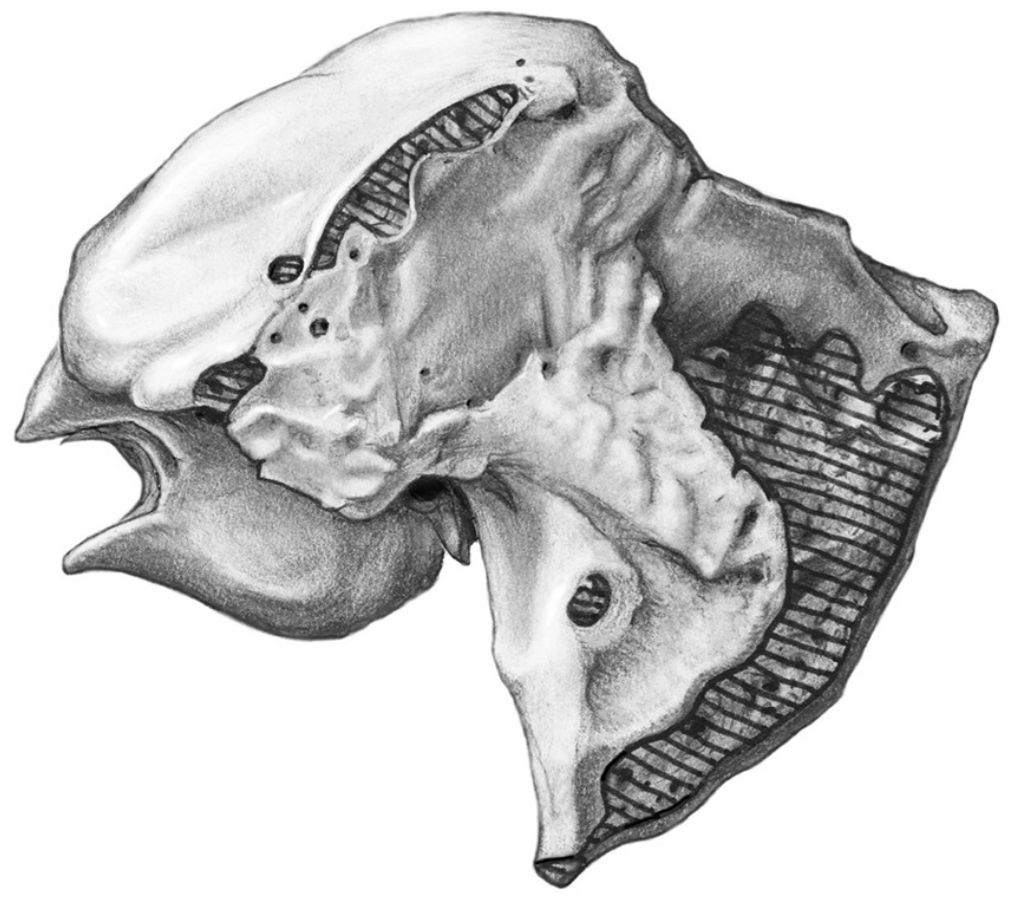

$\mathbf{G}$

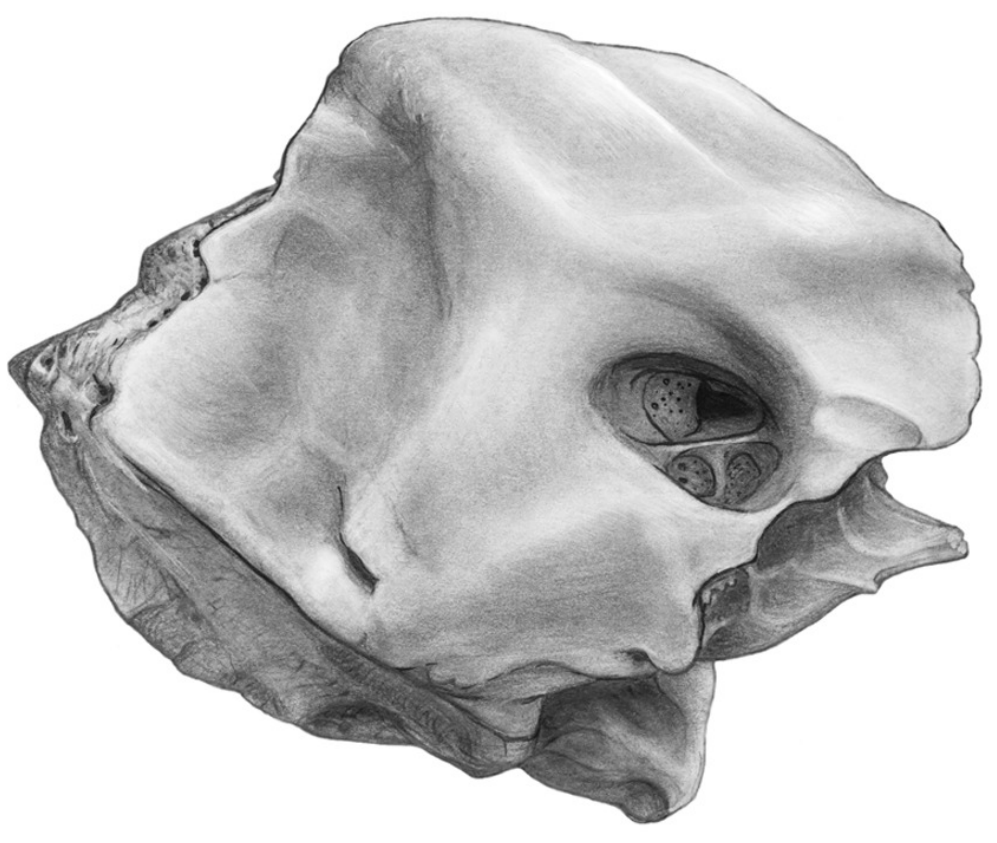

$\mathbf{F}$
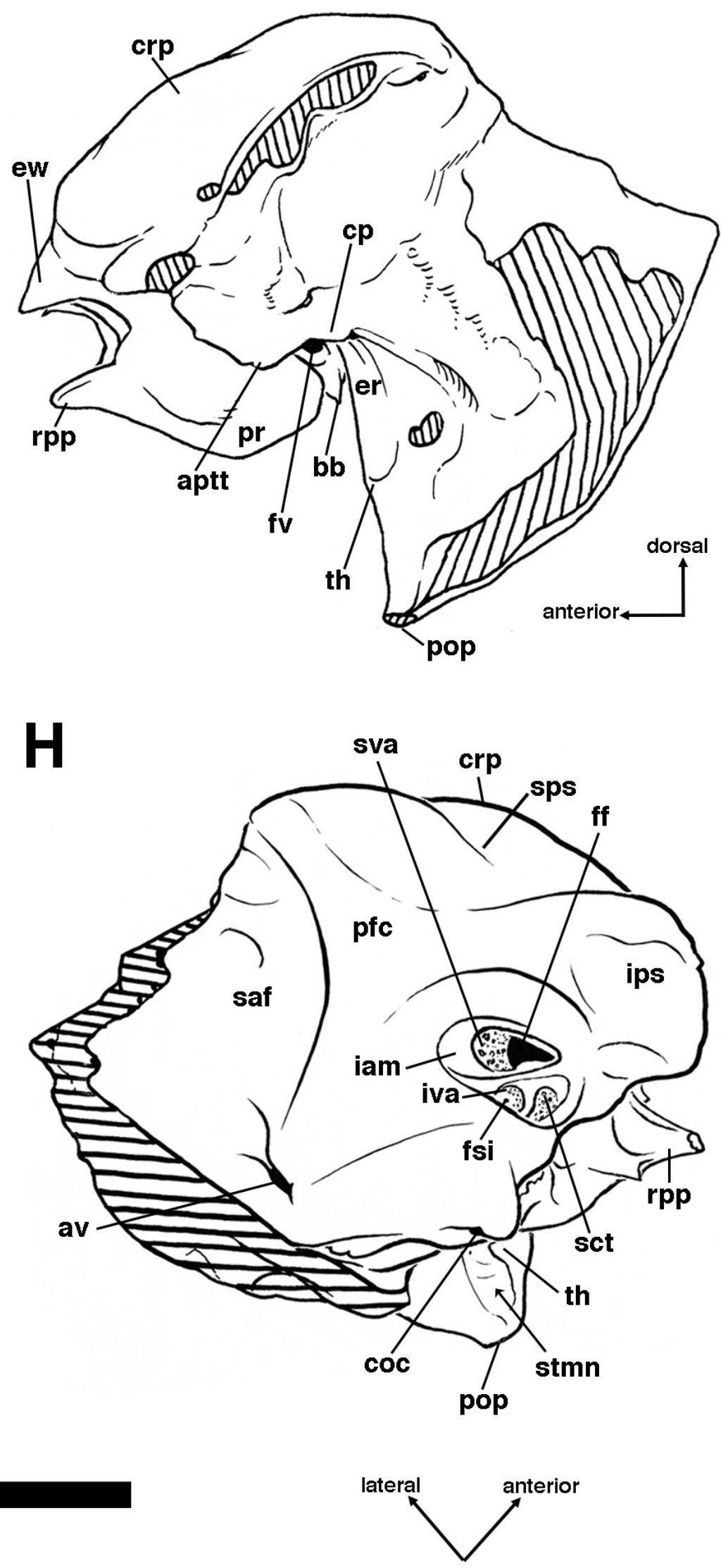


\section{Figure 12}

Image of Isolated right petrosal, left occipital condyle, and basicranium of Holmesina floridanus, UF 223813

A, petrosal, basicranium and condyle in dorsal view; B, petrosal in posterior view. Abbreviations: alf, fossa for alar ligament of atlas; av, aqueductus vestibuli; bs, basisphenoid; coc, cochlear canaliculus; cs, carotid sulcus for internal carotid artery; ew, epitympanic wing; fc, fenestra cochleae; hfo, hypophyseal fossa; iam, internal acoustic meatus; js, jugulum sphenoidale; occ, occipital condyle; opc, internal openings of optic canals; osc, orbitosphenoid crest; pe, petrosal; pr, promontorium of petrosal; rpp, rostral process of petrosal; tc, opening accommodating veins that connect to transverse canal foramen; ts, tuberculum sellae. Upper scale bar $(A)=2 \mathrm{~cm}$. Lower scale bar $(B)=1 \mathrm{~cm}$. 

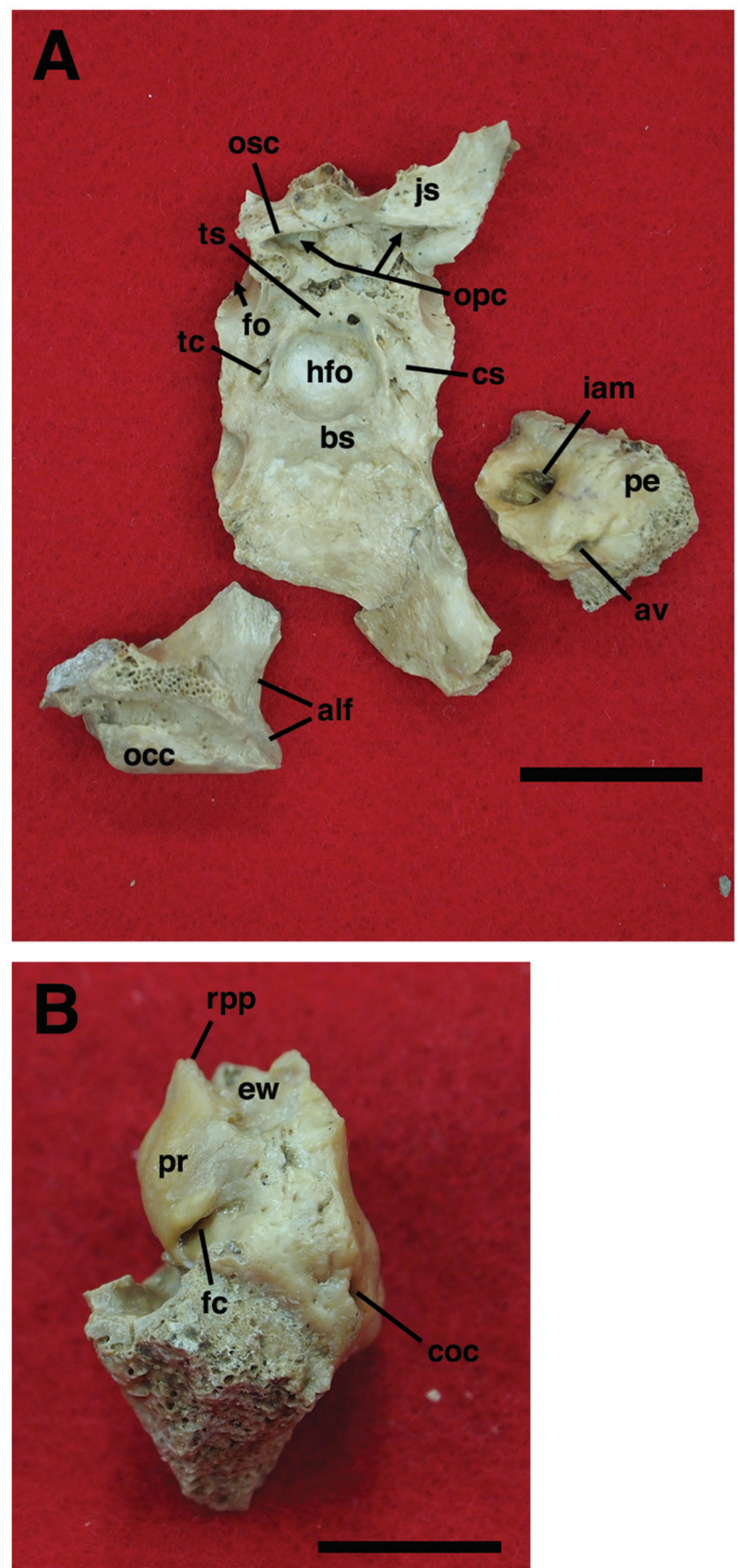


\section{Figure 13}

Skull of Holmesina floridanus in posterior view

A, UF 191448; B, Reconstruction. Abbreviations: bo, basioccipital; dcf, dorsal condyloid fossa; dgf, digastric fossa; eo, exoccipital; eoc, external occipital crest; eocc, exoccipital crest; fm, foramen magnum; Ici; lateral condyle indentation, i.e., indentation on lateral edge of occipital condyle; nc, nuchal crest; oc, occipital; occ, occipital condyle; og, groove for occipital artery; me, mastoid exposure of petrosal; pcp, paracondylar process of exoccipital (=paroccipital process of Patterson et al. 1989); ptc, posttemporal canal; so, supraoccipital; sq, squamosal. Scale bar $=5 \mathrm{~cm}$.

$\mathbf{A}$

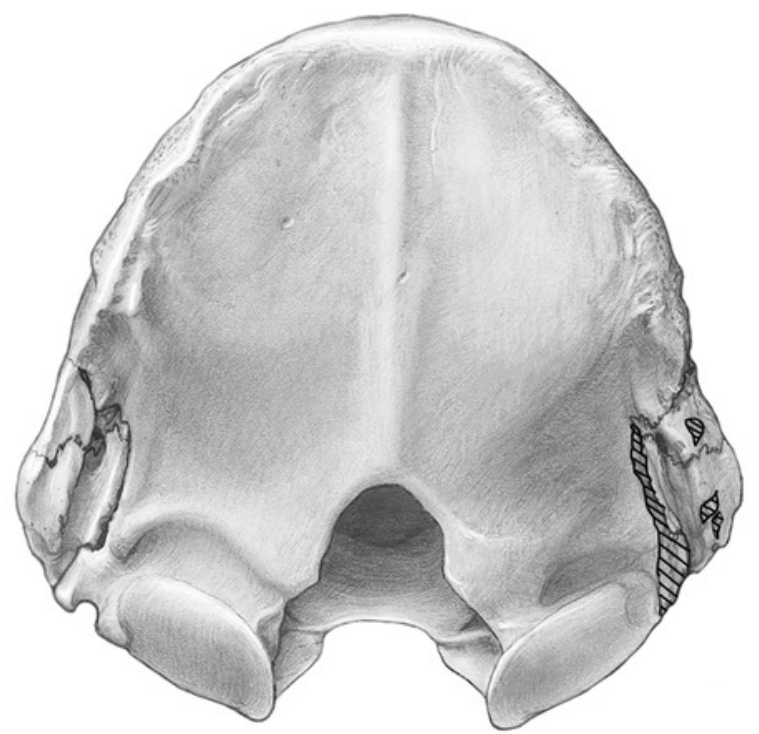

B

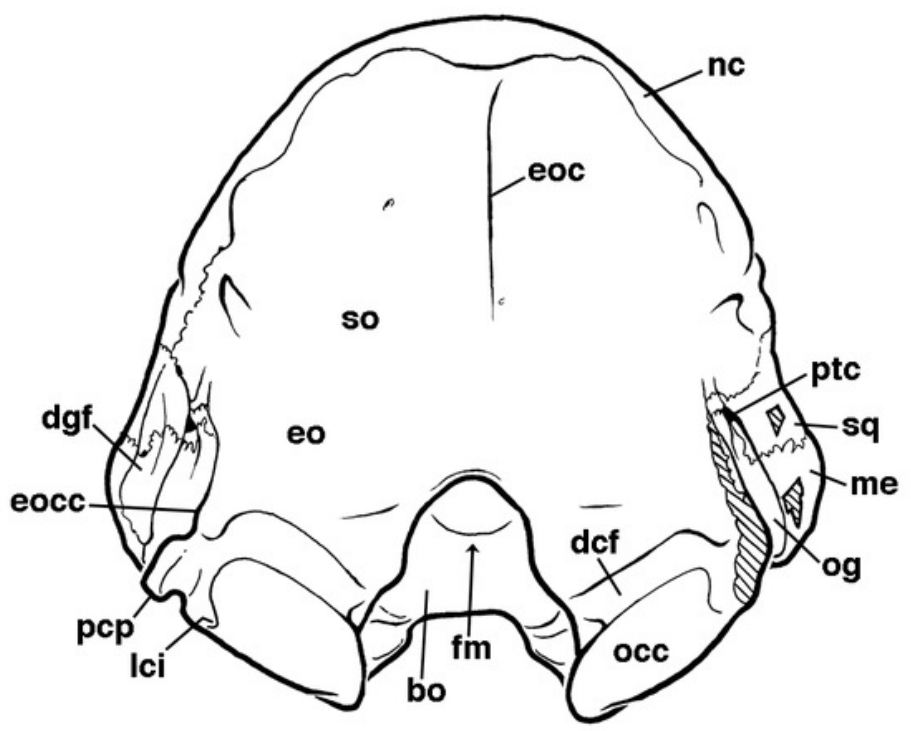




\section{Figure 14}

Left mandible of Holmesina floridanus (UF 224450)

A, lateral; B, occlusal; and, C, medial views. Abbreviations: ap, angular process; cnc, condyloid crest; cop, coronoid process; crc, coronoid crest; hr, horizontal ramus of mandible; imf, intermuscular fossa; Icc, lateral coronoid crest; $\mathbf{m} \mathbf{1}$, first lower molariform tooth; $\mathbf{m 6}$, sixth lower molariform tooth; $\mathbf{m 7}$, seventh lower molariform tooth; maf, masseteric fossa; mco, mandibular condyle; mf, mental foramen; mnf, mandibular foramen; ms, mandibular symphysis. Scale bar $=5 \mathrm{~cm}$. 

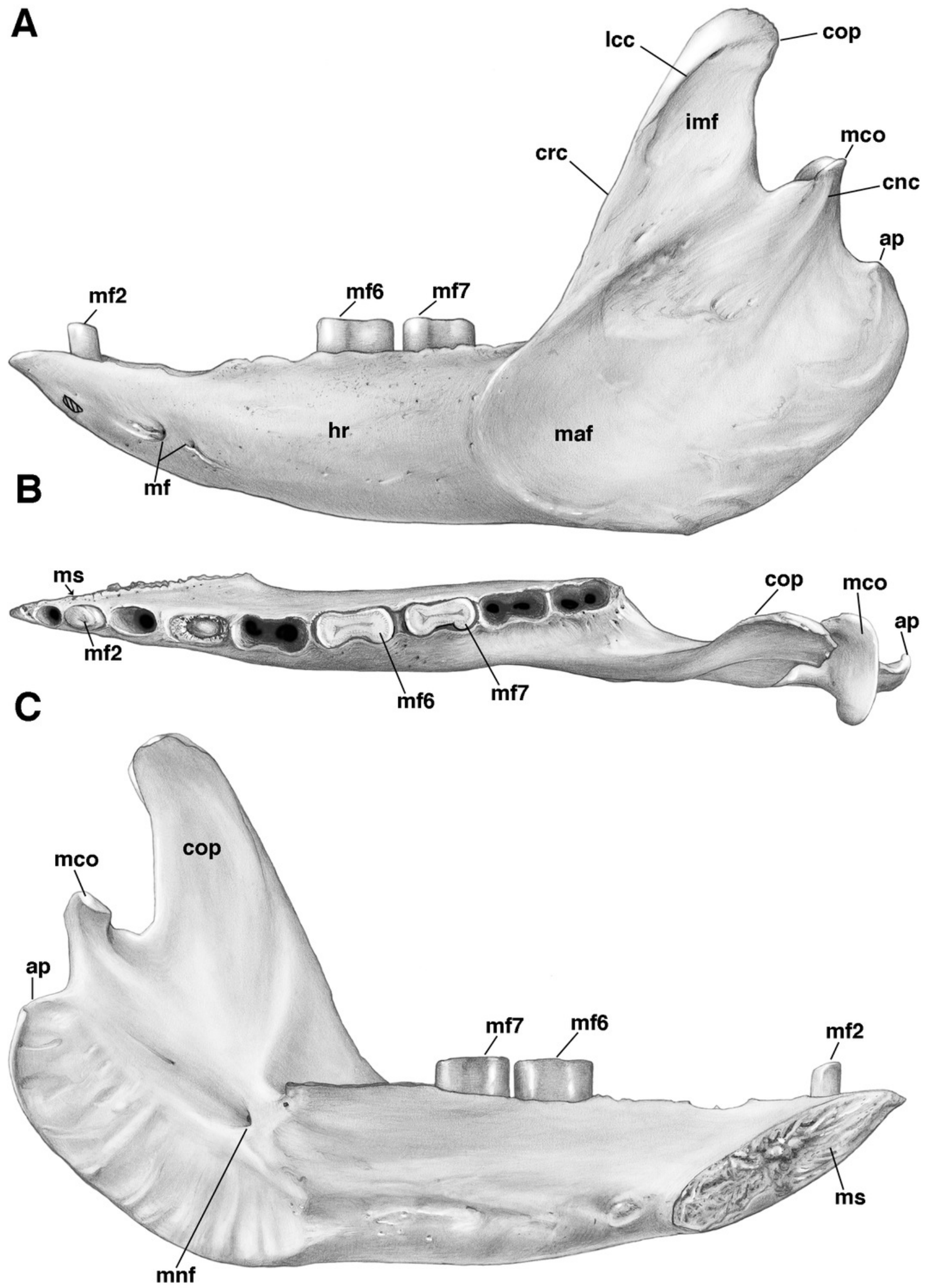